\title{
Exercise for rheumatoid arthritis of the hand (Review)
}

Williams MA, Srikesavan C, Heine PJ, Bruce J, Brosseau L, Hoxey-Thomas N, Lamb SE

Williams MA, Srikesavan C, Heine PJ, Bruce J, Brosseau L, Hoxey-Thomas N, Lamb SE.

Exercise for rheumatoid arthritis of the hand.

Cochrane Database of Systematic Reviews 2018, Issue 7. Art. No.: CD003832.

DOI: 10.1002/14651858.CD003832.pub3.

www.cochranelibrary.com 
TABLE OF CONTENTS

HEADER 1

ABSTRACT

PLAIN LANGUAGE SUMMARY ....

SUMMARY OF FINDINGS

BACKGROUND

OBJECTIVES

METHODS

RESULTS

Figure 1.

Figure 2.

Figure 3.

Figure 4.

Figure 5.

Figure 6.

DISCUSSION

AUTHORS' CONCLUSIONS

ACKNOWLEDGEMENTS

REFERENCES

CHARACTERISTICS OF STUDIES

DATA AND ANALYSES

Analysis 1.1. Comparison 1 Exercise versus no exercise, Outcome 1 Hand function.

Analysis 1.2. Comparison 1 Exercise versus no exercise, Outcome 2 Pain.

Analysis 1.3. Comparison 1 Exercise versus no exercise, Outcome 3 Hand impairment - power grip strength: short term. .........

Analysis 1.4. Comparison 1 Exercise versus no exercise, Outcome 4 Hand impairment - power grip strength: medium and long term.

Analysis 1.5. Comparison 1 Exercise versus no exercise, Outcome 5 Hand impairment - pinch grip strength.

Analysis 1.6. Comparison 1 Exercise versus no exercise, Outcome 6 Participant adherence.

Analysis 1.7. Comparison 1 Exercise versus no exercise, Outcome 7 General function.

Analysis 1.8. Comparison 1 Exercise versus no exercise, Outcome 8 Disease activity. ADDITIONAL TABLES

APPENDICES

HISTORY

CONTRIBUTIONS OF AUTHORS

DECLARATIONS OF INTEREST

SOURCES OF SUPPORT

DIFFERENCES BETWEEN PROTOCOL AND REVIEW

INDEX TERMS 
[Intervention Review]

\section{Exercise for rheumatoid arthritis of the hand}

Mark A Williams ${ }^{1 a}$, Cynthia Srikesavan $2 b$, Peter J Heine², Julie Bruce ${ }^{3}$, Lucie Brosseau4 ${ }^{4}$ Nicolette Hoxey-Thomas², Sarah E Lamb²

1Department of Sport and Health Sciences, Oxford Brookes University, Oxford, UK. ${ }^{2}$ Nuffield Department of Orthopaedics,

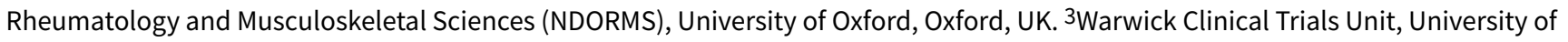
Warwick, Coventry, UK. ${ }^{4}$ School of Rehabilitation Sciences, Faculty of Health Sciences, University of Ottawa, Ottawa, Canada

a Joint first author. b Joint first author

Contact address: Sarah E Lamb, Nuffield Department of Orthopaedics, Rheumatology and Musculoskeletal Sciences (NDORMS), University of Oxford, Windmill road, Oxford, OX3 7LD, UK. sarah.lamb@ndorms.ox.ac.uk.

Editorial group: Cochrane Musculoskeletal Group.

Publication status and date: New, published in Issue 7, 2018.

Citation: Williams MA, Srikesavan C, Heine PJ, Bruce J, Brosseau L, Hoxey-Thomas N, Lamb SE. Exercise for rheumatoid arthritis of the hand. Cochrane Database of Systematic Reviews 2018, Issue 7. Art. No.: CD003832. DOI: 10.1002/14651858.CD003832.pub3.

Copyright ( 2018 The Cochrane Collaboration. Published by John Wiley \& Sons, Ltd.

\section{A B S T R A C T}

\section{Background}

Rheumatoid arthritis is an inflammatory polyarthritis that frequently affects the hands and wrists. Hand exercises are prescribed to improve mobility and strength, and thereby hand function.

\section{Objectives}

To determine the benefits and harms of hand exercise in adults with rheumatoid arthritis.

\section{Search methods}

We searched the Cochrane Central Register of Controlled Trials (CENTRAL) (the Cochrane Library), MEDLINE, Embase, CINAHL, AMED, Physiotherapy Evidence Database (PEDro), OTseeker, Web of Science, ClinicalTrials.gov and the World Health Organization International Clinical Trials Registry Platform (WHO ICTRP) up to July 2017.

\section{Selection criteria}

We considered all randomised or quasi-randomised controlled trials that compared hand exercise with any non-exercise therapy.

\section{Data collection and analysis}

We used standard methodological procedures as outlined by the Cochrane Musculoskeletal Group.

\section{Main results}

We included seven studies involving 841 people (aged 20 to 94 years) in the review. Most studies used validated diagnostic criteria and involved home programmes.

Very low-quality evidence (due to risk of bias and imprecision) from one study indicated uncertainty about whether exercise improves hand function in the short term ( $<3$ months). On a 0 to 80 points hand function test (higher scores mean better function), the exercise group $(n=11)$ scored 76.1 points and control group $(n=13)$ scored 75 points.

Moderate-quality evidence (due to risk of bias) from one study indicated that exercise compared to usual care probably slightly improves hand function (mean difference (MD) 4.5, 95\% confidence interval $(\mathrm{Cl}) 1.58$ to $7.42 ; \mathrm{n}=449$ ) in the medium term ( 3 to 11 months) and in the long term (12 months or beyond) (MD 4.3, 95\% Cl 0.86 to 7.74; $\mathrm{n}=438$ ). The absolute change on a 0-to-100 hand function scale (higher 
scores mean better function) and number needed to treat for an additional beneficial outcome (NNTB) were $5 \%$ (95\% Cl 2\% to 7\%); 8 (95\% $\mathrm{Cl} 5$ to 20$)$ and $4 \%(95 \% \mathrm{Cl} 1 \%$ to $8 \%) ; 9$ (95\% Cl 6 to 27), respectively. A 4\% to 5\% improvement indicates a minimal clinical benefit.

Very low-quality evidence (due to risk of bias and imprecision) from two studies indicated uncertainty about whether exercise compared to no treatment improved pain ( $\mathrm{MD}-27.98,95 \% \mathrm{Cl}-48.93$ to $-7.03 ; \mathrm{n}=124)$ in the short term. The absolute change on a 0-to-100-millimetre scale (higher scores mean more pain) was $-28 \%(95 \% \mathrm{Cl}-49 \%$ to $-7 \%)$ and NNTB $2(95 \% \mathrm{Cl} 2$ to 11$)$.

Moderate-quality evidence (due to risk of bias) from one study indicated that there is probably little or no difference between exercise and usual care on pain in the medium (MD -2.8, 95\% Cl- 6.96 to $1.36 ; n=445)$ and long term (MD $-3.7,95 \% \mathrm{Cl}-8.1$ to $0.7 ; n=437)$. On a 0-to-100 scale, the absolute changes were $-3 \%(95 \% \mathrm{Cl}-7 \%$ to $2 \%)$ and $-4 \%(95 \% \mathrm{Cl}-8 \%$ to $1 \%)$, respectively.

Very low-quality evidence (due to risk of bias and imprecision) from three studies ( $n=141)$ indicated uncertainty about whether exercise compared to no treatment improved grip strength in the short term. The standardised mean difference for the left hand was 0.44 (95\% $\mathrm{Cl} 0.11$ to 0.78$)$, re-expressed as $3.5 \mathrm{~kg}(95 \% \mathrm{Cl} 0.87$ to 6.1$)$; and for the right hand $0.46(95 \% \mathrm{Cl} 0.13$ to 0.8$)$, re-expressed as $4 \mathrm{~kg}(95 \% \mathrm{Cl}$ 1.13 to 7$)$.

High-quality evidence from one study showed that exercise compared to usual care has little or no benefit on mean grip strength (in kg) of both hands in the medium term (MD $1.4,95 \% \mathrm{Cl}-0.27$ to $3.07 ; n=400)$, relative change $11 \%(95 \% \mathrm{Cl}-2 \%$ to $13 \%)$; and in the long term (MD 1.2, $95 \% \mathrm{Cl}-0.62$ to $3.02 ; \mathrm{n}=355)$, relative change $9 \%(95 \% \mathrm{Cl}-5 \%$ to $23 \%)$.

Very low-quality evidence (due to risk of bias and imprecision) from two studies $(n=120)$ indicated uncertainty about whether exercise compared to no treatment improved pinch strength (in $\mathrm{kg}$ ) in the short term. The MD and relative change for the left and right hands were $0.51(95 \% \mathrm{Cl} 0.13$ to 0.9$)$ and $44 \%(95 \% \mathrm{Cl} 11 \%$ to $78 \%)$; and 0.82 (95\% $\mathrm{Cl} 0.43$ to 1.21$)$ and $68 \%$ (95\% $\mathrm{Cl} 36 \%$ to $101 \%)$.

High-quality evidence from one study showed that exercise compared to usual care has little or no benefit on mean pinch strength of both hands in the medium ( $\mathrm{MD} 0.3,95 \% \mathrm{Cl}-0.14$ to $0.74 ; \mathrm{n}=396$ ) and long term ( $\mathrm{MD} 0.4,95 \% \mathrm{Cl}-0.08$ to $0.88 ; \mathrm{n}=351$ ). The relative changes were $8 \%(95 \% \mathrm{Cl}-4 \%$ to $19 \%)$ and $10 \%(95 \% \mathrm{Cl}-2 \%$ to $22 \%)$.

No study evaluated the American College of Rheumatology 50 criteria.

Moderate-quality evidence (due to risk of bias) from one study indicated that people who also received exercise with strategies for adherence were probably more adherent than those who received routine care alone in the medium term (risk ratio $1.31,95 \% \mathrm{Cl} 1.15$ to $1.48 ; \mathrm{n}=438)$ and NNTB $6(95 \% \mathrm{Cl} 4$ to 10$)$. In the long term, the risk ratio was $1.09(95 \% \mathrm{Cl} 0.93$ to $1.28 ; \mathrm{n}=422)$.

Moderate-quality evidence (due to risk of bias) from one study $(n=246)$ indicated no adverse events with exercising. The other six studies did not report adverse events.

\section{Authors' conclusions}

It is uncertain whether exercise improves hand function or pain in the short term. It probably slightly improves function but has little or no difference on pain in the medium and long term. It is uncertain whether exercise improves grip and pinch strength in the short term, and probably has little or no difference in the medium and long term. The ACR50 response is unknown. People who received exercise with adherence strategies were probably more adherent in the medium term than who did not receive exercise, but with little or no difference in the long term. Hand exercise probably does not lead to adverse events. Future research should consider hand and wrist function as their primary outcome, describe exercise following the TIDieR guidelines, and evaluate behavioural strategies.

\section{PLAIN LANGUAGE SUMMARY}

\section{Exercise for rheumatoid arthritis of the hand}

\section{What is rheumatoid arthritis and what is exercise?}

Rheumatoid arthritis is a joint disease that frequently affects the hands and wrists. Hand exercise includes mobility, strengthening (with equipment, e.g. putty), or functional training.

\section{Study characteristics}

We found seven studies that compared hand exercise to non-exercise therapies in 841 adults with rheumatoid arthritis.

\section{Key results}

On a 0-to-80-points hand function test, (higher scores mean better function), people who did hand exercises rated their function 1.1 points higher in the short term (less than 3 months). People who did not exercise rated their function at 75 points. 
On a 0-to-100 scale (higher scores mean better function), compared with people who did not exercise, people who exercised rated their hand function 5 points higher in the medium term ( 3 to 11 months) and 4 points higher in the long term ( 12 months or beyond). People who did not exercise rated their function at 52.1 points.

On a 0-to-100-millimetre pain scale (lower scores mean less pain), people who exercised rated their pain $28 \mathrm{~mm}$ lower in the short term. People who did not exercise rated their pain at $68 \mathrm{~mm}$. On a 0-to-100-point scale (lower scores mean less pain), people who exercised rated their pain 3 points lower in the medium and 4 points lower in the long term. People who did not exercise rated their pain at 51.4 points.

People who exercised had 3\% and 4\% improvement in the left and right-hand grip strength in the short term. People who did not exercise measured $14.3 \mathrm{~kg}$ and $15.6 \mathrm{~kg}$, respectively. People who exercised had $1 \%$ improvement in the average grip strength of both hands in both medium and long term. People who did not exercise measured $13.2 \mathrm{~kg}$.

People who exercised had $4 \%$ and $6 \%$ improvement in the left and right hand pinch strength in the short term. People who did not exercise measured $1.2 \mathrm{~kg}$ and $1.2 \mathrm{~kg}$, respectively. People who exercised had $2 \%$ and $3 \%$ improvement in the average pinch strength of both hands in the medium and long term. People who did not exercise measured $4 \mathrm{~kg}$.

It must be noted that although there were apparently better scores in hand function, pain, and grip and pinch strength with hand exercise, these improvements may not equate to useful clinical benefits.

No studies evaluated the American College of Rheumatology 50 criteria (a measure that indicates greater than or equal to $50 \%$ improvement in patient's symptoms with treatment received).

Compared to participants who received usual care, those who also received hand exercises with strategies to stick with the programme were $19 \%$ and $5 \%$ more likely to adhere to their programme in less than a year and beyond one year.

One study reported no adverse effects due to exercising. The remaining studies did not measure this outcome.

\section{Quality of the evidence}

The quality of the evidence was very low to high across outcomes. We lowered the quality of the evidence due to problems with lack of blinding of participants to their allocated treatment and measurements, methods of allocation, and small study sizes. 
SUMMARY OF FINDINGS

\section{Summary of findings for the main comparison. Exercise compared to no exercise for rheumatoid arthritis of the hand}

\section{Exercise compared to no exercise for rheumatoid arthritis of the hand}

Patient or population: rheumatoid arthritis of the hand

Setting: outpatient therapy departments or home settings in Brazil, South Africa, Sweden, the UK, and the USA

Intervention: exercise

Comparison: no exercise

\begin{tabular}{|c|c|c|c|c|c|c|}
\hline \multirow[t]{2}{*}{ Outcomes } & \multicolumn{2}{|c|}{ Anticipated absolute effects ${ }^{*}(95 \% \mathrm{Cl})$} & \multirow{2}{*}{$\begin{array}{l}\text { Relative effect } \\
(95 \% \mathrm{Cl})\end{array}$} & \multirow{2}{*}{$\begin{array}{l}\text { № of partici- } \\
\text { pants } \\
\text { (studies) }\end{array}$} & \multirow{2}{*}{$\begin{array}{l}\text { Quality of the } \\
\text { evidence } \\
\text { (GRADE) }\end{array}$} & \multirow[t]{2}{*}{ Comments } \\
\hline & Risk with no exercise & Risk with exercise & & & & \\
\hline $\begin{array}{l}\text { Hand function - } \\
\text { medium term ( } 3 \text { to } \\
11 \text { months) }\end{array}$ & $\begin{array}{l}\text { Control group baseline } \\
\text { mean hand function was } \\
52.1 \text { points. }\end{array}$ & $\begin{array}{l}4.5 \text { points higher } \\
\text { ( } 1.58 \text { to } 7.42 \text { high- } \\
\text { er) }\end{array}$ & -------------- & $\begin{array}{l}449 \\
(1 \mathrm{RCT})\end{array}$ & $\begin{array}{l}\oplus \oplus \oplus \ominus \\
\text { Moderate } 2\end{array}$ & $\begin{array}{l}\text { Absolute percentage change }(95 \% \mathrm{Cl}) \\
=5 \%(2 \% \text { to } 7 \%)\end{array}$ \\
\hline
\end{tabular}

m term $(3$

52.1 points

Relative percentage change $(95 \% \mathrm{Cl})=$ $9 \%$ (3\% to $14 \%$ )

Overall hand func-

tion subscale of the

Michigan Hand Ques-

tionnaire, 0 to 100

(higher scores mean

better hand func-

An additional study that could not be included

in the meta-analysis provided change scores on

AIMS2. It found no statistically significant im-

\begin{tabular}{|c|c|}
\hline \multirow[t]{2}{*}{-------------- } & 36 \\
\hline & (1 RCT) \\
\hline
\end{tabular}

$\operatorname{NNTB}(95 \% \mathrm{Cl})=8(5$ to 20$)$

A rovements in the change in hand and finger

function from baseline to 6 months for exercise

in comparison to joint protection advice.

\begin{tabular}{|c|c|c|c|c|c|c|}
\hline $\begin{array}{l}\text { Hand function - long } \\
\text { term ( } 12 \text { months and } \\
\text { beyond) }\end{array}$ & $\begin{array}{l}\text { Control group baseline } \\
\text { mean hand function was } \\
52.1 \text { points. }\end{array}$ & $\begin{array}{l}4.3 \text { points higher } \\
\text { ( } 0.86 \text { to } 7.74 \text { high- } \\
\text { er) }\end{array}$ & --------------- & $\begin{array}{l}438 \\
(1 \mathrm{RCT})\end{array}$ & $\begin{array}{l}\oplus \oplus \oplus \ominus \\
\text { Moderate } 2\end{array}$ & $\begin{array}{l}\text { Absolute percentage change }(95 \% \mathrm{Cl}) \\
=4 \%(1 \% \text { to } 8 \%)\end{array}$ \\
\hline
\end{tabular}

Relative percentage change $(95 \% \mathrm{Cl})=$ $8 \%$ (2\% to $15 \%)$

36 participants ( 1 RCT included in narrative synthesis) 
(higher scores mean

better hand func-

tion)

\begin{tabular}{|c|c|c|c|c|c|c|}
\hline $\begin{array}{l}\text { Pain - short term } \\
\text { (less than } 3 \text { months) } \\
\text { visual analogue }\end{array}$ & $\begin{array}{l}\text { Control group base- } \\
\text { line mean pain was } \\
67.6 \mathrm{~mm} \text { a }\end{array}$ & $\begin{array}{l}27.98 \mathrm{~mm} \text { lower } \\
\text { (48.93 to } 7.03 \text { low- } \\
\mathrm{er} \text { ) }\end{array}$ & ---------------- & $\begin{array}{l}124 \\
\text { (2 RCTs) }\end{array}$ & $\begin{array}{l}\oplus \ominus \ominus \ominus \\
\text { Very low } 3\end{array}$ & $\begin{array}{l}\text { Absolute percentage change }(95 \% \mathrm{Cl}) \\
=-28 \%(-49 \% \text { to }-7 \%)\end{array}$ \\
\hline
\end{tabular}

(t)

$67.6 \mathrm{~mm}$ a $^{\mathrm{a}}$

Relative percentage change $(95 \% \mathrm{Cl})=$ $-41 \%(-72 \%$ to $-10 \%)$

higher score means more pain)

$\operatorname{NNTB}(95 \% \mathrm{Cl})=2(2$ to 11$)$

Pain - medium term

(3 to 11 months)

\section{Control group base-}

2.8 points lower

line mean pain was $51.4 \quad$ (6.96 lower to 1.36

higher)

445

Pain subscale of

points.

(1 RCT)

$\oplus \oplus \oplus \odot$

Absolute percentage change $(95 \% \mathrm{Cl})$

comes Questionnaire

(0 to 100 points,

higher score means

more pain)

Pain - long term (12 months and beyond)

Pain subscale of

Michigan Hand Out-

comes Questionnaire

(0 to 100 points,

higher score means

more pain)

Hand impairment -

power grip strength

$(\mathrm{kg})$ - left hand - short

term (less than 3

Control group base-

Control group base- $\quad 3.7$ points lower

line mean pain was $51.4 \quad$ (8.1 lower to 0.7

points.

higher)

Moderate 4

$=-3 \%(-7 \%$ to $2 \%)$

Relative percentage change $(95 \% \mathrm{Cl})=$ $-5 \%(-14 \%$ to $3 \%)$

NNTB was not applicable as results

were not statistically significant.

437

$437 \quad \oplus \oplus \oplus \odot$

Absolute percentage change $(95 \% \mathrm{Cl})$ $=-4 \%(-8 \%$ to $1 \%)$

Relative percentage change $(95 \% \mathrm{Cl})=$ $-7 \%(-15 \%$ to $1 \%)$

NNTB was not applicable as results were not statistically significant.

SMD $0.44(95 \%$ Cl 0.11 to 0.78$)$

SMD re-expressed in $\mathrm{kg}: 3.5 \mathrm{~kg}(95 \% \mathrm{Cl}$ 0.87 to 6.1 )

Relative percentage change $(95 \% \mathrm{Cl})=$ $24 \%$ (6\% to $42 \%$ )

Absolute change and NNTB were not applicable as there is no maximum scale for measuring grip strength.

$\begin{array}{ll}141 & \oplus \ominus \odot \odot \\ \text { (3 RCTs) } & \text { Very low } 5\end{array}$




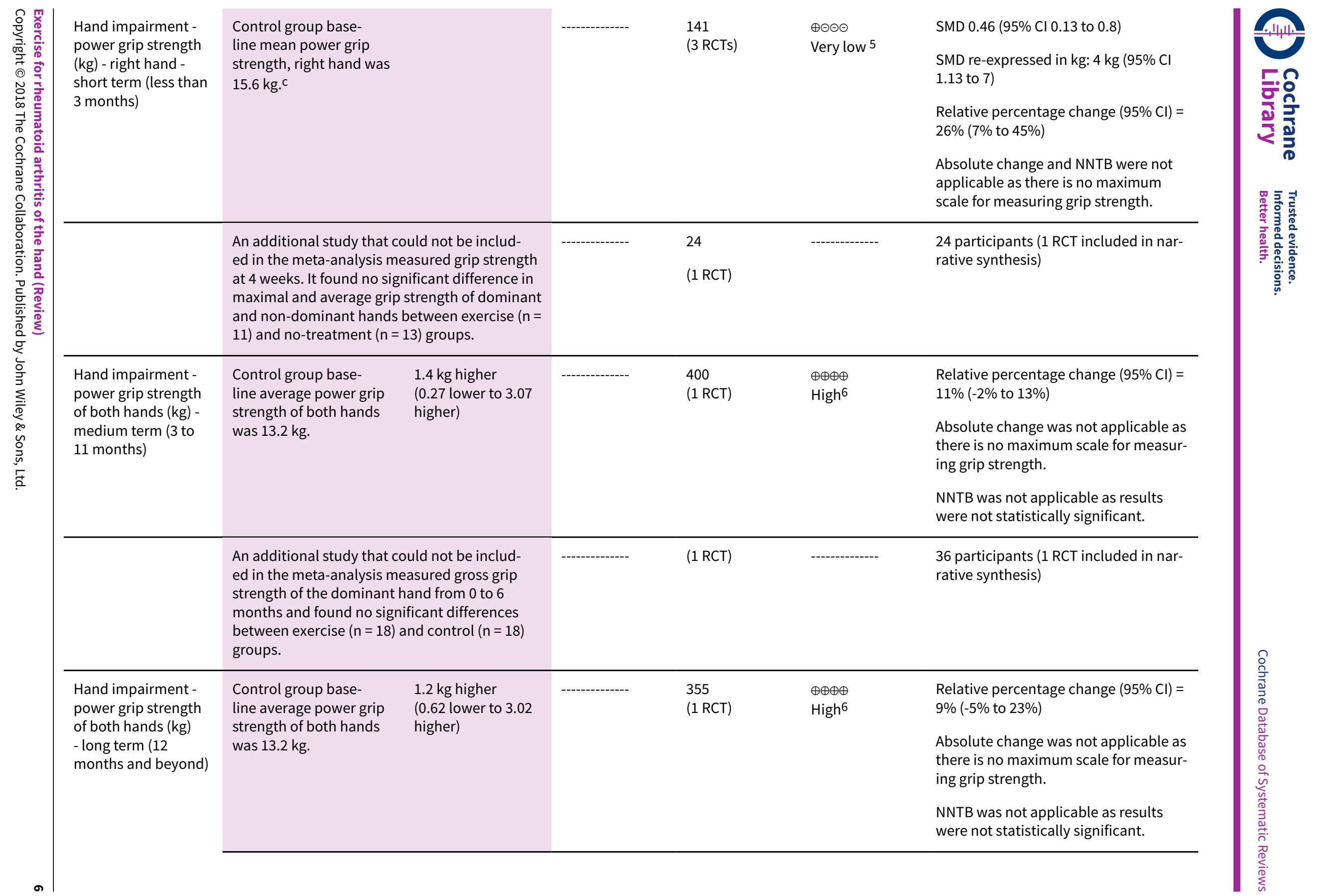


cally significant improvement in grip strength

in the exercise group compared to the no-ex-

ercise control group. At 48 months, the mean

grip strength in the exercise group $(n=19)$ was

$105.7 \mathrm{mmHg}$ and in the control group $(n=25)$

was $44.1 \mathrm{mmHg}$.

\begin{tabular}{|c|c|c|c|c|c|c|}
\hline $\begin{array}{l}\text { Hand impairment - } \\
\text { pinch grip strength } \\
\text { (kg) - left hand - short } \\
\text { term (less than } 3 \\
\text { months) }\end{array}$ & $\begin{array}{l}\text { Control group base- } \\
\text { line mean pinch grip } \\
\text { strength, left hand was } \\
1.2 \mathrm{~kg} .^{\mathrm{d}}\end{array}$ & $\begin{array}{l}0.51 \mathrm{~kg} \text { higher } \\
\text { ( } 0.13 \text { higher to } 0.9 \\
\text { higher) }\end{array}$ & -------------- & $\begin{array}{l}120 \\
\text { (2 RCTs) }\end{array}$ & $\begin{array}{l}\oplus \ominus \ominus \ominus \\
\text { Very low } 7\end{array}$ & $\begin{array}{l}\text { Relative percentage change }(95 \% \mathrm{Cl})= \\
44 \%(11 \% \text { to } 78 \%) \\
\text { Absolute change and NNTB were not } \\
\text { applicable as there is no maximum } \\
\text { scale for measuring pinch strength. }\end{array}$ \\
\hline $\begin{array}{l}\text { Hand impairment - } \\
\text { pinch grip strength } \\
\text { (kg) - right hand - } \\
\text { short term (less than } \\
3 \text { months) }\end{array}$ & $\begin{array}{l}\text { Control group base- } \\
\text { line mean pinch grip } \\
\text { strength, right hand was } \\
1.2 \mathrm{~kg} .\end{array}$ & $\begin{array}{l}0.82 \mathrm{~kg} \text { higher } \\
\text { ( } 0.43 \text { higher to } 1.21 \\
\text { higher) }\end{array}$ & --------------- & $\begin{array}{l}120 \\
\text { (2 RCTs) }\end{array}$ & $\begin{array}{l}\oplus \ominus \ominus \ominus \\
\text { Very low } 7\end{array}$ & $\begin{array}{l}\text { Relative percentage change }(95 \% \mathrm{CI})= \\
68 \%(36 \% \text { to } 101 \%) \\
\text { Absolute change and NNTB were not } \\
\text { applicable as there is no maximum } \\
\text { scale for measuring pinch strength. }\end{array}$ \\
\hline $\begin{array}{l}\text { Hand impairment - } \\
\text { pinch grip strength } \\
\text { of both hands (kg) - }\end{array}$ & $\begin{array}{l}\text { Control group base- } \\
\text { line average pinch grip } \\
\text { strength of both hands }\end{array}$ & $\begin{array}{l}0.3 \mathrm{~kg} \text { higher } \\
\text { ( } 0.14 \text { lower to } 0.74 \\
\text { higher) }\end{array}$ & --------------- & $\begin{array}{l}396 \\
(1 \mathrm{RCT})\end{array}$ & $\begin{array}{l}\oplus \oplus \oplus \oplus \\
\text { High }^{8}\end{array}$ & $\begin{array}{l}\text { Relative percentage change }(95 \% \mathrm{Cl})= \\
8 \%(-4 \% \text { to } 19 \%)\end{array}$ \\
\hline
\end{tabular}

strength

medium te

higher)

Absolute change was not applicable as there is no maximum scale for measuring pinch strength.

NNTB was not applicable as results were not statistically significant.

\begin{tabular}{|c|c|c|c|c|c|c|}
\hline \multirow[b]{2}{*}{$\begin{array}{l}\text { Hand impairment - } \\
\text { pinch grip strength } \\
\text { of both hands (kg) } \\
\text { - long term ( } 12 \\
\text { months and beyond) }\end{array}$} & \multicolumn{2}{|c|}{$\begin{array}{l}1 \text { study measured key grip strength of the dom- } \\
\text { inant hand from } 0 \text { to } 6 \text { months and found sig- } \\
\text { nificant differences between the exercise ( } n= \\
\text { 18) and control }(n=18) \text { groups. }\end{array}$} & \multirow{2}{*}{------------ } & \multirow{2}{*}{$\begin{array}{l}\text { (1 RCT) } \\
\\
351 \\
(1 \mathrm{RCT})\end{array}$} & \multirow{2}{*}{$\begin{array}{l}\text { } \\
\oplus \oplus \oplus \oplus \\
\text { High8 }\end{array}$} & \multirow{2}{*}{$\begin{array}{l}36 \text { participants ( } 1 \mathrm{RCT} \text { included in nar- } \\
\text { rative synthesis) } \\
\text { Relative percentage change }(95 \% \mathrm{Cl})= \\
10 \%(-2 \% \text { to } 22 \%) \\
\text { Absolute change was not applicable as } \\
\text { there is no maximum scale for measur- } \\
\text { ing pinch strength. }\end{array}$} \\
\hline & $\begin{array}{l}\text { Control group base- } \\
\text { line average pinch grip } \\
\text { strength of both hands } \\
\text { was } 4 \mathrm{~kg} .\end{array}$ & $\begin{array}{l}0.4 \text { kg higher } \\
\text { ( } 0.08 \text { lower to } 0.88 \\
\text { higher) }\end{array}$ & & & & \\
\hline
\end{tabular}




\begin{tabular}{|c|c|c|c|c|c|c|}
\hline & & & & & & $\begin{array}{l}\text { NNTB was not applicable as results } \\
\text { were not statistically significant. }\end{array}$ \\
\hline & \multicolumn{2}{|c|}{$\begin{array}{l}\text { An additional, } 4 \text {-year study that could not be } \\
\text { meta-analysed reported a statistically signif- } \\
\text { icant improvement in pinch strength in the } \\
\text { exercise group compared to the no-exercise } \\
\text { control group. At } 48 \text { months, the mean pinch } \\
\text { strength in the exercise group }(n=19) \text { at } 48 \\
\text { months was } 54.8 \mathrm{mmHg} \text { and in the control } \\
\text { group ( } n=25 \text { ) was } 24.8 \mathrm{mmHg} \text {. }\end{array}$} & -------------- & $(1 \mathrm{RCT})$ & -------------- & $\begin{array}{l}44 \text { participants (1 RCT included in nar- } \\
\text { rative synthesis) }\end{array}$ \\
\hline ACR50 response & -------------- & & -------------- & (0 RCTs) & ------------- & No studies evaluated this outcome. \\
\hline $\begin{array}{l}\text { Participant adher- } \\
\text { ence - medium term } \\
\text { ( } 3 \text { to } 11 \text { months) }\end{array}$ & 617 per 1000 & $\begin{array}{l}808 \text { per } 1000 \\
\text { (710 to } 913 \text { ) }\end{array}$ & $\begin{array}{l}\text { RR } 1.31 \\
\text { (1.15 to } 1.48)\end{array}$ & $\begin{array}{l}438 \\
(1 \mathrm{RCT})\end{array}$ & $\begin{array}{l}\oplus \oplus \oplus \odot \\
\text { Moderate } 9\end{array}$ & $\begin{array}{l}\text { Absolute percentage change }(95 \% \mathrm{Cl}) \\
=19 \%(9 \% \text { to } 29 \%) \\
\text { NNTB }(95 \% \mathrm{Cl})=6(4 \text { to } 10)\end{array}$ \\
\hline $\begin{array}{l}\text { Participant adher- } \\
\text { ence - long term ( } 12 \\
\text { months and beyond) }\end{array}$ & 569 per 1000 & $\begin{array}{l}621 \text { per } 1000 \\
(530 \text { to } 729)\end{array}$ & $\begin{array}{l}\text { RR } 1.09 \\
\text { (0.93 to } 1.28 \text { ) }\end{array}$ & $\begin{array}{l}422 \\
(1 \mathrm{RCT})\end{array}$ & $\begin{array}{l}\oplus \oplus \oplus \ominus \\
\text { Moderate }^{9}\end{array}$ & $\begin{array}{l}\text { Absolute percentage change }(95 \% \mathrm{Cl}) \\
=5 \%(-4 \% \text { to } 15 \%) \\
\text { NNTB was not applicable as results } \\
\text { were not statistically significant. }\end{array}$ \\
\hline $\begin{array}{l}\text { Adverse events due } \\
\text { to exercise }\end{array}$ & $\begin{array}{l}\text { No adverse events were } \\
\text { reported in } 246 \text { exercise } \\
\text { group participants. }\end{array}$ & -------------- & ------------- & $\begin{array}{l}490 \\
(1 \mathrm{RCT})\end{array}$ & $\begin{array}{l}\oplus \oplus \oplus \ominus \\
\text { Moderate } 10\end{array}$ & $\begin{array}{l}\text { No adverse events were reported in } \\
\text { either the exercise or control group, } \\
\text { therefore it was not possible to calcu- } \\
\text { late an estimate of absolute/relative } \\
\text { effect. The other } 6 \text { studies did not re- } \\
\text { port adverse events. }\end{array}$ \\
\hline
\end{tabular}

${ }^{\star}$ The risk in the intervention group (and its $95 \%$ confidence interval) is based on the assumed risk in the comparison group and the relative effect of the intervention (and its $95 \% \mathrm{Cl})$.

ACR50: American College of Rheumatology 50; AIMS2: Arthritis Impact Measurement Scales 2; CI: confidence interval; NNTB: number needed to treat for an additional beneficial outcome; $\mathbf{R C T}$ : randomised controlled trial; RR: risk ratio; SMD: standardised mean difference

\section{GRADE Working Group grades of evidence}

High quality: We are very confident that the true effect lies close to that of the estimate of the effect.

Moderate quality: We are moderately confident in the effect estimate: the true effect is likely to be close to the estimate of the effect, but there is a possibility that it is substantially different.

Low quality: Our confidence in the effect estimate is limited: the true effect may be substantially different from the estimate of the effect.

Very low quality: We have very little confidence in the effect estimate: the true effect is likely to be substantially different from the estimate of effect. 
1Downgraded three levels for risk of bias (unclear risk of selection bias, high risk of performance bias, unclear risk of detection bias in measuring objective hand function, unclear risk of attrition bias) and imprecision (total number of participants less than 400).

2Downgraded one level for risk of bias (high risk of performance and detection bias in measuring self reported hand function).

${ }^{3}$ Downgraded three levels for risk of bias (unclear risk of selection bias, high risk of performance and detection bias in measuring self reported pain, unclear risk of attrition bias) and imprecision (total number of participants less than 400 ).

${ }^{4}$ Downgraded one level for risk of bias (high risk of performance and detection biases in measuring self reported pain).

${ }^{5}$ Downgraded three levels for risk of bias (unclear risk of selection bias, high risk of performance bias, unclear or high risk of detection bias in measuring objective grip strength, unclear or high risk of attrition bias) and imprecision (total number of participants less than 400).

6 We considered the risk of performance bias with objectively measured grip strength not a significant reason for downgrading the evidence.

${ }^{7}$ Downgraded three levels for risk of bias (unclear risk of selection bias, high risk of performance bias, and unclear or high risk of detection bias) and imprecision (total number of participants less than 400).

8 We considered the risk of performance bias with objectively measured pinch strength not a significant reason for downgrading the evidence.

9 Downgraded one level for risk of bias (high risk of performance and detection bias in measuring self reported participant adherence).

10Downgraded one level for risk of bias (high risk of performance and detection bias in measuring self reported adverse events).

a, b, c, d, eBuljina 2001 is the source document for the control group baseline data. 


\section{B A C K G R O U N D}

\section{Description of the condition}

Rheumatoid arthritis (RA) is the most common inflammatory polyarthritis, affecting approximately $1 \%$ of the population (Symmons 2002). The aetiology is still unclear, but the pathogenesis involves a series of immunological events that result in chronic inflammation. A majority of people with RA have involvement of the hands and wrists (Horsten 2010). Frequent problems for the hands and wrists are inflammation, deformity, pain, weakness, and restricted mobility, resulting in loss of function (Adams 2004). There are common types of deformities at the wrists, metacarpal-phalangeal, finger, and thumb joints. It has been reported that hand strength in people with RA is 75\% lower than in the non-RA population (Jones 1991). Reduction in mobility of the hands and wrists has also been documented (Horsten 2010). Rheumatoid arthritis has no known cure, although there are increasingly effective drug treatments for providing symptomatic control (Katchamart 2010; Singh 2009; Suarez-Almazor 1998). The goals of management are therefore to prevent or control joint damage, improve hand function, and reduce pain.

\section{Description of the intervention}

The goals of management are to prevent or control joint damage, improve hand function, and reduce pain. People with RA are often referred to physical and occupational therapists to achieve these goals. The three most common components of the therapies they provide for hands with RA are exercise, joint protection advice, and provision of functional splinting and assistive devices (Hammond 2004b; Steultjens 2004; Tuntland 2009).

\section{How the intervention might work}

Exercises are aimed at improving both the mobility and strength of the hand, and therefore improving functional ability. Exercises may include simple through-range mobilising exercises to increase and/ or maintain range of motion in joints and surrounding soft tissues, or strengthening exercises that use resistance from putty, a gel ball, or elastic band to strengthen hand and wrist muscles. Exercises usually incorporate the wrist due to the essential involvement of the wrist in functional activities of the hand (i.e. positioning for mechanical efficiency).

\section{Why it is important to do this review}

There is one previously published systematic review evaluating studies of exercises for RA of the hand, which concluded that the value of hand exercise for RA was uncertain (Wessel 2004). It did not attempt a meta-analysis. A number of new trials have been published since that review (e.g. Cima 2013; Lamb 2015; O'Brien 2006). To date, it is unclear if hand exercise for RA is effective.

\section{OB JECTIVES}

To determine the benefits and harms of hand exercise in adults with rheumatoid arthritis.

\section{METHODS}

\section{Criteria for considering studies for this review}

\section{Types of studies}

We included all randomised controlled trials or controlled clinical trials that used quasi-randomised methods for treatment allocation.

\section{Types of participants}

We included trials in which adults (males and females aged above 18 years) with a diagnosis of RA participated. We excluded studies that included a mixture of both adults and participants less than 18 years unless there were sufficiently detailed data to isolate the findings for the adult participants.

\section{Types of interventions}

We included trials where exercise for RA of the hand was compared with no treatment, usual care, placebo, medication, surgery, therapeutic modalities, or other non-exercise therapies. We considered all forms of exercise such as range of motion, stretching, and strength exercises and functional skills training.

\section{Types of outcome measures}

We included trials where the assessment had at least one measure covering the following constructs. For outcomes assessing benefits and harms, we extracted and defined outcomes at three time point categories: short term (less than 3 months), medium term ( 3 to 11 months), and long term (12 months or beyond), and at the end of the trial for adverse events. For trials that reported outcomes at multiple time points, we selected the longest follow-up (Deeks 2011).

\section{Major outcomes}

1. Hand function: consists of several combined components including strength, mobility, co-ordination, and structure, and is assessed objectively or by self report (e.g. measured by a subscale of the Arthritis Impact Measurement Scale 2; Michigan Hand Outcomes Questionnaire; Disabilities of Arm, Shoulder and Hand questionnaire; Sequential Occupational Dexterity Assessment; Arthritis Hand Function Test).

2. Pain (e.g. measured with a visual analogue scale).

3. Hand impairment measures: power grip strength (gross hand grip).

4. Hand impairment measures: pinch grip strength (tip-to-tip/ tripod pinch grip).

5. American College of Rheumatology (ACR) 50 response criteria (Felson 1995).

6. Participant adherence.

7. Adverse events due to exercise (exercise-induced injuries, substantial increase in pain, increase in number of swollen or tender joints, radiological damage to joints in the hand).

\section{Minor outcomes}

1. Hand impairment measures of range of motion, dexterity, deformity, and hand stiffness.

2. General function (preferably measured by the Health Assessment Questionnaire).

3. Disease Activity Score (DAS 28) (Van der Heijde 1993). 
4. Patient satisfaction.

5. Costs.

6. Change in splint or assistive device usage.

\section{Search methods for identification of studies}

\section{Electronic searches}

We searched the Cochrane Central Register of Controlled Trials (CENTRAL; published in the Cochrane Library, June 2017), MEDLINE (1946 to 17 July 2017), Embase (1947 to 14 July 2017), CINAHL (Cumulative Index of Nursing and Allied Health Literature) (1982 to 25 July 2017), AMED (Allied and Complementary Medicine Database) (1985 to 25 July 2017), PEDro (Physiotherapy Evidence Database), OTseeker, Web of Science database, and the trial registers ClinicalTrials.gov (clinicaltrials.gov) and World Health Organization International Clinical Trials Registry Platform (WHO ICTRP) (www.who.int/ictrp/en) on 25 July 2017.

We consulted the Cochrane Musculoskeletal Group Information Specialist to develop an optimal search strategy. There were search strings for condition, intervention, body area, and identifying randomised trials (according to the sensitivity-maximising version of the Cochrane Highly Sensitive Search Strategy (Lefebvre 2011). See Appendix 1 for the full search strategy. We modified the MEDLINE search strategy for use in Embase, CINAHL, and the Cochrane Library. In addition, investigation of the bibliographies of retrieved studies and personal communication with recognised leaders in the field completed the search for relevant studies. We applied no language restrictions in the searches.

\section{Data collection and analysis}

\section{Selection of studies}

Two review authors (MW, PH) independently screened the titles or abstracts obtained by our search of the databases and screened the retrieved studies for inclusion. Each potential title was examined and, where titles were ambiguous, the abstract was sought. Studies that clearly or potentially contained an exercise component aimed at RA of the hand were retrieved for further evaluation. We attempted to contact authors for additional information where necessary.

\section{Data extraction and management}

Two of four review authors (MW, PH, NH-T, and JB) extracted the data for each of the included studies. We developed a standard data extraction form to list study details. We systematically extracted the following information: sample size, sample demographics (age, sex, disease duration), recruitment method, selection criteria, description of intervention and control groups (location, type of exercise, frequency, duration, and intensity), supervision and delivery of intervention (trained professional, therapy assistant, other, self administered, and group versus individual), other methods, outcomes. We anticipated that the analysis would mainly be concerned with continuous outcome measures, in which case mean changes from baseline with standard deviations were extracted where possible.

\section{Assessment of risk of bias in included studies}

Two of four review authors (MW, PH, NH-T, and JB) assessed the risk of bias.The six key domains to assess risk of bias were: adequate sequence generation; allocation concealment and blinding of participants, personnel, and outcome assessors; incomplete outcome data; free of selective reporting; free of other biases (Higgins 2011a). Any disagreements were resolved by discussion or by consulting a third review author (JB) when necessary.

Three of the authors of this systematic review, Sarah E Lamb, Peter Heine, and Mark Williams, are authors of one of the studies included in the review (Lamb 2015, also reported in Williams 2015). Sarah E Lamb, Peter Heine, and Mark Williams were not involved in data extraction or 'Risk of bias' assessment for their own study (Lamb 2015); two other review authors (JB, NH-T) carried this out.

\section{Measures of treatment effect}

For continuous variables, a mean difference (MD) or standardised mean difference (SMD) with corresponding 95\% confidence interval (CI) was expressed, depending on the similarity of measurement scales. We calculated risk ratios (RRs) with corresponding 95\% Cls for dichotomous variables. We also calculated absolute percentage change, relative percentage change from baseline, and number needed to treat for an additional beneficial outcome (NNTB) only when an outcome showed a statistically significant difference. We calculated the NNTB for continuous outcomes with the available minimal clinically important difference (MCID) values using the Codfish calculator provided by the Cochrane Musculoskeletal Group (musculoskeletal.cochrane.org).

\section{Dealing with missing data}

We undertook analysis with the available data. Where data were missing from trial reports, we attempted to contact trial authors. We planned to consider the potential impact of missing data on the findings of the review in the interpretation of bias. Where possible, we planned to calculate missing standard deviations from other statistics such as standard errors, confidence intervals, or $\mathrm{P}$ values, according to the methods recommended in the Cochrane Handbook for Systematic Reviews of Interventions (Higgins 2011b).

\section{Assessment of heterogeneity}

We judged heterogeneity from both a clinical and a statistical perspective. We evaluated statistical heterogeneity using the $\mathrm{Chi}^{2}$ test for trend and a graphical display of the data (funnel plot). We quantified inconsistency across studies using the $\mathrm{I}^{2}$ statistic, which we interpreted as follows: $0 \%$ to $40 \%$ might not be important; $30 \%$ to $60 \%$ may represent moderate heterogeneity; $50 \%$ to $90 \%$ may represent substantial heterogeneity; $75 \%$ to $100 \%$ considerable heterogeneity (Deeks 2011).

We judged clinical heterogeneity on the basis of the similarities between study participants, exercise protocols, and outcome measures. If there was moderate heterogeneity ( $\mathrm{Chi}^{2} \mathrm{P}<0.05$ and $1^{2}$ value $>30 \%$ ), we planned to use a random-effects model. We combined data using a fixed-effect model if there was no clinical and no important statistical heterogeneity $(12<40 \%)$.

\section{Assessment of reporting biases}

To assess the potential for reporting bias, we determined whether the protocol of the randomised controlled trial was published before recruitment of participants had begun. For trials published after 1 July 2005, we screened the World Health Organization International Clinical Trials Registry Platform (WHO 
ICTRP) (apps.who.int/trialsearch). We reported the potential for selective reporting of outcomes in the 'Risk of bias' assessment. We planned to explore publication bias with funnel plots if 10 or more studies were available (Sterne 2011).

\section{Data synthesis}

Where appropriate, we performed meta-analysis. For analysis of continuous data, we used mean difference and a fixed-effect model as the default. For dichotomous data, we planned to calculate risk ratios using a fixed-effect model. The Summary of findings for the main comparison includes comments on the quality of the body of evidence according to the GRADE approach (Schünemann 2011).

\section{Subgroup analysis and investigation of heterogeneity}

Where the data allowed, we planned to perform subgroup analysis to assess the effect of exercise type (resistance versus mobility); intervention frequency (at least once per day versus other less frequent); and intervention duration ( $<3$ months versus 12 months or beyond).

\section{Sensitivity analysis}

If there were sufficient data, we planned to conduct sensitivity analysis for our primary outcomes to assess the effect of bias (e.g. by restricting the analysis to studies with low risk of selection bias due to the use of adequate methods of allocation concealment).

\section{Summary of findings table}

We produced the Summary of findings for the main comparison table using the GRADEPro software. The table lists the magnitude of effects of hand exercise and the quality of the available evidence. We compared hand exercise to no-exercise, waiting list or usual care in people with rheumatoid arthritis on the outcomes mentioned below. We used the GRADE approach recommended in the Cochrane handbook for systematic reviews of interventions to evaluate the quality of the evidence.

1. Hand function.

2. Pain.

3. Hand impairment: power grip strength.

4. Hand impairment: pinch grip strength.

5. ACR50 response criteria.

6. Participant adherence.

7. Adverse events.

\section{RESULTS}

\section{Description of studies}

See: Characteristics of included studies; Characteristics of excluded studies.

\section{Results of the search}

The search yielded 1335 records, of which 951 were non-duplicate citations. We excluded 910 records on the basis of title and abstract screening and retrieved the remaining 41 for full-text review. We deemed seven randomised controlled trials eligible for inclusion in the review. A flow diagram of the selection process is presented in Figure 1. 
Figure 1. Flow diagram of search outcomes.

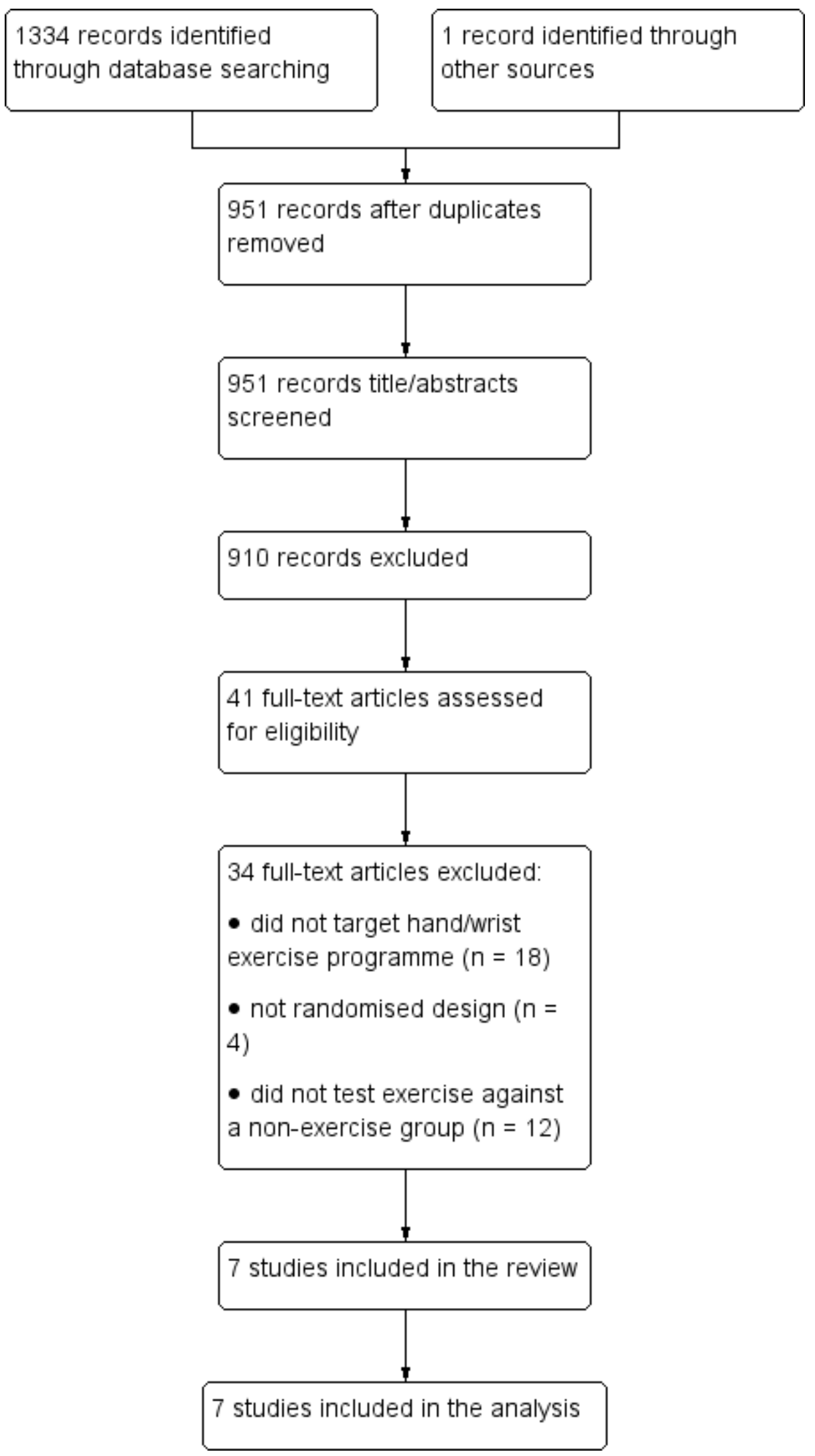




\section{Included studies}

\section{Contact with authors}

We attempted to contact authors of all seven included studies to retrieve information about study conduct, outcome measures, information required to complete 'Risk of bias' assessments, or incomplete data. We received responses from authors of Cima 2013, Hoenig 1993, and Lamb 2015. The authors of two studies provided details on study methods, outcomes, and further data (Cima 2013; Lamb 2015). The authors of one study replied saying they no longer had access to the requested data (Hoenig 1993).

\section{Study design}

The included studies were published between 1993 and 17 July 2017, and all were randomised controlled trials using two-, three-, or four-arm comparisons. Two studies used a control intervention of joint protection advice (in Lamb 2015 and O'Brien 2006), plus optional functional splinting (in Lamb 2015). The remaining five studies used a control intervention of no treatment with maintenance of normal medication regimen. The studies were conducted in outpatient or home settings in Brazil, South Africa, Sweden, the UK, and the USA.

\section{Participants}

All studies included participants with a diagnosis of RA, although only four studies reported using validated diagnostic criteria (either American College of Rheumatology or American Rheumatism Association) (Buljina 2001; Hoenig 1993; Lamb 2015; O'Brien 2006). Disease duration was specified as a selection criterion in two studies (Buljina 2001; Dellhag 1992). In the six studies that reported disease duration, this ranged from five to 14 years. Three studies stipulated that medications should be stable on entry (Hoenig 1993; Lamb 2015; O'Brien 2006).

The total number of participants within studies ranged from 20 , in Cima 2013, to 490, in Lamb 2015, and group sizes ranged from 7, in Cima 2013, to 246, in Lamb 2015. The majority of participants across studies were female ( $n=655,78 \%$ ), with two studies including solely female participants (Brighton 1993; Cima 2013). The age range of participants was 20 to 94 years, although only four studies provided data on age range (Cima 2013; Hoenig 1993; Lamb 2015; O'Brien 2006).

Baseline disease activity measures were reported in the form of erythrocyte sedimentation rate (ESR) in three studies (Brighton 1993; Buljina 2001; Lamb 2015), on swollen and tender joint counts in four studies (Buljina 2001; Hoenig 1993; Lamb 2015; O'Brien 2006), and on C-reactive protein (CRP) levels in one study (Lamb 2015). Three studies also reported medication status at or near baseline (Brighton 1993; Buljina 2001; Lamb 2015). Lamb 2015 reported that over $90 \%$ of participants were being treated with conventional, non-biologic disease-modifying antirheumatic drugs (DMARDs) (e.g. methotrexate, hydroxychloroquine) or biologic DMARDs at baseline. Another study reported on medication three months prior to the study, with the majority of participants prescribed traditional DMARDs or steroids, or both, alongside non-steroidal anti-inflammatory drugs (NSAIDs) (Buljina 2001). All participants in Brighton 1993 were reported to be having either gold salt injections or D-penicillamine together with an antiinflammatory drug.

\section{Interventions}

Types of exercises, exercise goals, numbers of repetitions, numbers of sets, duration of the intervention, types of supervision, and methods of exercise instruction were reviewed.

All seven studies evaluated different hand exercise interventions (Table 1). Six studies evaluated hand exercise programmes involving a combination of different exercise types (e.g. strengthening, stretching, and dexterity) (Brighton 1993; Buljina 2001; Cima 2013; Hoenig 1993; Lamb 2015; O'Brien 2006). Two of these studies also had additional groups randomised to programmes of the separate exercise types (Hoenig 1993; O'Brien 2006).

Brighton 1993 evaluated a combined daily exercise programme of dexterity, stretching, and strengthening exercises compared to a control of no exercises. Buljina 2001 evaluated a combined daily exercise programme of stretching and strengthening exercises compared to a waiting-list control. Cima 2013 evaluated a combined exercise programme of stretching and strengthening exercises performed five days per week compared to a control of no exercises. Dellhag 1992 evaluated three different thrice-weekly exercise regimens compared to no therapy treatments: stretching exercises only, stretching exercises with a wax bath, and a wax bath only. Hoenig 1993 evaluated three different daily interventions compared to no exercises: stretching exercises only, strengthening exercises only, and a combination of stretching and strengthening exercises and treatments. Lamb 2015 evaluated a combined daily exercise programme of strengthening and stretching exercises along with joint protection education and advice compared to joint protection education and advice alone. O'Brien 2006 evaluated two different daily interventions compared to joint protection education: stretching and strengthening exercises and stretching exercises alone.

Exercise supervision varied considerably from daily supervision with a therapist for three weeks in Buljina 2001 to four years with six-monthly check-ups in Brighton 1993. The majority of studies relied on participants performing exercise programmes at home (Brighton 1993; Cima 2013; Hoenig 1993; Lamb 2015; O'Brien 2006).

\section{Outcomes}

Across the seven studies, outcomes were measured in 11 different domains (hand function, pain, adverse events, hand impairment, general function, disease activity, adherence, treatment satisfaction, costs/cost-effectiveness, medication changes, and health-related quality of life). All studies measured hand impairment in some form, although variation of measurement tools was wide. Three studies measured hand function, all with different tools (Dellhag 1992; Lamb 2015; O'Brien 2006). Length of follow-up ranged from three weeks, in Buljina 2001, to four years, in Brighton 1993 , the most common endpoint being short term (i.e. less than 3 months) (Buljina 2001; Cima 2013; Dellhag 1992; Hoenig 1993). Medium-term outcomes were available from two studies (Lamb 2015; O'Brien 2006). Only two studies reported long-term outcomes (i.e. 12 months or beyond) (Brighton 1993; Lamb 2015).

\section{Excluded studies}

Of the 41 studies retrieved for full-text review, most did not evaluate an exercise programme specific to RA of the hand $(n=18$, Azeez 2014; Baillet 2009; Bearne 2012; Berntzen 2016; Cakir 2014; Dash 
2001; De Jong 2004; Flint-Wagner 2009; Hansen 1993; Kiraly 2015; Lineker 2001; Minor 1995; Orlova 2016; Pineda-Juárez 2016; PotVaucel 2016; Seneca 2015; Shapoorabadi 2016; Tee 2016), or did not compare an exercise programme to a non-exercise comparator ( $n=12$, Brorsson 2014; Byers 1985; Dogu 2013; Dulgeroglu 2014; Dülgeroğlu 2016; Hammond 2004a; Hawkes 1985; Hawkes 1986; Khedekar 2017; Piga 2014; Srikesavan 2016; Veitiene 2004). Another reason for exclusion was studies not using a randomised design $(n=$ 4, Brorsson 2009; Maxwell 2005; Rapoliene 2006; Ronningen 2008).

\section{Risk of bias in included studies}

Full details of risk of bias for the seven included studies are available in the 'Risk of bias' tables (see Characteristics of included studies), and a summary is presented in Figure 2. We considered no studies to be at low risk of bias for all of the eight defined categories, although we judged two studies to be at low risk for all categories apart from blinding of participants and therapy personnel, which is likely to be the best scenario that can be achieved for these types of interventions (Lamb 2015; O'Brien 2006). The remaining studies varied in their risk of bias across categories. 
Figure 2. Risk of bias summary: review authors' judgements about each risk of bias item for each included study.

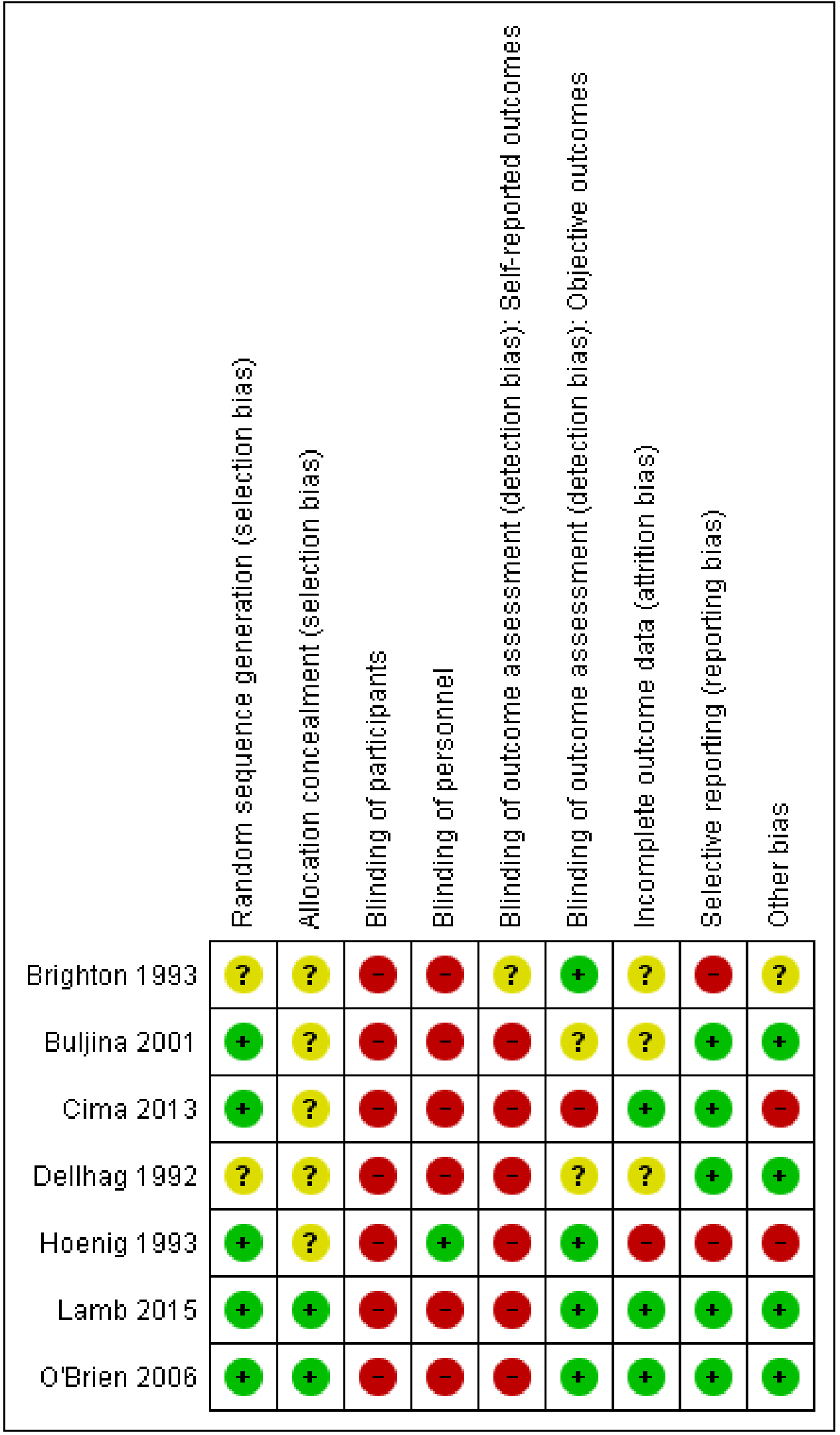




\section{Allocation}

\section{Random sequence generation}

Five studies were at low risk of bias for sequence generation (Buljina 2001; Cima 2013; Hoenig 1993; Lamb 2015; O'Brien 2006): two studies used a random number table (Buljina 2001; Hoenig 1993), and three studies employed a computer-generated randomisation list (Cima 2013; Lamb 2015; O'Brien 2006).

Two studies did not provide sufficient details of the method used and were therefore considered to be at unclear risk of bias for sequence generation (Brighton 1993; Dellhag 1992).

\section{Allocation concealment}

Only two studies provided details of their allocation procedure; we considered these to be at low risk of bias (Lamb 2015; O'Brien 2006). The remaining studies did not provide any information as to whether the allocation was concealed and were considered to be at unclear risk of bias for allocation concealment.

\section{Blinding}

\section{Participants}

We judged all seven included studies to be at high risk of bias due to lack of blinding of participants.

\section{Study personnel}

We judged six studies to be at high risk of bias due to lack of blinding of personnel. In one study (Hoenig 1993), participants were instructed in all exercise programmes and then informed in writing which programme to continue. Therapists were therefore blinded to which intervention the participant received, hence this study was considered to be at low risk of bias for therapist blinding. However this solution raises another potential source of bias in the form of treatment contamination.

\section{Outcome assessment}

All studies except Brighton 1993 that measured self reported outcomes were at high risk of detection bias, as participants were not blinded to self reported outcomes assessment. We judged four studies to be at low risk of detection bias, as they reported blinded assessors for measuring objective outcomes (Brighton 1993; Hoenig 1993; Lamb 2015; O'Brien 2006). In two studies the risk of bias was unclear (Buljina 2001; Dellhag 1992). In Cima 2013, the assessor and therapists were not blinded as they were involved in both the assessment and evaluation, though not the analysis. We therefore deemed this study as at high risk for detection bias.

\section{Incomplete outcome data}

We assessed three studies as at low risk of bias for this domain (Cima 2013; Lamb 2015; O'Brien 2006). O'Brien 2006 and Lamb 2015 used intention-to-treat analysis, and Lamb 2015 investigated the effects of missing data. Following our obtaining unpublished data and rationale for dropouts, we also considered Cima 2013 to be at low risk of bias. We considered three studies as at unclear risk of bias (Brighton 1993; Buljina 2001; Dellhag 1992). We judged Hoenig 1993 as at high risk of bias as the dropouts had RA for a significantly longer period of time, and the analysis also excluded non-compliant participants and those with changes to medication.

\section{Selective reporting}

We rated five studies as at low risk of bias (Buljina 2001; Cima 2013; Dellhag 1992; Lamb 2015; O'Brien 2006). Two studies reported measuring outcomes but failed to present corresponding data (Brighton 1993; Hoenig 1993). Brighton 1993 failed to present any data on intermediate outcome time points between baseline and four years, and Hoenig 1993 failed to report on the global assessment of arthritis severity, so we judged both of these studies as at high risk of bias.

\section{Other potential sources of bias}

We judged the majority of studies to be balanced at baseline (Buljina 2001; Dellhag 1992; Lamb 2015; O'Brien 2006). The Cima 2013 study presented no baseline characteristics other than participant age, and Brighton 1993 made no reference to the comparability of participant baseline characteristics between groups. The Hoenig 1993 control group had a higher baseline function in the left hand.

Two studies did not declare their funding sources (Brighton 1993; Buljina 2001). We deemed there to be a risk of treatment contamination bias in the Hoenig 1993 study, as all three exercise regimens were demonstrated to all participants, and then they were instructed remotely to only carry out one of the exercise regimens they had been taught.

\section{Effects of interventions}

See: Summary of findings for the main comparison Exercise compared to no exercise for rheumatoid arthritis of the hand

See Summary of findings for the main comparison for the main comparison.

\section{Major outcomes \\ Hand function}

Three studies evaluated hand function (Table 2) (Dellhag 1992; Lamb 2015; O'Brien 2006). Dellhag 1992 clinically assessed hand grip function of the dominant hand using the Sollerman grip function test; Lamb 2015 used the Michigan Hand Outcome Questionnaire (MHQ) overall hand function subscale; and O'Brien 2006 used the Arthritis Impact Measurement Scale 2 (AIMS 2) hand function subscale. Lamb 2015 assessed hand function at 4 and 12 months, whilst the other studies did not evaluate the long-term effects of exercise on hand function.

Dellhag 1992 reported no statistically significant differences between groups for Sollerman grip function scores at four weeks. The exercise group $(n=11)$ measured 76.1 points, while the notreatment control group $(n=13)$ measured 75 points on the Sollerman grip function test scale of 0 to 80 points (higher scores mean better grip function). We could not meta-analyse the results from this study due to insufficient reporting of data.

Two studies reported hand function outcomes in the medium term (Lamb 2015; O'Brien 2006). Raw scores were only available for Lamb 2015 ( $n=490)$, and O'Brien 2006 presented change scores on the AIMS 2 scale. The change in hand and finger function of the AIMS scale (0 to 10 , higher scores mean more difficulty) from baseline to 6 months in the exercise group $(n=18)$ was $0.97(1.72)$ and in the 
control group ( $\mathrm{n}=18)$, which received joint protection advice, 0.38 (1.68), $\mathrm{P}=0.414$ (O'Brien 2006).

Figure 3 (Analysis 1.1) presents the forest plot for the results from Lamb 2015. Compared to usual care (joint protection education, general exercise advice, and functional splinting), exercise in additon to the usual care improved hand function (both hands) in the medium term (mean difference (MD) 4.5 points, $95 \%$ confidence interval $(\mathrm{Cl}) 1.58$ to $7.42 ; n=449)$ and in the long term (MD 4.3, $95 \% \mathrm{Cl} 0.86$ to $7.74 ; \mathrm{n}=438)$. In the medium term, the absolute percentage change on the 0 -to- 100 overall hand function subscale of the MHQ (higher scores mean better hand function) was 5\% (95\% $\mathrm{Cl} 2 \%$ to $7 \%$ ); relative percentage change $9 \%$ (95\% Cl $3 \%$ to $14 \%$ ); and number needed to treat for an additional beneficial outcome (NNTB) $8(95 \% \mathrm{Cl} 5$ to 20$)$. In the long term, the absolute percentage change was $4 \%(95 \% \mathrm{Cl} 1 \%$ to $8 \%)$; relative percentage change $8 \%$ ( $95 \% \mathrm{Cl} 2 \%$ to $15 \%)$; and NNTB 9 (95\% $\mathrm{Cl} 6$ to 27 ). Based on the MCID of 13 points for MHQ overall hand function in RA (Shauver 2009), a $4 \%$ to $5 \%$ absolute improvement on a 0 -to-100 scale suggests a minimal clinical benefit.

\section{Figure 3. Forest plot of comparison: 1 Exercise versus control, outcome: 1.1 Hand function as measured by the} Michigan Hand Outcomes Questionnaire.

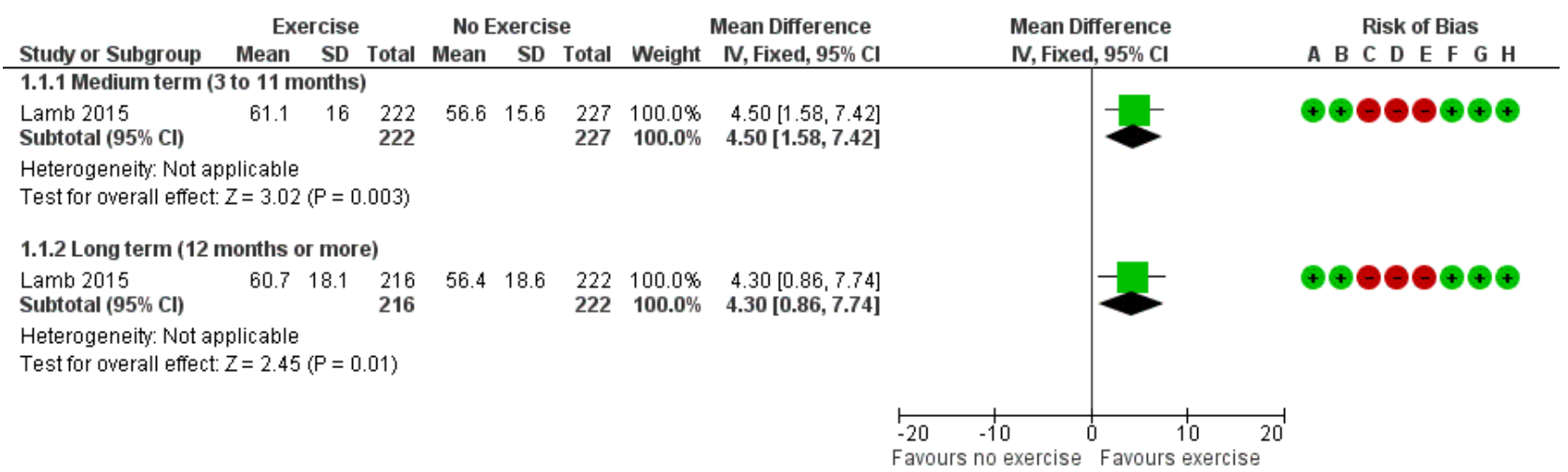

Risk of bias legend

(A) Random sequence generation (selection bias)

(B) Allocation concealment (selection bias)

(C) Blinding of participants

(D) Blinding of personnel

(E) Blinding of outcome assessment (detection bias): Self-reported outcomes

(F) Incomplete outcome data (attrition bias)

(G) Selective reporting (reporting bias)

(H) Other bias

The same study, Lamb 2015, conducted an extended follow-up on hand function outcome (Williamson 2017). The mean follow-up time was 26 months (range 19 to 40 months), and there was no difference in change in hand function from baseline between the two groups (MD 1.52, 95\% Cl-1.71 to 4.76; $\mathrm{n}=328$ ). As these data were collected through postal questionnaires and did not represent the primary endpoint of the trial, we did not include them in the analysis.

\section{Pain}

Four studies evaluated pain (Buljina 2001; Dellhag 1992; Hoenig 1993; Lamb 2015). Hoenig 1993 did not report pain results.
Two studies reported the effects of exercise on pain intensity in the short term and found statistically significant improvements in favour of hand exercise (Buljina 2001; Dellhag 1992). Figure 4 presents the forest plot for the results from Buljina 2001 and Dellhag 1992. The results indicated that exercise compared to waiting list or no treatment reduced pain intensity in the short term (MD -27.98, 95\% Cl-48.93 to -7.03; $\mathrm{n}=124$ ). The absolute percentage change on 0-to-100-millimetre scale (higher scores mean more pain) was $-28 \%(95 \% \mathrm{Cl}-49 \%$ to $-7 \%)$; relative percentage change $-41 \%(95 \% \mathrm{Cl}-72 \%$ to $-10 \%)$; and NNTB 2 ( $95 \% \mathrm{Cl} 2$ to 11 ). Although the difference between groups exceeded the MCID of $10 \mathrm{~mm}$ of pain (Kitchen 2013), these findings should be interpreted with caution as both studies were downgraded for risk of bias and imprecision. 
Figure 4. Forest plot of comparison: 1 Exercise versus control, outcome: 1.2 Pain.

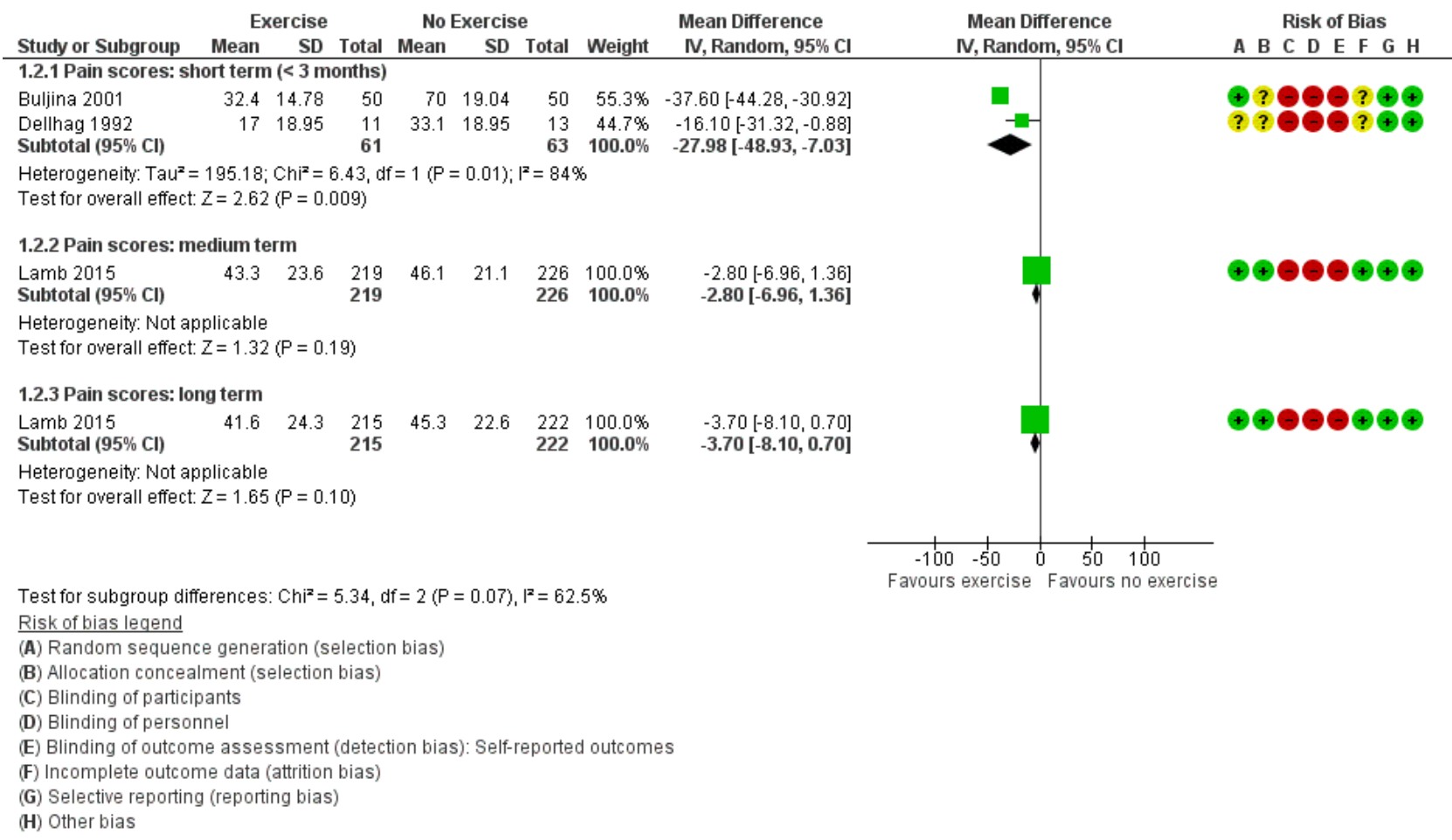

One large study, Lamb 2015, showed a non-significant decrease in pain intensity in the exercise group compared to usual care in the medium term (MD -2.8, 95\% Cl -6.96 to $1.36 ; n=445$ ) (Figure 4; Analysis 1.2), with an absolute percentage change of $-3 \%(95 \% \mathrm{Cl}$ $-7 \%$ to $2 \%)$ and relative percentage change $-5 \%(95 \% \mathrm{Cl}-14 \%$ to $3 \%)$ on 0-to-100 pain subscale of the MHQ (higher scores mean more pain). The same study indicated a non-significant decrease in pain in the exercise group compared to usual care in the long term (MD $-3.7,95 \% \mathrm{Cl}-8.1$ to $0.7 ; \mathrm{n}=437$ ) (Figure 4; Analysis 1.2); absolute percentage change $-4 \%(95 \% \mathrm{Cl}-8 \%$ to $1 \%)$; and relative percentage change $-7 \%(95 \% \mathrm{Cl}-15 \%$ to $1 \%)$. The NNTB was not applicable as results were non-significant.

Lamb 2015 also reported pain intensity scores adjusted for centre, sex, age, and medication type (Table 3 ). The mean treatment differences in the medium and long term were $-3.30(95 \% \mathrm{Cl}-6.50$ to -0.11$)$ and $-2.40(95 \% \mathrm{Cl}-5.92$ to 1.12$)$, respectively.

\section{Hand impairment measures (power grip strength and pinch grip strength)}

\section{Power grip strength (gross grip)}

All seven studies investigated the effect of exercise on power grip strength. Three studies found statistically significant differences between groups in favour of exercise (Brighton 1993; Buljina 2001; Cima 2013), whilst the remaining four studies found no statistically significant differences between groups (O'Brien 2006; Dellhag 1992;
Hoenig 1993; Lamb 2015). In Dellhag 1992, at four weeks, the maximal grip strength of the dominant hand was $126.2 \mathrm{~N}$ in the exercise group $(n=11)$ and $105.9 \mathrm{~N}$ in the no-treatment control group ( $n=13$ ). The maximal grip strength of the non-dominant hand was $145.1 \mathrm{~N}$ in the exercise group and $120.3 \mathrm{~N}$ in the control group. The average grip strength of the dominant hand was 109.7 $\mathrm{N}$ in the exercise group and $85.4 \mathrm{~N}$ in the control group. The average grip strength of the non-dominant hand was $108 \mathrm{~N}$ in the exercise group and $99.9 \mathrm{~N}$ in the control group. There were no significant differences in the maximum or average grip strength of dominant and non-dominant hands between groups. We pooled data from three studies that reported effects of exercise on power grip strength in the short term (Buljina 2001; Cima 2013; Hoenig 1993). Lamb 2015 provided medium- and long-term outcomes. We could not pool other studies due to lack of data or incompatible measures.

Figure 5 (Analysis 1.3) presents the forest plot for the results for Buljina 2001, Cima 2013, and Hoenig 1993 ( $n=141)$. Compared to waiting list or no treatment, exercise improved power grip strength in the short term. For the left hand, the standardised mean difference (SMD) was $0.44(95 \% \mathrm{Cl} 0.11$ to 0.78$)$ re-expressed to an equivalent improvement of $3.5 \mathrm{~kg}(95 \% \mathrm{Cl} 0.87$ to 6.1$)$, and the relative percentage change was $24 \%(95 \% \mathrm{Cl} 6 \%$ to $42 \%)$. For the right hand, the SMD was 0.46 ( $95 \% \mathrm{Cl} 0.13$ to 0.8 ) re-expressed to 4 $\mathrm{kg}(95 \% \mathrm{Cl} 1.13$ to 7$)$, and the relative percentage change was $26 \%$ (95\% $\mathrm{Cl} 7 \%$ to $45 \%$ ). 
Figure 5. Forest plot of comparison: 1 Exercise versus control, outcome: 1.3 Hand impairment - power grip strength: short term (< 3 months).

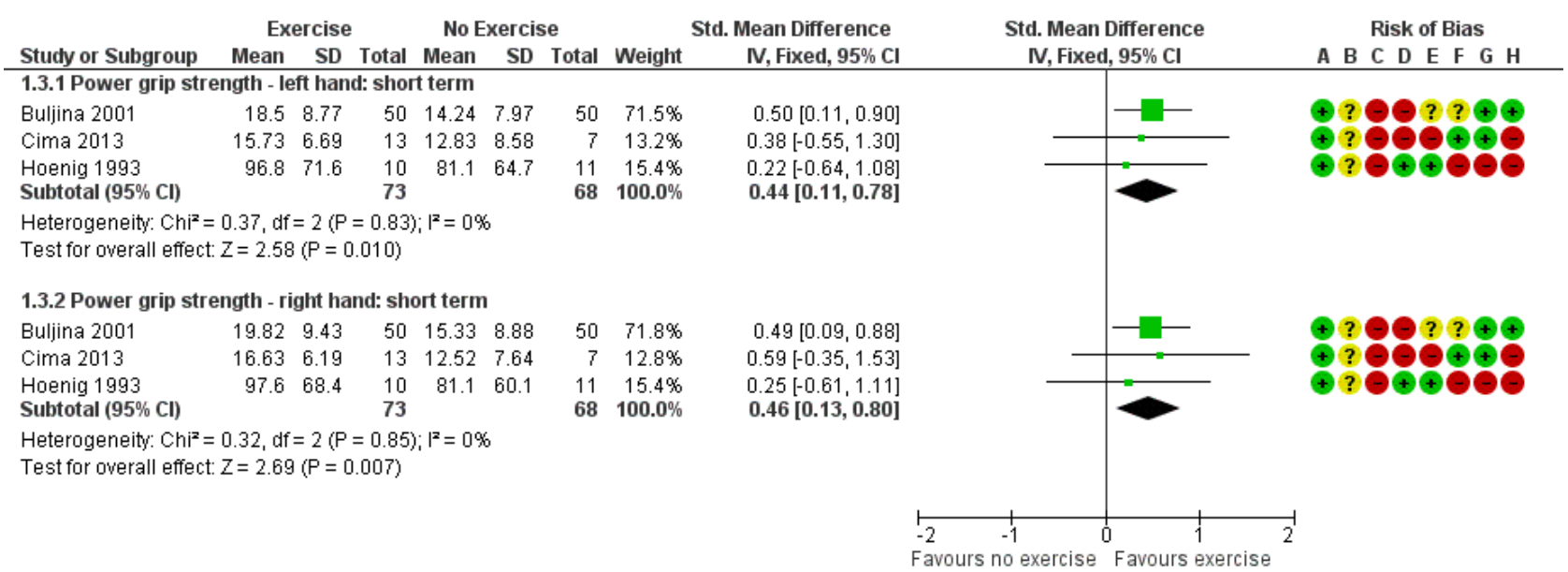

\author{
Risk of bias legend \\ A) Random sequence generation (selection bias) \\ B) Allocation concealment (selection bias) \\ (C) Blinding of participants \\ D) Blinding of personne \\ E) Blinding of outcome assessment (detection bias): Objective outcomes \\ F) Incomplete outcome data (attrition bias) \\ (G) Selective reporting (reporting bias) \\ (H) Other bias
}

Lamb 2015 provided data for medium- and long-term power grip strength Figure 6 (Analysis 1.4). The study provided mean power grip strength data of both hands in newtons, which were converted to kilograms for analysis. Compared to usual care, the exercise group showed a non-significant increase in mean power grip strength of both hands in the medium term (MD $1.4 \mathrm{~kg}, 95 \% \mathrm{Cl}-0.27$ to $3.07 ; \mathrm{n}=400)$; relative percentage change $11 \%(95 \% \mathrm{Cl}-2 \%$ to $13 \%$ ), and in the long term (MD $1.2 \mathrm{~kg}, 95 \% \mathrm{Cl}-0.62$ to $3.02 ; \mathrm{n}=$ $355)$; relative percentage change $9 \%(95 \% \mathrm{Cl}-5 \%$ to $23 \%)$. Absolute percentage change and NNTB are not applicable for lack of scale with maximum limit and non-significant outcomes.

Figure 6. Forest plot of comparison: 1 Exercise versus no exercise, outcome: 1.4 Hand impairment - power grip strength: medium and long term.

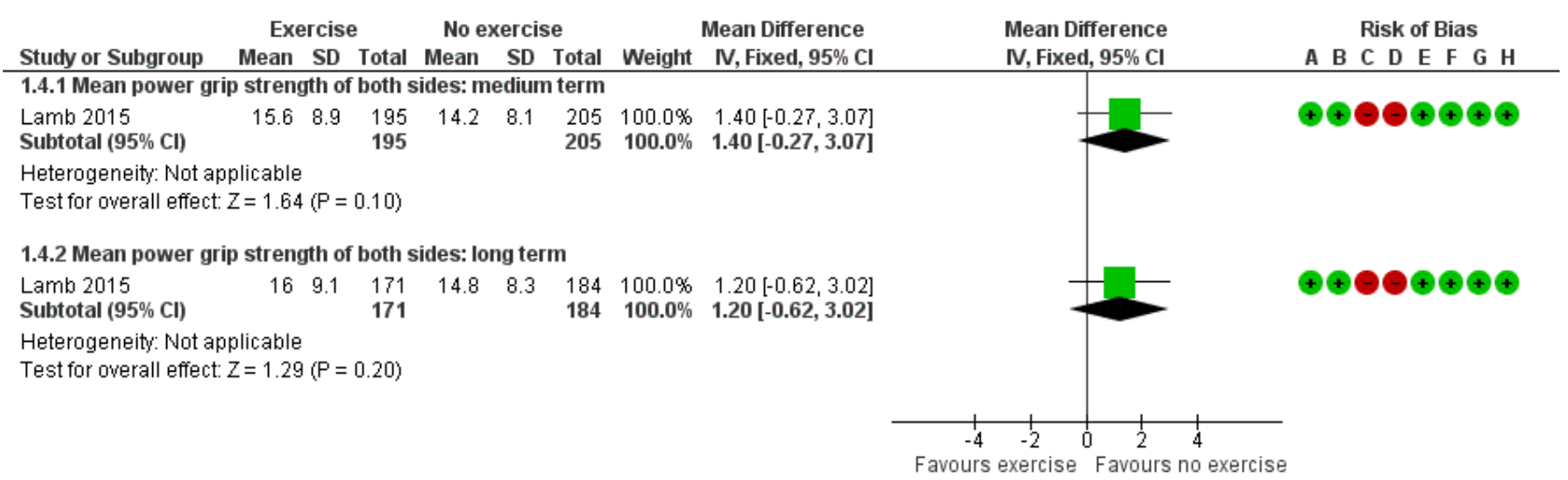

\footnotetext{
Risk of bias legend

(A) Random sequence generation (selection bias)

(B) Allocation concealment (selection bias)

C) Blinding of participants

(D) Blinding of personnel

(E) Blinding of outcome assessment (detection bias): Objective outcomes

(F) Incomplete outcome data (attrition bias)

(G) Selective reporting (reporting bias)

(H) Other bias
} 
In O'Brien 2006, the change in gross grip strength of the dominant hand from baseline to 6 months in the exercise group $(n=18)$ was 9.7 lbs (11.5) and in the control group $(n=18)$, which received joint protection advice, was $3.4 \mathrm{lbs}(21.32)(P=0.300)$. Brighton 1993 provided grip strength data measured in $\mathrm{mmHg}$. The study reported that there was a statistically significant improvement in grip strength in the exercise group compared to the control group, which did not receive exercises, over the four-year period. The mean grip strength in the exercise group $(n=19)$ was $105.7 \mathrm{mmHg}$ and in the control group $(n=25)$ was $44.1 \mathrm{mmHg}$ at 48 months. We could not meta-analyse results from this study due to insufficient reporting of data.

\section{Pinch grip strength (tip-to-tip/tripod pinch)}

Five studies investigated effect of hand exercise on pinch grip strength (Brighton 1993; Buljina 2001; Cima 2013; Lamb 2015; O'Brien 2006). These studies assessed different types of pinch grips and all found statistically significant differences in favour of hand exercise. Two studies provided data that could be pooled for shortterm outcome (Buljina 2001; Cima 2013).

Data from Buljina 2001 and Cima 2013 ( $n=120$ ) indicated that compared to waiting list or no treatment, exercise improved tipto-tip pinch grip strength in the short term Analysis 1.5. For the left hand, the MD was $0.51 \mathrm{~kg}(95 \% \mathrm{Cl} 0.13$ to 0.9$)$; relative change $44 \%$ (95\% Cl $11 \%$ to $78 \%$ ), and for the right hand, the MD was $0.82 \mathrm{~kg}(95 \% \mathrm{Cl} 0.43$ to 1.21$)$; relative change $68 \%$ (95\% Cl 36\% to $101 \%$ ). Lamb 2015 provided data for medium- and long-term pinch grip strength. The study provided data as mean tripod pinch grip strength of both hands in newtons, which were converted to kilograms for analysis. Compared to usual care, the exercise group showed a non-significant increase in mean pinch grip strength of both hands in the medium term (MD $0.3 \mathrm{~kg}, 95 \% \mathrm{Cl}-0.14$ to 0.74 ; $\mathrm{n}=396)$; relative percentage change $8 \%(95 \% \mathrm{Cl}-4 \%$ to $19 \%)$, and in the long term (MD $0.4 \mathrm{~kg}, 95 \% \mathrm{Cl}-0.08$ to $0.88 ; \mathrm{n}=351$ ); relative percentage change $10 \%(95 \% \mathrm{Cl}-2 \%$ to $22 \%)$. Absolute percentage change and NNTB are not applicable for lack of scale with maximum limit and non-significant outcomes.

In O'Brien 2006, the change in key grip strength of the dominant hand from baseline to 6 months in the exercise group $(n=18)$ was $1 \mathrm{lb}(2.97)$ and in the control group $(\mathrm{n}=18)$, which received joint protection advice, was $-1 \mathrm{lb}(2.45)(\mathrm{P}=0.014)$.

Brighton 1993 provided pinch strength data measured in $\mathrm{mmHg}$. The study reported that there was a statistically significant improvement in pinch strength in the exercise group compared to the control group, which did not receive exercises, over the fouryear period. The mean grip strength in the exercise group $(n=19)$ was $54.8 \mathrm{mmHg}$ and in the control group $(n=25)$ was $24.8 \mathrm{mmHg}$ at 48 months. We could not meta-analyse results from this study due to insufficient reporting of data.

\section{ACR50 response}

None of the studies reported disease activity ACR50 responder criteria.

\section{Participant adherence}

Only one study Lamb 2015 reported participant adherence rates for treatment attendance and subsequent unsupervised exercise adherence Analysis 1.6. Seventy-five per cent of exercise programme participants $(n=246)$ attended the full number of six supervised exercise sessions compared to $93 \%$ of usual care participants $(n=242)$ who attended the full number of sessions (a maximum of three).

Exercise adherence was measured using a five-item self reported exercise behaviour questionnaire. At four months, 174/216 (81\%) of the exercise group participants self reported more than 1 to 2 unsupervised exercise sessions per week compared to 137/222 $(62 \%)$ of the participants who received usual care alone. The risk ratio was $1.31(95 \% \mathrm{Cl} 1.15$ to 1.48$)$ and NNTB $6(95 \% \mathrm{Cl} 4$ to 10). At 12 months, 128/206 (62\%) of the participants who received hand exercises with usual care self reported more than 1 to 2 unsupervised exercise sessions per week compared to 123/216 $(57 \%)$ of the participants who received usual care alone. The risk ratio was 1.09 ( $95 \% \mathrm{Cl} 0.93$ to 1.28 ). Number needed to treat for an additional beneficial outcome was not applicable as results were not significant.

In the extended follow-up of Lamb 2015, 31\% of the exercise group participants $(48 / 155)$ reported that they exercised at least three times a week compared to $35 \%$ of the control group participants (60/173), showing no between-group differences (Williamson 2017). As these data did not represent the primary endpoint of the trial and were collected through postal questionnaires, we did not include them in the analysis.

\section{Adverse events}

Only one study measured this outcome (Lamb 2015), which found that no adverse events related to exercising were reported when 246 exercise therapy group participants were followed up for one year.

\section{Minor outcomes}

\section{Hand impairment (range of motion, dexterity, deformity, and hand stiffness)}

\section{Range of motion}

All studies except Cima 2013 evaluated hand range of motion as an outcome. We were unable to pool data due to deficiencies in reporting for the majority of studies. Two studies found no statistically significant differences between groups (Hoenig 1993; O'Brien 2006); two studies found inconsistent betweengroup differences (Dellhag 1992; Lamb 2015); one study found a statistically significant difference between groups (Buljina 2001); and another study failed to present between-group analyses (Brighton 1993).

\section{Dexterity}

Two studies evaluated the effect of hand exercise on dexterity (Hoenig 1993; Lamb 2015). Lamb 2015 found that there was a statistically significant difference between groups, with improved dexterity in the exercise group compared to usual care at 12 months, whereas Hoenig 1993 found no statistically significant difference between groups. We were unable to pool data due to lack of data from one study (Hoenig 1993).

\section{Deformity}

Two studies evaluated the effect of hand exercise on hand deformity (Hoenig 1993; Lamb 2015). Lamb 2015 used goniometric measurement of metacarpophalangeal ulnar/radial deviation in maximum pronation position, while Hoenig 1993 measured degree 
of ulnar deviation of the third digit with a goniometer. Hoenig 1993 also used clinician rating of hand deformity, which was not reported. Both studies found no statistically significant differences between groups. We were unable to pool data due to lack of data from one study (Hoenig 1993).

\section{Hand stiffness}

Three studies reported hand stiffness (Brighton 1993; Dellhag 1992; Hoenig 1993), although only one, Dellhag 1992, presented results, therefore we were unable to pool the data. Two studies found no statistically significant differences between groups.

\section{General function}

Three studies evaluated the effect of hand exercise on general function, two for short-term outcome (Buljina 2001; Cima 2013), and one for medium- and long-term outcomes (Lamb 2015). We pooled data (Analysis 1.7) from two studies (Buljina 2001; Cima 2013), finding a positive effect of hand exercise on function in the short term (SMD 0.79, 95\% Cl 0.42 to $1.17 ; n=120$ ). Lamb 2015 found a larger effect on general function at medium term in those who received hand exercise (SMD $1.45,95 \% \mathrm{Cl} 1.24$ to $1.66 ; \mathrm{n}=449$ ). There was considerable heterogeneity among the data at different time points ( $\mathrm{Chi}{ }^{2} \mathrm{P}=0.003, \mathrm{~L}=89 \%$ ), and so it was not appropriate to present a pooled estimate.

\section{Disease activity}

\section{Tender and swollen joints}

Four studies evaluated the effect of hand exercise on swollen and tender joint counts (Buljina 2001; Hoenig 1993; Lamb 2015; O'Brien 2006). We pooled only medium-term outcome data from two studies, Lamb 2015 and O'Brien 2006, due to incomplete data reporting by the other two studies. We used an SMD analysis due to variation in the numbers of joints counted. O'Brien 2006 evaluated the whole body as recommended by European League Against Rheumatism, whilst Lamb 2015 used a modified joint count of the hand and wrists only. We found a small positive effect in favour of hand exercise in the medium term for swollen joint counts (MD $-0.16,95 \% \mathrm{Cl}-0.34$ to $0.01 ; \mathrm{n}=492$ ) and tender joint counts (SMD $-0.19,95 \% \mathrm{Cl}-0.37$ to $-0.01 ; \mathrm{n}=492$ ) (Analysis 1.8 ).

\section{Other measures of disease activity}

Other measures of disease activity were used but were not reported consistently enough for data pooling. These included the blood tests for erythrocyte sedimentation rate (ESR) (Buljina 2001; Lamb 2015), C-reactive protein (CRP) levels (Lamb 2015), and proximal interphalangeal joint swelling (Buljina 2001; Hoenig 1993). No statistically significant differences between groups were found for these outcomes in individual studies (Buljina 2001; Hoenig 1993; Lamb 2015).

\section{Patient satisfaction}

One study reported outcomes of patient satisfaction using two measures (Lamb 2015). At 12 months after treatment, participants in the exercise group had higher MHQ satisfaction scores compared to the control group (MD $3.76,95 \% \mathrm{Cl}-0.02$ to $7.54 ; \mathrm{n}=436$ ), and patient satisfaction was significantly higher for those receiving exercise therapy (Wilcoxon test, $\mathrm{P}<0.0001$ ).

\section{Costs}

One study reported costs of interventions and results of costeffectiveness analyses (Lamb 2015), finding that the cost of exercise was GBP $103,95 \% \mathrm{Cl}$ GBP -622 to GBP 838 higher than usual care. Quality-adjusted life year (QALY) gains were $0.01,95 \% \mathrm{Cl}-0.03$ to 0.05 in favour of hand exercise treatment, translating into an incremental cost per QALY gain of GBP 9549.

\section{Change in splint or assistive device usage}

No trials reported rates of change in splint or assistive devices.

\section{Subgroup and sensitivity analyses}

Data did not allow for valid subgroup analyses to assess the effects of exercise type, intervention frequency, or intervention duration on treatment effect, or sensitivity analyses for effect of bias.

\section{Assessment of reporting bias}

Only one study published a protocol of the study prior to publication of results (Lamb 2015). There was not a sufficient number of studies to warrant exploration of publication bias with funnel plots (Sterne 2011), so our assessment of selective reporting was limited to comparing reporting in methods and results sections of publications.

\section{DISCUSSION}

\section{Summary of main results}

We set out to determine the benefits and harms of hand exercise for people with rheumatoid arthritis. We included seven studies with 841 participants. The findings of the review were driven by one large multicentre study conducted in the UK, which contributed $58 \%$ of participants (Lamb 2015, n = 490). The heterogeneity of outcomes used and the quality of reporting of data limited the pooling of results. In addition, most included studies only evaluated shortterm effectiveness.

Of the three studies that evaluated hand function (Dellhag 1992; Lamb 2015; O'Brien 2006), Dellhag 1992 did not find significant differences in favour of exercise in the short term. Exercise probably slightly improves hand function with a minimal clinical benefit in the medium and long term (Lamb 2015).

Two small studies showed that exercise has a beneficial effect on pain in the short term. Lamb 2015 showed that there is probably little or no difference on pain with exercise when compared to usual care in the medium and long term.

The most commonly evaluated outcomes were of impairments. All studies measured power grip strength, but we could only pool data from three small studies, resulting in improvements in favour of exercise on power grip strength and pinch grip strength in the short term. Whether these levels of effect are clinically important remains unclear. Lamb 2015 showed that there is little or no difference on improving power grip and pinch grip strength with exercise when compared to usual care in the medium and long term.

\section{No studies evaluated ACR50 criteria.}

In the medium term, people who received hand exercise delivered with behavioural support strategies for exercise adherence (e.g. exercise diary, goal setting, action planning) along with usual care 
were more likely to be adherent than those who did not receive exercise. There was little or no difference between groups in the long term.

In Lamb 2015, the only study that reported on safety, no adverse events were attributed to exercises.

Findings for range of motion and dexterity were the most inconsistent of any outcome, whereas there was greater clarity that exercise did not influence deformity or self reported stiffness. With regard to disease activity, as measured by the number of swollen and tender joints, there appeared to be a small positive effect in the medium term as evidenced by two studies (Lamb 2015; O'Brien 2006). Lamb 2015 provided outcome data on a multitude of constructs and was the only study to investigate and report on the important issues of participant adherence, patient satisfaction, and cost-effectiveness of exercise. These are important outcomes to investigate in future studies.

\section{Overall completeness and applicability of evidence}

The evidence included and synthesised in this review was largely driven by the findings from one multicentre study (Lamb 2015). Overall, the evidence ranged from 'very low' to 'high' across major outcomes. Heterogeneity of interventions and outcome measures, methodological limitations, risk of bias, and poor reporting or lack of data were barriers for determining the quality of the evidence.

The study populations appeared to be representative of patients seen in outpatient or home settings in Brazil, South Africa, Sweden, the UK, and the USA, and there was a greater inclusion of females $(78 \%)$ in the studies that were reviewed. We found frequency of the interventions to be fairly consistent, with most studies prescribing a daily exercise programme with varying levels of supervision. The duration of interventions was much more variable, ranging from just a few weeks with daily supervision to four years. The evidence derived from the included studies does not allow conclusions to be drawn about which format is best in terms of frequency and supervision. Disease duration ranged from five to 14 years, which may be considerably longer than therapists are used to now seeing. Future studies should make an effort to evaluate effectiveness at different stages of the disease and if possible to ascertain the optimum point at which to start exercising.

\section{Quality of the evidence}

\section{Hand function}

For short-term hand function, we downgraded the quality of evidence from Dellhag 1992 three levels to 'very low' due to risk of bias (unclear risk of selection bias, high risk of performance bias, unclear risk of detection bias in measuring objective hand function, unclear risk of attrition bias) and imprecision (sample size less than 400). We are therefore uncertain as to whether exercise has a beneficial effect on hand function in the short term.

For medium- and long-term hand function, we downgraded the quality of evidence from Lamb 2015 one level to 'moderate' due to risk of bias (high risk of performance and detection biases in measuring self reported hand function). Exercise therefore probably slightly improves hand function in the medium and long term. Further research is likely to have an important impact on our confidence in the estimate of effect and may change the estimate.

\section{Pain}

For short-term pain, we downgraded the quality of evidence from Buljina 2001 and Dellhag 1992 three levels to 'very low' due to risk of bias (unclear risk of selection bias, high risk of performance and detection biases in measuring self reported pain, unclear risk of attrition bias) and imprecision (sample size less than 400). We are therefore uncertain as to whether exercise reduces pain in the short term.

For medium- and long-term pain, we downgraded the quality of evidence from Lamb 2015 one level to 'moderate' due to risk of bias (high risk of performance and detection biases in measuring self reported pain). Exercise therefore probably has little or no difference on pain in the medium and long term. Further research is likely to have an important impact on our confidence in the estimate of effect and may change the estimate.

\section{Power grip strength}

For short-term power grip strength, we downgraded the quality of evidence from Buljina 2001, Cima 2013, and Hoenig 1993 three levels to 'very low' due to risk of bias (unclear risk of selection bias, high risk of performance bias, unclear or high risk of detection bias in measuring objective grip strength, unclear or high risk of attrition bias) and imprecision (sample size less than 400 ). We are therefore uncertain as to whether exercise improves power grip strength in the short term.

For medium- and long-term power grip strength, we graded the quality of evidence from Lamb 2015 as 'high', as we considered the risk of performance bias with objectively measured grip strength not a significant reason for downgrading the evidence. Exercise therefore has little or no difference on mean power grip strength of both hands in the medium and long term. Further research is very unlikely to change our confidence in the estimate of effect.

\section{Pinch grip strength}

For short-term pinch grip strength, we downgraded the quality of evidence from Buljina 2001 and Cima 2013 three levels to 'very low' due to risk of bias (unclear risk of selection bias, high risk of performance bias, and unclear or high risk of detection bias) and imprecision (sample size less than 400). We are therefore uncertain as to whether exercise improves pinch grip strength in the short term.

For medium- and long-term pinch grip strength, we graded the quality of evidence from Lamb 2015 as 'high', as we considered the risk of performance bias with objectively measured pinch strength not a significant reason for downgrading the evidence. Exercise therefore has little or no difference on mean pinch grip strength of both hands in the medium and long term. Further research is very unlikely to change our confidence in the estimate of effect.

\section{Participant adherence}

We downgraded the quality of evidence from Lamb 2015 one level to 'moderate' due to risk of bias (high risk of performance and detection biases in measuring self reported participant adherence). This evidence suggests that people who received hand exercises with behavioural support strategies along with usual care were more adherent than those who received usual care alone in the medium term, but there was not much difference between groups in the long term. Further research is likely to have an important 
impact on our confidence in the estimate of effect and may change the estimate.

\section{Adverse events}

We downgraded the quality of evidence from Lamb 2015 one level to 'moderate' due to risk of bias (high risk of performance and detection biases in measuring self reported adverse events). This evidence suggests no adverse events were reported in people who received hand exercises with behavioural support strategies along with usual care. Further research is likely to have an important impact on our confidence in the estimate of effect and may change the estimate.

\section{Potential biases in the review process}

The main limitations of the review process were the paucity of appropriate data that were necessary for meta-analysis, and the variation in outcome measures used. Most of our attempts to contact study authors were unsuccessful, and therefore the majority of data has come from published data. Only one study published a protocol prior to conduct of the study (Lamb 2015), making it difficult to assess selective outcome reporting. This also demonstrates a clear need for future studies to publish a protocol prior to conduct of the study in order to improve assessment of reporting bias. We were unable to perform formal assessment of publication bias of the included studies due to data limitations. Several reviews have used the Cochrane 'Risk of bias' tool, which is recognised to have limited reliability (Armijo-Olivo 2014; Hartling 2013).

There was wide variation in the details of the evaluated interventions, with no two studies being truly alike. This is a commonly cited flaw of pooling data for meta-analysis, and a reason why we have restricted the meta-analysis to very few cases where the clinical heterogeneity appears to be acceptably low. If, as we believe, function of the hand and wrist is of primary interest for exercise interventions, and coupled with the fact that it is impossible to blind participants to allocation, care needs to be taken when recording self report measures and the inherent risk of bias this brings. It is therefore important to evaluate effects at an 'objective' impairment level simultaneously to check the signal is consistent.

\section{Agreements and disagreements with other studies or reviews}

In 2004, Wessel conducted a narrative review of nine Englishlanguage only randomised and non-randomised studies published up to 2003, including four of the seven studies in this review (Wessel 2004). Wessel concluded that there was little evidence to support or refute hand exercise. Since this time only one other systematic review has been published (Bergstra 2014), which drew more positive conclusions about the effectiveness of exercise on the RA hand. Bergstra 2014 included eight randomised and nonrandomised studies and inferred that grip strength and function were consistently improved, but changes for range of motion were inconsistent. The conclusions from our review differ slightly, showing moderate evidence for small beneficial effects on hand function, but little or no effect on grip strength in the medium and long term. Our review is the only review to include only randomised trials assessing the effectiveness of hand exercises in RA. No reviews prior to this have attempted a meta-analysis.

\section{AUTHORS' CONCLUSIONS}

\section{Implications for practice}

The results of this review indicate that it is uncertain whether exercise improves hand function in the short term. Exercise probably improves hand function with a minimal clinical benefit in the medium and long term. It is uncertain whether exercise improves pain in the short term, and it probably has little or no difference in the medium and long term. It is uncertain whether exercise improves power grip strength and pinch grip strength in the short term, but shows little or no difference on these outcomes in the medium and long term. The effects of hand exercise on American College of Rheumatology 50 (ACR50) response criteria are unknown. In the medium term, people who received hand exercise with behavioural support strategies for adherence in addition to routine care were probably more adherent than those who received routine care alone, however there was little or no difference between groups in the long term. Exercise seems to be safe without any adverse effects.

\section{Implications for research}

Given our conclusions that the current evidence is based on studies with variable quality, it is clear that further studies of high quality in conduct and reporting are warranted to evaluate the effectiveness of exercise therapy for the rheumatoid arthritis hand. Certainly, the development of a core set of outcomes for conservative treatments for rheumatoid arthritis would improve the ability to synthesise evidence in this and similar areas. Studies need to be clear in their reporting of the primary outcome of interest; we suggest that function of the hand and wrist is most appropriate. Going one step further, research to ascertain the clinically important change in hand function is also required.

Another important issue in improving upon existing reporting of trials of exercise therapy is how authors should attempt to define, control, and report dosage of exercise and related adherence in accordance with the template for intervention description and replication (TIDieR) guidelines (Hoffman 2014). Incorporating different, evidence-based behavioural support strategies for adherence and evaluating their impact on long-term adherence is also an important area to be explored. With the majority of the studies included in this review evaluating short-term effectiveness, there is a need for incorporating evaluation of longterm effectiveness, especially for a chronic health condition such as rheumatoid arthritis. Finally, we have already highlighted that we are unable to recommend one exercise programme over another with any certainty. Future research to evaluate the efficacy of different modes of exercise intensity, frequency, and duration would therefore be a welcome addition to the evidence base.

\section{ACKNOWLEDGEMENTS}

Sarah E Lamb and Cynthia Srikesavan receive funding from the National Institute for Health Research (NIHR) Collaboration for Leadership in Applied Health Research and Care Oxford (CLARHC) at Oxford Health NHS Foundation Trust. The views expressed are those of the author (s) and not necessarily those of the NHS, the NIHR or the Department of Health and Social Care.

The review authors would like to thank Renea Johnston and Lara Maxwell, Managing Editor at the Australian and Canadian editorial 
bases of the Cochrane Musculoskeletal Group, for their support, and Louise Falzon, Tamara Rader, and Manosilah Yoganathan
(Information Specialists) for their assistance with developing and performing searches. 


\section{RE F E R E N C E S}

\section{References to studies included in this review}

Brighton 1993 \{published data only\}

Brighton SW, Lubbe JE, Van Der Merwe CA. The effect of a longterm exercise programme on the rheumatoid hand. British Journal of Rheumatology 1993;32(5):392-5.

Buljina 2001 \{published data only\}

Buljina A, Taljanovic MS, Avdic DM, Hunter TB. Physical and exercise therapy for treatment of the rheumatoid hand. Arthritis Care and Research 2001;45(4):392-7.

Cima 2013 \{published data only\}

Cima SR, Barone A, Porto JM, de Abreu DC. Strengthening exercises to improve hand strength and functionality in rheumatoid arthritis with hand deformities: a randomized, controlled trial. Rhematology International 2013;33(3):725-32.

\section{Dellhag 1992 \{published data only\}}

Dellhag B, Wollersjo I, Bjelle A. Effect of active hand exercise and wax bath treatment in rheumatoid arthritis patients. Arthritis Care and Research 1992;5(2):87-92.

\section{Hoenig 1993 \{published data only\}}

Hoenig H, Groff G, Pratt K, Goldberg E, Franck W. A randomised controlled trial of home exercise on the rheumatoid hand. Journal of Rheumatology 1993;20(5):785-9.

\section{Lamb 2015 \{published data only}

Lamb SE, Williamson E, Heine P, Adams J, Dosanjh S, Dritsaki M, et al. Exercises to improve function of the rheumatoid hand (SARAH): a randomised controlled trial. Lancet 2015;385(9966):421-9.

\section{O'Brien 2006 \{published data only\}}

O'Brien AV, Jones P, Mullis R, Mulherin D, Dziedzic K. Conservative hand therapy treatments in rheumatoid arthritis a randomised controlled trial. Rheumatology 2006;45(5):577-83.

\section{References to studies excluded from this review}

\section{Azeez 2014 \{published data only\}}

Azeez M, Clancy C, O'Dwyer T, Wilson F, Cunnane G. Effects of exercise on body composition, cardiovascular fitness, muscle strength, and cognition in patients with rheumatoid arthritis: a randomised controlled trial of a patient-specific exercise programme. Arthritis \& Rheumatology 2014;66:S1274.

\section{Baillet 2009 \{published data only\}}

Baillet A, Payraud E, Niderprim VA, Nissen MJ, Allenet B, Francois $P$, et al. A dynamic exercise programme to improve patients' disability in rheumatoid arthritis: a prospective randomized controlled trial. Rheumatology 2009;48(4):410-5

\section{Bearne 2012 \{published data only\}}

Bearne L, Manning V, Scott DL, Hurley M. Exercise therapy in the management of upper limb dysfunction in rheumatoid arthritis. Conference publication: British Society for Rheumatology and
British Health Professionals in Rheumatology Annual Meeting 2012, Glasgow, United Kingdom 2012;1:iii16-7.

Berntzen 2016 \{published data only\}

Berntzen B, Erwood L, Bellerby T, Price E, Collins D, Williamson L. THU0190 A six-week progressive resistance training class improves function and fatigue in RA patients. Annals of the Rheumatic Diseases 2016;75:254.

\section{Brorsson 2009 \{published data only\}}

Brorsson S, Hilliges M, Sollerman C, Nilsdotter A. A six-week hand exercise programme improves strength and hand function in patients with rheumatoid arthritis. Journal of Rehabilitation Medicine 2009;41(5):338-42.

\section{Brorsson 2014 \{published data only\}}

Brorsson S, Thorstensson C, Nilsdotter A, Bremander A. Two different sets of hand exercises improved grip strength after eight weeks in patients with arthritis. Annals of the Rheumatic Diseases 2014;73(S2):1210.

Byers 1985 \{published data only\}

Byers PH. Effect of exercise on morning stiffness and mobility in patients with rheumatoid arthritis. Research in Nursing \& Health 1985;8(3):275-81

\section{Cakir 2014 \{published data only\}}

Cakir T, Evcik FD, Subasi V, Gokce IY, Kavuncu V. The effectiveness of aquatic exercises in the treatment of rheumatoid arthritis [Romatoid Artrit Tedavisinde Akuaterapinin Etkinliği]. Turk Osteoporoz Dergisi 2014;20(1):10-5.

\section{Dash 2001 \{published data only\}}

Dash M, Telles S. Improvement in hand grip strength in normal volunteers and rheumatoid arthritis patients following yoga training. Indian Journal of Physiology \& Pharmacology 2001;45(3):355-60.

\section{De Jong 2004 \{published data only\}}

De Jong Z, Munneke M, Zwinderman AH, Kroon HM, Ronday KH, Lems WF, et al. Long term high intensity exercise and damage of small joints in rheumatoid arthritis. Annals of the Rheumatic Diseases 2004;63(11):1399-405.

Dogu 2013 \{published data only\}

Dogu B, Sirzai H, Yilmaz F, Polat B, Kuran B. Effects of isotonic and isometric hand exercises on pain, hand functions, dexterity and quality of life in women with rheumatoid arthritis. Rheumatology International 2013;33:2625-30.

\section{Dulgeroglu 2014 \{published data only\}}

Dulgeroglu D. The effectiveness of galvanic current therapy and a conservative hand exercise program in a rheumatoid hand: a randomized controlled trial. Clinical and Experimental Rheumatology 2014;32(4 Suppl 83):S22. 
Dülgeroğlu 2016 \{published data only\}

Dülgeroğlu D, Bal A, Karaahmet O, Umay E, Noyan S, Çakci A. The effectiveness of galvanic electrotherapy and a conservative hand exercise program in a rheumatoid hand: a randomized controlled trial [Romatizmal elde galvani elektroterapisinin ve konservatif el egzersiz programının etkinliği: randomize kontrollü çalışma]. Turkiye Fiziksel Tip Ve Rehabilitasyon Dergisi [Turkish Journal of Physical Medicine \& Rehabilitation] 2016;62(2):132-42.

\section{Flint-Wagner 2009 \{published data only\}}

Flint-Wagner HG, Lisse J, Lohman TG, Going SB, Guido T, Cussler E, et al. Assessment of a sixteen-week training program on strength, pain, and function in rheumatoid arthritis patients. Journal of Clinical Rheumatology 2009;15(4):165-71.

\section{Hammond 2004a \{published data only\}}

Hammond A, Young A, Kidao R. A randomised controlled trial of occupational therapy for people with early rheumatoid arthritis. Annals of the Rheumatic Diseases 2004;63(1):23-30.

\section{Hansen 1993 \{published data only\}}

Hansen TM, Hansen G, Langgaard AM, Rasmussen JO. Longterm physical training in rheumatoid arthritis. A randomized trial with different training programs and blinded observers. Scandinavian Journal of Rheumatology 1993;22(3):107-12.

\section{Hawkes 1985 \{published data only\}}

Hawkes J, Care G, Dixon JS, Bird HA, Wright V. Comparison of three physiotherapy regimens for hands with rheumatoid arthritis. British Medical Journal Clinical Research 1985;291(6501):1016.

\section{Hawkes 1986 \{published data only\}}

Hawkes J, Care G, Dixon JS, Bird HA, Wright VA. A comparison of three different physiotherapy treatments for rheumatoid arthritis of the hands. Physiotherapy Theory and Practice 1986;2(4):155-60.

\section{Khedekar 2017 \{published data only\}}

Khedekar S, Shimpi P, Shyam A, Sancheti P. Use of art as therapeutic intervention for enhancement of hand function in patients with rheumatoid arthritis: a pilot study. Indian Journal of Rheumatology 2017;12:94-6.

\section{Kiraly 2015 \{published data only\}}

Kiraly M, Szanyó F, Bender T. AB1198 Effect of underwater ultrasound therapy on hand function and quality of life in patients with rheumatoid arthritis. Annals of the Rheumatic Diseases 2017;74(2):1304.

\section{Lineker 2001 \{published data only\}}

Lineker SC, Bell MJ, Wilkins AL, Badley EM. Improvements following short term home based physical therapy are maintained at one year in people with moderate to severe rheumatoid arthritis. Journal of Rheumatology 2001;28(1):165-8.

\section{Maxwell 2005 \{published data only\}}

Maxwell L, Tugwell P. High-intensity exercise for rheumatoid arthritis was associated with less joint damage of the hands and feet than physical therapy. American College of Physicians Journal Club 2005;142(3):73.

Minor 1995 \{published data only\}

Minor MA, Hewett JE. Physical fitness and work capacity in women with rheumatoid arthritis. Arthritis Care \& Research 1995;88(3):146-54.

\section{Orlova 2016 \{published data only\}}

Orlova E, Karateev D, Denisov L, Kochetkov A, Nasonov E. SAT0617 12-month complex rehabilitation program for rheumatoid arthritis patients receiving biologic DMARDs. Annals of the Rheumatic Diseases 2016; Vol. 75:893.

\section{Piga 2014 \{published data only\}}

Piga M, Tradori I, Pani D, Barabino G, Dessì A, Raffo L, et al. Telemedicine applied to kinesiotherapy for hand dysfunction in patients with systemic sclerosis and rheumatoid arthritis: recovery of movement and telemonitoring technology. Journal of Rheumatology 2014;41(7):1324-33.

Pineda-Juárez 2016 \{published data only\}

Pineda-Juárez JA, Ogata-Medel M, Lozada-Mellado M, CastiloMartinez L, Hinojosa-Azaola A, Gonzalez-Contreras M, et al. Effect of a dynamic exercise program in combination with a Mediterranean diet in strength, joint mobility and disease activity in women with rheumatoid arthritis [abstract]. Arthritis \& Rheumatology. 2016; Vol. 68, issue Suppl 10.

Pot-Vaucel 2016 \{published data only\}

Pot-Vaucel M, Aubert MP, Guillot P, Glemarec J, Berthelot JM, Le Goff B, et al. Randomised study versus control group of customised therapeutic education for patients in follow-up for rheumatoid arthritis. Joint Bone Spine 2015;83(2):199-206.

\section{Rapoliene 2006 \{published data only\}}

Rapoliene J, Krisciunas A. The effectiveness of occupational therapy in restoring the functional state of hands in rheumatoid arthritis patients. Medicina 2006;42(10):823-8.

\section{Ronningen 2008 \{published data only\}}

Ronningen A, Kjeken I. Effect of an intensive hand exercise programme in patients with rheumatoid arthritis. Scandinavian Journal of Occupational Therapy 2008;15:173-83.

\section{Seneca 2015 \{published data only\}}

Seneca T, Hauge EM, Maribo T. Comparable effect of partly supervised and self-administered exercise programme in early rheumatoid arthritis - a randomised controlled trial. Danish Medical Journal 2015;62:A5127.

\section{Shapoorabadi 2016 \{published data only\}}

Shapoorabadi YJ, Vahdatpour B, Salesi M, Ramezanian H. Effects of aerobic exercise on hematologic indices of women with rheumatoid arthritis: a randomized clinical trial. Journal of Research in Medical Sciences: the official journal of Isfahan University of Medical Sciences 2016;21:9.

\section{Srikesavan 2016 \{published data only\}}

Srikesavan CS, Shay B, Szturm T. Task-oriented training with computer games for people with rheumatoid arthritis or hand 
osteoarthritis: a feasibility randomized controlled trial. Games for Health Journal 2016;5(5):295-303.

\section{Tee 2016 \{published data only\}}

Tee M, Lim P. Comparison of center-based and home-based exercises on rheumatoid arthritis patients experiencing fatigue. 18th Asia Pacific League of Associations for Rheumatology Congress, APLAR. China. Blackwell Publishing, 2016; Vol. 19.

\section{Veitiene 2004 \{published data only\}}

Veitiene D, Tamulaitiene M. The efficiency of home and outpatient exercise program in patients with rheumatoid arthritis [Namuose ir ambulatoriskai atliekamu fiziniu pratimu efektyvumas sergant reumatoidiniu artritu]. Medicina 2004;40(5):434-8.

\section{Additional references}

\section{Adams 2004}

Adams J, Burridge J, Mullee M, Hammond A, Cooper C. Correlation between upper limb functional ability and structural hand impairment in an early rheumatoid population. Clinical Rehabilitation 2004;18(4):405-13.

\section{Armijo-Olivo 2014}

Armijo-Olivo S, Ospina M, da Costa BR, Egger M, Saltaji H, Fuentes J, et al. Poor reliability between Cochrane reviewers and blinded external reviewers when applying the Cochrane risk of bias tool in physical therapy trials. PLOS ONE 2014;9(5):e96920.

\section{Bergstra 2014}

Bergstra SA, Murgia A, Te Velde AF, Caljouw SR. A systematic review into the effectiveness of hand exercise therapy in the treatments of rheumatoid arthritis. Clinical Rheumatology 2014;33(11):1539-48.

\section{Deeks 2011}

Deeks JJ, Higgins JPT, Altman DG. Chapter 9: Analysing data and undertaking meta-analyses. In: Higgins JPT, Green S, editor(s). Cochrane Handbook for Systematic Reviews of Interventions Version 5.1.0 (updated March 2011). The Cochrane Collaboration, 2011. Available from handbook.cochrane.org. Available from www.cochrane-handbook.org.

\section{Felson 1995}

Felson DT, Anderson JJ, Boers M, Bombardier C, Furst D, Goldsmith C, et al. American College of Rheumatology preliminary definition of improvement in rheumatoid arthritis. Arthritis \& Rheumatology 1995;38:727-35.

\section{Hammond 2004b}

Hammond A. Rehabilitation in rheumatoid arthritis: a critical review. Musculoskeletal Care 2004;2(3):135-51.

\section{Hartling 2013}

Hartling L, Hamm MP, Milne A, Vandermeer B, Santaguid PL, Ansari M. Testing the Risk of Bias tool showed low reliability between individual reviewers and across consensus assessments of reviewer pairs. Journal of Clinical Epidemiology 2013;66:973-81.

\section{Higgins 2011a}

Higgins JP, Altman DG, Sterne JAC. Chapter 8: Assessing risk of bias in included studies. In: Higgins JP, Green S, editor(s). Cochrane Handbook for Systematic Reviews of Interventions Version 5.1.0 (updated March 2011). The Cochrane Collaboration, 2011. Available from handbook.cochrane.org.

\section{Higgins 2011b}

Higgins JP, Deeks JJ. Chapter 7: Selecting studies and collecting data. In: Higgins JP, Green S, editor(s), Cochrane Handbook for Systematic Reviews of Interventions Version 5.1.0 (updated March 2011). The Cochrane Collaboration, 2011. Available from handbook.cochrane.org.

\section{Hoffman 2014}

Hoffman TC, Glasziou PP, Boutron I, Milne R, Perera R, Moher D, et al. Better reporting of interventions: template for intervention description and replication (TIDieR) checklist and guide. BMJ 2014;348:1687.

\section{Horsten 2010}

Horsten NC, Ursum J, Roorda LD, van Schaardenburg D, Dekker J, Hoeksma AF. Prevalence of hand symptoms, impairments and activity limitations in rheumatoid arthritis in relation to disease duration. Journal of Rehabilitation Medicine 2010;42(10):916-21.

\section{Jones 1991}

Jones E, Hanly JG, Mooney R. Strength and function in the normal and rheumatoid hand. Journal of Rheumatology 1991;18:1313-8.

\section{Katchamart 2010}

Katchamart W, Trudeau J, Phumethum V, Bombardier C. Methotrexate monotherapy versus methotrexate combination therapy with non-biologic disease modifying anti-rheumatic drugs for rheumatoid arthritis. Cochrane Database of Systematic Reviews 2010, Issue 4. [DOI: 10.1002/14651858.CD008495]

\section{Kitchen 2013}

Kitchen H, Hansen BB, Abetz L, Højbjerre L, StrandbergLarsen M. Patient-reported outcome measures for rheumatoid arthritis: minimal important differences review. Arthritis \& Rheumatism 2013;65:S965.

\section{Lefebvre 2011}

Lefebvre C, Manheimer E, Glanville J. Chapter 6: Searching for studies. In: Higgins JP, Green S, editor(s). Cochrane Handbook for Systematic Reviews of Interventions Version 5.1.0 (updated March 2011). The Cochrane Collaboration, 2011. Available from handbook.cochrane.org.

\section{Schünemann 2011}

Schünemann HJ, Oxman AD, Vist GE, Higgins JP, Deeks JJ, Glasziou P, et al. Chapter 12: Interpreting results and drawing conclusions. In: Higgins JP, Green S, editor(s). Cochrane Handbook for Systematic Reviews of Interventions Version 5.1.0 (updated March 2011). The Cochrane Collaboration, 2011. Available from handbook.cochrane.org. 


\section{Shauver 2009}

Shauver MJ, Chung KC. The minimal clinically important difference of the Michigan Hand Outcomes Questionnaire. Journal of Hand Surgery 2009;34(9):509-14.

\section{Singh 2009}

Singh JA, Christensen R, Wells GA, Suarez-Almazor ME, Buchbinder R, Lopez-Olivo MA, et al. Biologics for rheumatoid arthritis: an overview of Cochrane Reviews. Cochrane Database of Systematic Reviews 2009, Issue 4. [DOI: 10.1002/14651858.CD007848.pub2]

\section{Sterne 2011}

Sterne JA, Egger M, Moher D. Chapter 10: Addressing reporting biases. In: Higgins JPT, Green S, editor(s). Cochrane Handbook for Systematic Reviews of Interventions Version 5.1.0 (updated March 2011). The Cochrane Collaboration, 2011. Available from handbook.cochrane.org.

\section{Steultjens 2004}

Steultjens EE, Dekker JJ, Bouter LM, Schaardenburg DD, Kuyk MAMAH, Van den Ende EC. Occupational therapy for rheumatoid arthritis. Cochrane Database of Systematic Reviews 2004, Issue 1. [DOI: 10.1002/14651858.CD003114.pub2]

\section{Suarez-Almazor 1998}

Suarez-Almazor ME, Belseck E, Shea B, Wells G, Tugwell P. Methotrexate for rheumatoid arthritis. Cochrane Database of Systematic Reviews 1998, Issue 2. [DOI: 10.1002/14651858.CD000957]

\section{Symmons 2002}

Symmons D, Turner G, Webb R, Asten P, Barrett E, Lunt M, et al. The prevalence of rheumatoid arthritis in the United

\section{CHARACTERISTICS OF STUDIES}

Characteristics of included studies [ordered by study ID]
Kingdom: new estimates for a new century. Rheumatology 2002;41(7):793-800.

\section{Tuntland 2009}

Tuntland H, Kjeken I, Nordheim LV, Falzon L, Jamtvedt G, Hagen KB. Assistive technology for rheumatoid arthritis. Cochrane Database of Systematic Reviews 2009, Issue 4. [DOI: 10.1002/14651858.CD006729.pub2]

\section{Van der Heijde 1993}

Van der Heijde DM, van Hof M, van Riel PL, van de Putte LB. Development of a disease activity score based on judgment in clinical practice by rheumatologists. Journal of Rheumatology 1993;20:579-81.

\section{Wessel 2004}

Wessel J. The effectiveness of hand exercises for persons with rheumatoid arthritis: a systematic review. Journal of Hand Therapy 2004;17:174-80.

\section{Williams 2015}

Williams MA, Williamson EM, Heine PJ, Nichols V, Glover MJ, Dritsaki M, et al. Strengthening And stretching for Rheumatoid Arthritis of the Hand (SARAH). A randomised controlled trial and economic evaluation. Health Technology Assessment Report 2015; Vol. 19, issue 19.

\section{Williamson 2017}

Williamson E, McConkey C, Heine P, Dosanjh S, Williams M, Lamb SE. Hand exercises for patients with rheumatoid arthritis: an extended follow-up of the SARAH randomised controlled trial. BMJ Open 2017;7(4):e013121.

\section{Brighton 1993}

\begin{tabular}{|c|c|}
\hline Methods & $\mathrm{RCT}$ \\
\hline Participants & $\begin{array}{l}55 \text { female participants ( } 25 \text { intervention group, } 30 \text { control group) with active rheumatoid arthritis for at } \\
\text { least } 1 \text { year (ESR }>25 \text { ), aged }>18 \text { years (range } 27 \text { to } 61 \text { years), housewives or sedentary occupation, RF } \\
\text { positive, erosions present in MCPs and/or PIPs, Steinbrocker functional class I, all on either gold injec- } \\
\text { tions or D-penicillamine plus anti-inflammatories }\end{array}$ \\
\hline & Country: South Africa \\
\hline
\end{tabular}

Interventions Intervention group: daily home exercise programme consisting of range of motion and strengthening exercises for 48 months, 6 -monthly checks with reinforcement

Control group: no treatment

Outcomes

Grip strength (sphygmomanometer, $\mathrm{mmHg}$, higher score = greater strength)

Pincer grip strength (sphygmomanometer, $\mathrm{mmHg}$, higher score = greater strength)

MCP and PIP total ROM score (goniometer, degrees, sum of flexion and extension ROM of all fingers, higher score $=$ greater movement) 
Brighton 1993 (Continued)

Outcome time points: baseline; 4 years

Notes Source of funding not declared.

\section{Risk of bias}

\begin{tabular}{|c|c|c|}
\hline Bias & Authors' judgement & Support for judgement \\
\hline $\begin{array}{l}\text { Random sequence genera- } \\
\text { tion (selection bias) }\end{array}$ & Unclear risk & $\begin{array}{l}\text { Quote: "The patients were divided into two groups by random allocation"; } \\
\text { however, details regarding randomisation method unclear }\end{array}$ \\
\hline $\begin{array}{l}\text { Allocation concealment } \\
\text { (selection bias) }\end{array}$ & Unclear risk & No method described. \\
\hline $\begin{array}{l}\text { Blinding of participants } \\
\text { All outcomes }\end{array}$ & High risk & Not possible \\
\hline $\begin{array}{l}\text { Blinding of personnel } \\
\text { All outcomes }\end{array}$ & High risk & Not possible \\
\hline $\begin{array}{l}\text { Blinding of outcome as- } \\
\text { sessment (detection bias) } \\
\text { Self-reported outcomes }\end{array}$ & Unclear risk & $\begin{array}{l}\text { Participants were aware of treatment allocation. No subjective outcome mea- } \\
\text { sures used. }\end{array}$ \\
\hline $\begin{array}{l}\text { Blinding of outcome as- } \\
\text { sessment (detection bias) } \\
\text { Objective outcomes }\end{array}$ & Low risk & $\begin{array}{l}\text { Quote: "All the patients were examined by the same examiner unaware of } \\
\text { which patient was in the test or control group" }\end{array}$ \\
\hline $\begin{array}{l}\text { Incomplete outcome data } \\
\text { (attrition bias) } \\
\text { All outcomes }\end{array}$ & Unclear risk & No explanation given for withdrawals and how they were treated in analysis. \\
\hline $\begin{array}{l}\text { Selective reporting (re- } \\
\text { porting bias) }\end{array}$ & High risk & No information on data from interim follow-up assessments \\
\hline Other bias & Unclear risk & No description of baseline characteristics of 2 groups other than age \\
\hline
\end{tabular}

\section{Buljina 2001}

\begin{tabular}{ll}
\hline Methods & RCT \\
\hline Participants & $\begin{array}{l}100 \text { participants ( } 50 \text { intervention group, } 50 \text { in control group) with rheumatoid arthritis according to ACR } \\
\text { criteria; years since diagnosis } 6 \text { months to } 22 \text { years; } 25 \text { male, } 75 \text { female; age range } 20 \text { to } 67 \text { years; ESR }> \\
25 ; \geq 3 \text { swollen joints in both hands; } \geq 5 \text { tender joints in both hands; decreased ROM and grip } \\
\text { Country: USA }\end{array}$ \\
\hline
\end{tabular}

Interventions

Intervention group: daily radon bath plus faradic hand bath plus wax bath plus a hand exercise programme (Flatt's range of motion and strengthening exercises for 3 weeks as an inpatient in rehabilitation facility

Control group: waiting-list control

Outcomes

ESR ( $\mathrm{mm}$ in first hour - Westergren method, higher score = greater disease activity)

PIP joint size (arthrocircometer, $\mathrm{mm}$, higher score = greater swelling) 
Hand pain (0-to-100 VAS, higher score = greater pain)

Joint mobility of MCPs, PIPs and wrist of dominant hand (goniometer, degrees converted to a 0-to-10 scale, greater score $=$ better ROM)

Grip strength (Jamar dynamometer, kg, higher score = greater strength)

Tip-to-tip pinch strength (Jaymar dynamometer, kg, higher score = greater strength)

Palmar pinch strength (Jaymar dynamometer, $\mathrm{kg}$, higher score = greater strength)

Key pinch strength (Jaymar dynamometer, kg, higher score = greater strength)

ADLs (1-to-6 scale where 1 = very poor and 6 = excellent; activities unknown)

Outcome time points: baseline, 3 weeks

Notes Source of funding not declared.

\section{Risk of bias}

\begin{tabular}{|c|c|c|}
\hline Bias & Authors' judgement & Support for judgement \\
\hline $\begin{array}{l}\text { Random sequence genera- } \\
\text { tion (selection bias) }\end{array}$ & Low risk & $\begin{array}{l}\text { Quote: "Patients were randomly divided into } 2 \text { groups using a table of random } \\
\text { numbers" }\end{array}$ \\
\hline $\begin{array}{l}\text { Allocation concealment } \\
\text { (selection bias) }\end{array}$ & Unclear risk & No method described. \\
\hline $\begin{array}{l}\text { Blinding of participants } \\
\text { All outcomes }\end{array}$ & High risk & Not possible \\
\hline $\begin{array}{l}\text { Blinding of personnel } \\
\text { All outcomes }\end{array}$ & High risk & Not possible \\
\hline $\begin{array}{l}\text { Blinding of outcome as- } \\
\text { sessment (detection bias) } \\
\text { Self-reported outcomes }\end{array}$ & High risk & Participants were aware of treatment allocation. \\
\hline $\begin{array}{l}\text { Blinding of outcome as- } \\
\text { sessment (detection bias) } \\
\text { Objective outcomes }\end{array}$ & Unclear risk & $\begin{array}{l}\text { Quote: "All patients were assessed by } 2 \text { physiatrists, one of whom was un- } \\
\text { aware of the patient's study group assignment. The participants were first as- } \\
\text { sessed by the "blinded" physiatrist, followed by the second physiatrist's as- } \\
\text { sessment the next day. Final patient evaluations were conducted in the same } \\
\text { manner at the end of the 3-week study period. Patients were instructed to } \\
\text { avoid discussing their group assignment." }\end{array}$ \\
\hline
\end{tabular}

Incomplete outcome data Unclear risk

No withdrawals or missing data reported.

(attrition bias)

All outcomes

\begin{tabular}{lll}
\hline $\begin{array}{l}\text { Selective reporting (re- } \\
\text { porting bias) }\end{array}$ & Low risk & All outcomes reported \\
\hline Other bias & Low risk & None \\
\hline
\end{tabular}


Cima 2013

\begin{tabular}{|c|c|}
\hline Methods & $\mathrm{RCT}$ \\
\hline \multirow[t]{3}{*}{ Participants } & $\begin{array}{l}20 \text { participants ( } 13 \text { intervention group, } 7 \text { control group), women diagnosed with rheumatoid arthritis } \\
\text { and presenting deformity in at least } 1 \text { of the fingers of each hand, ulnar deviation obligatorily present in } \\
\text { both hands }\end{array}$ \\
\hline & Mean age: 53 (10) intervention group; 60.4 (7.4) control group \\
\hline & Country: Brazil \\
\hline \multirow[t]{3}{*}{ Interventions } & $\begin{array}{l}12 \text { supervised exercises comprising co-ordination, range of movement, and strengthening, } 2 \text { times/ } \\
\text { week for } 2 \text { months ( } 20 \text { sessions) }\end{array}$ \\
\hline & $\begin{array}{l}\text { Unsupervised exercises excluding those using equipment, } 3 \text { times/week on alternate days to super- } \\
\text { vised sessions, total } 5 \text { days per week }\end{array}$ \\
\hline & Control: no treatment \\
\hline \multirow[t]{4}{*}{ Outcomes } & Health Assessment Questionnaire (0 to 3, lower score = greater improvement) \\
\hline & Handgrip strength (dynamometer, kgf, higher score = greater strength) \\
\hline & Pinch grip strength (pinch gauge, kgf, higher score = greater strength) \\
\hline & $\begin{array}{l}\text { Outcome time points: baseline; } 10 \text { sessions and } 20 \text { sessions (approximately } 2 \text { months) for intervention; } \\
2 \text { months for control }\end{array}$ \\
\hline Notes & Funding source declared: State of Sao Paulo Foundation for Research. \\
\hline
\end{tabular}

\section{Risk of bias}

\begin{tabular}{|c|c|c|}
\hline Bias & Authors' judgement & Support for judgement \\
\hline $\begin{array}{l}\text { Random sequence genera- } \\
\text { tion (selection bias) }\end{array}$ & Low risk & $\begin{array}{l}\text { Quote: "The women ... were randomised (by a computer-generated pro- } \\
\text { gram) ..." }\end{array}$ \\
\hline $\begin{array}{l}\text { Allocation concealment } \\
\text { (selection bias) }\end{array}$ & Unclear risk & Not specified \\
\hline $\begin{array}{l}\text { Blinding of participants } \\
\text { All outcomes }\end{array}$ & High risk & Not possible \\
\hline $\begin{array}{l}\text { Blinding of personnel } \\
\text { All outcomes }\end{array}$ & High risk & $\begin{array}{l}\text { Quote: "The evaluator and the research therapists were not blinded because } \\
\text { they were involved in the processes of assessment and intervention ..." }\end{array}$ \\
\hline $\begin{array}{l}\text { Blinding of outcome as- } \\
\text { sessment (detection bias) } \\
\text { Self-reported outcomes }\end{array}$ & High risk & Participants were aware of treatment allocation. \\
\hline $\begin{array}{l}\text { Blinding of outcome as- } \\
\text { sessment (detection bias) } \\
\text { Objective outcomes }\end{array}$ & High risk & $\begin{array}{l}\text { Quote: "The evaluator and the research therapists were not blinded because } \\
\text { they were involved in the processes of assessment and intervention ..." }\end{array}$ \\
\hline $\begin{array}{l}\text { Incomplete outcome data } \\
\text { (attrition bias) } \\
\text { All outcomes }\end{array}$ & Low risk & $\begin{array}{l}\text { Losses due to transportation and personal issues; none due to exacerbation of } \\
\text { symptoms }\end{array}$ \\
\hline $\begin{array}{l}\text { Selective reporting (re- } \\
\text { porting bias) }\end{array}$ & Low risk & Raw data supplied on request. \\
\hline
\end{tabular}


Cima 2013 (Continued)
Other bias
High risk
No baseline characteristics other than age

Dellhag 1992

\begin{tabular}{|c|c|}
\hline Methods & RCT \\
\hline Participants & $\begin{array}{l}52 \text { participants (13 intervention group } 1 ; 11 \text { intervention group } 2 ; 15 \text { intervention group } 3 ; 13 \text { control) } \\
\text { with sero-positive rheumatoid arthritis; disease duration } 6 \text { to } 10 \text { years; } 19 \text { male, } 33 \text { female; age range } 2 \\
\text { to } 69 \text {; Streinbrocker functional class I-II; decreased ROM or grip strength, or both } \\
\text { Country: Sweden }\end{array}$ \\
\hline Interventions & $\begin{array}{l}\text { Intervention group 1: wax bath and ROM exercises } 3 \text { times per week for } 4 \text { weeks } \\
\text { Intervention group 2: ROM exercise only } 3 \text { times per week for } 4 \text { weeks } \\
\text { Intervention group 3: wax bath only } 3 \text { times per week for } 4 \text { weeks } \\
\text { Control group: no treatment }\end{array}$ \\
\hline Outcomes & $\begin{array}{l}\text { Finger flexion deficit (ruler, mm, higher score = greater impairment) } \\
\text { Finger extension deficit (ruler, mm, higher score = greater impairment) } \\
\text { Total grip function dominant hand (Sollerman test, 0-to-80 scale, higher score = better grip function) } \\
\text { Pinch grip function dominant hand (Sollerman test, 0-to-32 scale, higher score = better grip function) } \\
\text { Grip strength (Grippit electronic instrument, N, higher score = greater strength) } \\
\text { Pain during grip function tests (10-point scale, higher score = greater pain) } \\
\text { Pain during finger movement (0-to-100-millimetre VAS, higher score = greater pain) } \\
\text { Hand stiffness (0-to-100-millimetre VAS, higher score = greater stiffness) } \\
\text { Outcome time points: baseline, } 4 \text { weeks }\end{array}$ \\
\hline
\end{tabular}

Notes

Source of funding declared: supported by a grant from Riksforbundet mot Reumatism, Stockholm.

\section{Risk of bias}

Bias

Authors' judgement Support for judgement

Random sequence genera- Unclear risk tion (selection bias)

Quote: "Patients were randomised into four groups using sequential allocation according to sex, age, duration of the disease, and/or previous hand surgery"; no method described

\begin{tabular}{lll}
\hline $\begin{array}{l}\text { Allocation concealment } \\
\text { (selection bias) }\end{array}$ & Unclear risk & No method described. \\
\hline $\begin{array}{l}\text { Blinding of participants } \\
\text { All outcomes }\end{array}$ & High risk & Not possible \\
\hline $\begin{array}{l}\text { Blinding of personnel } \\
\text { All outcomes }\end{array}$ & High risk & Not possible \\
\hline $\begin{array}{l}\text { Blinding of outcome as- } \\
\text { sessment (detection bias) }\end{array}$ & High risk & Participants were aware of treatment allocation. \\
\hline
\end{tabular}


Dellhag 1992 (Continued)

Self-reported outcomes

\begin{tabular}{lll}
\hline $\begin{array}{l}\text { Blinding of outcome as- } \\
\text { sessment (detection bias) }\end{array}$ & Unclear risk & $\begin{array}{l}\text { Quote: "Two occupational therapists ... did all measurements, the same thera- } \\
\text { pist seeing the individual patient before and after treatment ... Subjects were } \\
\text { Objective outcomes }\end{array}$ \\
not told the measurement results during the study period"
\end{tabular}

No withdrawals or missing data reported.

Incomplete outcome data Unclear risk

(attrition bias)

All outcomes

\begin{tabular}{lll}
\hline $\begin{array}{l}\text { Selective reporting (re- } \\
\text { porting bias) }\end{array}$ & Low risk & $\begin{array}{l}\text { All outcomes reported as described in methods apart from pre-post session } \\
\text { pain. }\end{array}$ \\
\hline Other bias & Low risk & None \\
\hline
\end{tabular}

Hoenig 1993

\begin{tabular}{ll}
\hline Methods & RCT \\
\hline Participants & $\begin{array}{l}57 \text { participants (14 intervention group 1; } 16 \text { intervention group 2; } 16 \text { intervention group 3; } 11 \text { control } \\
\text { group) with rheumatoid arthritis according to the ARA criteria who had no change in medication for } 6 \\
\text { weeks prior to enrolment } \\
\text { Country: USA }\end{array}$
\end{tabular}

Interventions

Intervention group 1: ROM home exercise programme for hands performed twice daily for 12 weeks

Intervention group 2: strengthening home exercise programme for hands performed twice daily for 12 weeks

Intervention group 3: ROM and strengthening exercise programme for hands performed twice daily for 12 weeks

Control group: no treatment

Outcomes

$$
\begin{aligned}
& \text { Grip strength (aneroid manometer, mmHg, higher score = greater strength) } \\
& \text { MCP extension ROM (goniometer, degrees, higher score = greater movement) } \\
& \text { PIP extension ROM (goniometer, degrees, higher score = greater movement) } \\
& \text { Hand articular index (Ritchie articular index, higher score = greater disease activity) } \\
& \text { PIP circumference (arthrocircometer, cm, higher score = greater swelling) } \\
& \text { Ulnar deviation of 3rd digit (goniometer, degrees, higher score = greater deformity) } \\
& \text { clinician rating of hand deformities (no detail given) } \\
& \text { dexterity (9-hole peg test, seconds, greater score = worse dexterity) } \\
& \text { Morning stiffness (participant reported, minutes, higher score = worse stiffness) } \\
& \text { Hand pain (VAS, higher score = greater pain) } \\
& \text { Arthritis severity (no details given) } \\
& \text { Medication dosage/frequency (participant reported) } \\
& \text { Outcome time points: baseline; } 3 \text { months; } 6 \text { months (exercise group only) }
\end{aligned}
$$


Hoenig 1993 (Continued)

Notes

Funding source declared: The Bassett Research Foundation and Fred Sammons, Inc.

\section{Risk of bias}

\begin{tabular}{lll}
\hline Bias & Authors' judgement & Support for judgement \\
\hline $\begin{array}{l}\text { Random sequence genera- } \\
\text { tion (selection bias) }\end{array}$ & Low risk & $\begin{array}{l}\text { Quote: "Consecutive patients were randomly assigned in blocks of 4, using a } \\
\text { random numbers table, to } 1 \text { of } 3 \text { exercise groups or a control group" }\end{array}$ \\
\hline $\begin{array}{l}\text { Allocation concealment } \\
\text { (selection bias) }\end{array}$ & Unclear risk & No method described. \\
\hline $\begin{array}{l}\text { Blinding of participants } \\
\text { All outcomes }\end{array}$ & High risk & $\begin{array}{l}\text { All } 3 \text { exercise regimens were demonstrated by the OT, although participants } \\
\text { were aware that they would carry out only } 1 \text { of the regimens, depending on } \\
\text { their assignment. }\end{array}$ \\
\hline $\begin{array}{l}\text { Blinding of personnel } \\
\text { All outcomes }\end{array}$ & Low risk & $\begin{array}{l}\text { Quote: "Treating physicians and OT evaluator were unaware of the patient's } \\
\text { study group assignment. Patients were instructed to avoid discussing their ex- } \\
\text { ercise assignment with either the OT evaluator or their physician and to con- } \\
\text { tact one of the investigators with questions or problems." }\end{array}$ \\
\hline
\end{tabular}

\begin{tabular}{lll}
\hline $\begin{array}{l}\text { Blinding of outcome as- } \\
\text { sessment (detection bias) } \\
\text { Self-reported outcomes }\end{array}$ & High risk & Participants were aware of treatment allocation. \\
\hline $\begin{array}{l}\text { Blinding of outcome as- } \\
\text { sessment (detection bias) } \\
\text { Objective outcomes }\end{array}$ & Low risk & $\begin{array}{l}\text { Quote: "Treating physicians and OT evaluator were unaware of the patient's } \\
\text { study group assignment. Patients were instructed to avoid discussing their ex- } \\
\text { ercise assignment with either the OT evaluator or their physician and to con- } \\
\text { tact one of the investigators with questions or problems." }\end{array}$
\end{tabular}

Incomplete outcome data High risk (attrition bias) Quote: "Our data were analysed excluding noncompliant patients and patients

All outcomes who had changes in their medication."

\begin{tabular}{lll}
\hline $\begin{array}{l}\text { Selective reporting (re- } \\
\text { porting bias) }\end{array}$ & High risk & $\begin{array}{l}\text { No data or comments regarding morning stiffness, hand pain, or severity of } \\
\text { arthritis provided. }\end{array}$ \\
\hline Other bias & High risk & $\begin{array}{l}\text { Contamination risk: all 3 exercise regimens were demonstrated by the OT, al- } \\
\text { though participants were aware that they would carry out only } 1 \text { of the regi- } \\
\text { mens, depending on their assignment. }\end{array}$ \\
\hline
\end{tabular}

Lamb 2015

\begin{tabular}{ll}
\hline Methods & RCT \\
\hline Participants & 490 participants randomised ( 2 withdrew use of data consent); 374 females, 114 males \\
& $\begin{array}{l}\text { Adults ( } \geq 18 \text { years) with RA with pain and dysfunction of hands who were either not on a DMARD regi- } \\
\text { men, or who had been on a stable DMARD regimen (including biologic agents if used) for } 3 \text { months or } \\
\text { beyond } \\
\text { Country: UK }\end{array}$
\end{tabular}

Interventions

7 mobility exercises ( 1 set $x 5$ reps), progression with increased reps ( $\max 10)$ and increased hold time (max 10 seconds) 
4 strengthening exercises ( 1 set $\times 10$ reps ( $\min 8$, max 12$) \times 10$ of initial load between 3 to 4 on modified 10 -point Borg scale), stepwise progression of increased reps, and increased Borg scale scores

6 contact sessions, of which 5 were exercise sessions

Daily at home in between exercise sessions

Usual care control comprising an initial assessment and the provision of joint protection information, splinting, assistive devices, and other general advice as required

Hand function: MHQ - overall hand function subscale; summed MHQ score - participant-reported questionnaire; range 0 to 100 (higher score indicates greater function)

Pain: pain subscale of the MHQ - questionnaire; 0 to 100 (high score is worse) Troublesomeness grid: questionnaire; 0 to 20 (higher score indicates greater pain)

Activities of daily living: subscale of the MHQ - questionnaire; range 0 to 100 (higher score indicates greater function)

Work performance subscale of the MHQ: questionnaire; range 0 to 100 (higher score indicates greater function)

Satisfaction: subscale of the MHQ - questionnaire; range 0 to 100 (higher score indicates greater function)

Self reported improvement: participant-rated global change questionnaire; range 1-to-7-point Likert scale ("completely recovered" to "vastly worsened" - higher score = better outcome)

Self reported benefit/harm of treatment: treatment satisfaction questionnaire; range 1 to 5 ("substantial benefit" to "substantial harm")

Satisfaction questions: range 1 to 7 (extremely dissatisfied to extremely satisfied)

Aesthetics: subscale of the MHQ - questionnaire; range 0 to 100 (higher score indicates greater function)

Grip strength: MIE digital grip analyser in the standard test position recommended by the American Society of Hand Therapists; $\mathrm{N}$ (higher value = better)

Pinch grip: MIE digital grip analyser in the standard test position recommended by the American Society of Hand Therapists; $\mathrm{N}$ (higher value = better)

Dexterity: 9-hole peg test; seconds (higher score is worse)

Hand and wrist active range of motion: wrist flexion and extension from the neutral position - goniometer; degrees (greater score $=$ greater movement)

Combined finger flexion and combined finger extension: ruler; $\mathrm{mm}$ (lesser score = greater movement) Thumb opposition: observation; 0 to 10 (higher value = better)

Joint alignment/deformity: MCP ulnar/radial deviation in maximum pronation, where ulnar deviation is recorded as a positive value - goniometer; degrees (higher score is worse)

Self efficacy: Arthritis Self-Efficacy Scale - 7-item questionnaire (higher score = greater self efficacy)

Changes in disease activity: ESR; mm/hour

C-reactive protein: blood tests, collected from patient records; $\mathrm{mg} /$ litre

Tender and swollen joint count of the hands and wrists: examination; count 0 to 22 (high score is worse)

Quality of life: 12-Item Short Form Health Survey (SF-12) (mental and physical); range 0 to 100 (higher scores = higher quality of life); EQ-5D: range 0 to 1 (higher score = better outcome) 
Exercise adherence: 5 -item self reported current exercise behaviour questionnaire $>/=1$ to 2 sessions per week

Economics: resource use questionnaire; cost per quality adjusted life year

Outcome time points: baseline; 4 months; 12 months

Notes

Funding source declared: National Institute for Health Research Health Technology assessment programme.

\section{Risk of bias}

\begin{tabular}{|c|c|c|}
\hline Bias & Authors' judgement & Support for judgement \\
\hline $\begin{array}{l}\text { Random sequence genera- } \\
\text { tion (selection bias) }\end{array}$ & Low risk & Quote: "We used a central telephone randomisation service ..." \\
\hline $\begin{array}{l}\text { Allocation concealment } \\
\text { (selection bias) }\end{array}$ & Low risk & $\begin{array}{l}\text { Quote: "Allocation was computer-generated and only revealed once the par- } \\
\text { ticipant was registered into the trial ... The research clinician will then tele- } \\
\text { phone the randomisation service, and once the patient is registered in the tri- } \\
\text { al, will the random allocation be generated" }\end{array}$ \\
\hline $\begin{array}{l}\text { Blinding of participants } \\
\text { All outcomes }\end{array}$ & High risk & $\begin{array}{l}\text { Quote: "It was not possible to mask participants and therapists to treatment } \\
\text { allocation." }\end{array}$ \\
\hline $\begin{array}{l}\text { Blinding of personnel } \\
\text { All outcomes }\end{array}$ & High risk & $\begin{array}{l}\text { Quote: "It was not possible to mask participants and therapists to treatment } \\
\text { allocation." }\end{array}$ \\
\hline $\begin{array}{l}\text { Blinding of outcome as- } \\
\text { sessment (detection bias) } \\
\text { Self-reported outcomes }\end{array}$ & High risk & Participants were aware of allocation. \\
\hline $\begin{array}{l}\text { Blinding of outcome as- } \\
\text { sessment (detection bias) } \\
\text { Objective outcomes }\end{array}$ & Low risk & $\begin{array}{l}\text { Quote: "The outcome assessors were independent of intervention delivery and } \\
\text { masked to group allocation. Participants were asked not to reveal allocation } \\
\text { to the assessors at follow-up. We asked outcome assessors if they could guess } \\
\text { the allocation of participants at the end of each assessment." }\end{array}$ \\
\hline $\begin{array}{l}\text { Incomplete outcome data } \\
\text { (attrition bias) } \\
\text { All outcomes }\end{array}$ & Low risk & $\begin{array}{l}\text { Quote: "The analysis was intention to treat"; "We used published score specif- } \\
\text { ic guidance for managing missing data and investigated the effects of missing } \\
\text { data using multiple imputation analysis." }\end{array}$ \\
\hline $\begin{array}{l}\text { Selective reporting (re- } \\
\text { porting bias) }\end{array}$ & Low risk & All outcomes reported. \\
\hline Other bias & Low risk & $\begin{array}{l}\text { Quote: "None of the authors declare any conflict of interest"; "The randomised } \\
\text { groups were well matched in clinical and demographic characteristics." }\end{array}$ \\
\hline
\end{tabular}

O'Brien 2006

\begin{tabular}{|c|c|}
\hline Methods & $\mathrm{RCT}$ \\
\hline Participants & $\begin{array}{l}67 \text { participants ( } 21 \text { intervention group } 1 ; 24 \text { intervention group } 2 ; 22 \text { control group) with rheumatoid } \\
\text { arthritis according to ACR criteria; stable medication for } 3 \text { months prior to enrolment; not on oral or in- } \\
\text { jected corticosteroids; } 21 \text { male, } 46 \text { female; > } 18 \text { years; no surgery in the } 6 \text { months prior to enrolment; no } \\
\text { sensory impairment to hands; and not pregnant }\end{array}$ \\
\hline & Country: UK \\
\hline
\end{tabular}


O'Brien 2006 (Continued)

Interventions
Intervention group 1: joint protection advice plus strengthening and ROM home exercise programme twice daily for 6 months taught by a musculoskeletal therapist

Intervention group 2: joint protection advice plus ROM home exercise programme twice daily for 6 months taught by a musculoskeletal therapist

Control group: joint protection advice taught by a musculoskeletal therapist

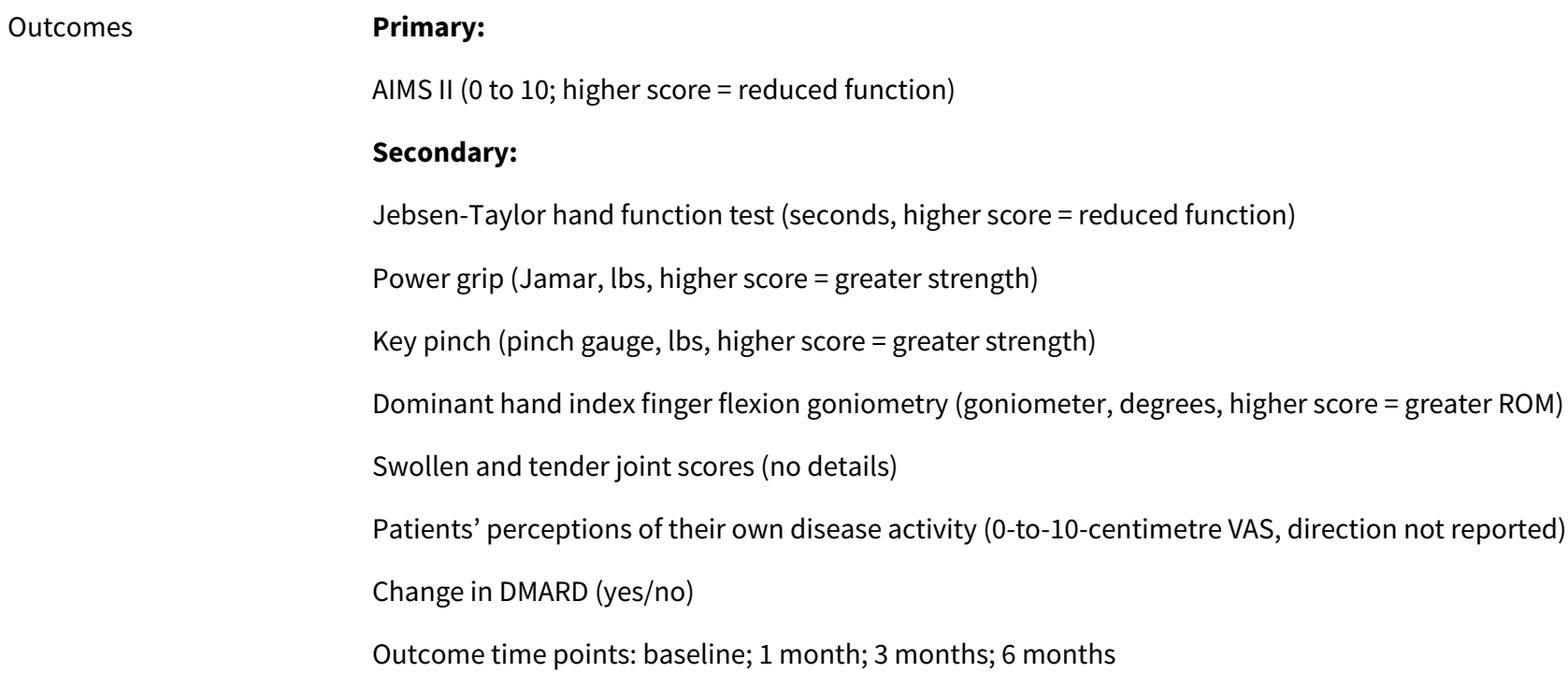

\section{Risk of bias}

\begin{tabular}{lll}
\hline Bias & Authors' judgement & Support for judgement \\
\hline $\begin{array}{ll}\text { Random sequence genera- } \\
\text { tion (selection bias) }\end{array}$ & Low risk & $\begin{array}{l}\text { Quote: "A computer-generated randomisation list with permuted blocks with- } \\
\text { in strata (17) was devised which stratified by length of time since diagnosis } \\
\text { (less than or beyond than } 5 \mathrm{yr} \text { ) as well as rheumatoid factor serology (positive } \\
\text { or negative)." }\end{array}$
\end{tabular}

Allocation concealment Low risk
(selection bias)
(selection bias)
Quote: "Following screening and consent, the research physiotherapist tele- phoned a blinded third party (from a central administrative team) informing them of stratification details; this person then subsequently identified treat- ment allocation. The research therapist ... then referred the participant to the treating therapist ... who undertook the allocated treatment according to a protocol."

\begin{tabular}{|c|c|c|}
\hline $\begin{array}{l}\text { Blinding of participants } \\
\text { All outcomes }\end{array}$ & High risk & Not possible \\
\hline $\begin{array}{l}\text { Blinding of personnel } \\
\text { All outcomes }\end{array}$ & High risk & Not possible \\
\hline $\begin{array}{l}\text { Blinding of outcome as- } \\
\text { sessment (detection bias) } \\
\text { Self-reported outcomes }\end{array}$ & High risk & Participants were aware of treatment allocation. \\
\hline $\begin{array}{l}\text { Blinding of outcome as- } \\
\text { sessment (detection bias) } \\
\text { Objective outcomes }\end{array}$ & Low risk & $\begin{array}{l}\text { Quote: "(Following randomisation) the research therapist ... then referred the } \\
\text { participant to the treating therapist ... who undertook the allocated treatment }\end{array}$ \\
\hline
\end{tabular}


according to a protocol. All outcome assessments were undertaken blinded at baseline, 1, 3 and 6 months by one of two additional therapists ..."

\begin{tabular}{lll}
\hline $\begin{array}{l}\text { Incomplete outcome data } \\
\text { (attrition bias) } \\
\text { All outcomes }\end{array}$ & Low risk & Quote: "An intention to treat analysis was undertaken" \\
\hline $\begin{array}{l}\text { Selective reporting (re- } \\
\text { porting bias) }\end{array}$ & Low risk & All outcomes reported \\
\hline Other bias & Low risk & $\begin{array}{l}\text { Quote: "Participants in group 1 were older and had longer mean disease du- } \\
\text { ration and higher scores for all disease activity measures compared with par- } \\
\text { ticipants in groups 2 and 3, although differences were not statistically signifi- } \\
\text { cant." Note: AlMS II adjusted for baseline values. }\end{array}$ \\
\hline
\end{tabular}

ACR: American College of Rheumatology

ADL: activities of daily living

AIMS: Arthritis Impact Measurement Scale

ARA: American Rheumatism Association

CRP: C-reactive protein

DMARDs: disease-modifying antirheumatic drugs

ESR: erythrocyte sedimentation rate

HAQ: Health Assessment Questionnaire

kgf: kilogram-force

MCP: metacarpophalangeal

MHQ: Michigan Hand Outcomes Questionnaire

OT: occupational therapist

PIP: proximal interphalangeal

RCT: randomised controlled trial

RF: rheumatoid factor

ROM: range of motion

VAS: visual analogue scale

Characteristics of excluded studies [ordered by study ID]

\begin{tabular}{ll}
\hline Study & Reason for exclusion \\
\hline Azeez 2014 & Did not evaluate an exercise programme specific to the hand or wrist \\
\hline Baillet 2009 & Did not evaluate an exercise programme specific to the hand or wrist \\
\hline Bearne 2012 & Did not evaluate an exercise programme specific to the hand or wrist \\
\hline Berntzen 2016 & Did not evaluate an exercise programme specific to the hand or wrist \\
\hline Brorsson 2009 & Study did not use a randomised design. \\
\hline Brorsson 2014 & Did not compare an exercise programme to a non-exercise comparator \\
\hline Byers 1985 & Did not compare an exercise programme to a non-exercise comparator \\
\hline Cakir 2014 & Did not evaluate an exercise programme specific to the hand or wrist \\
\hline Dash 2001 & Did not evaluate an exercise programme specific to the hand or wrist \\
\hline De Jong 2004 & Did not evaluate an exercise programme specific to the hand or wrist \\
\hline
\end{tabular}




\begin{tabular}{|c|c|}
\hline Study & Reason for exclusion \\
\hline Dogu 2013 & Did not compare an exercise programme to a non-exercise comparator \\
\hline Dulgeroglu 2014 & Did not compare an exercise programme to a non-exercise comparator \\
\hline Dülgeroğlu 2016 & Did not compare an exercise programme to a non-exercise comparator \\
\hline Flint-Wagner 2009 & Did not evaluate an exercise programme specific to the hand or wrist \\
\hline Hammond 2004a & Did not compare an exercise programme to a non-exercise comparator \\
\hline Hansen 1993 & Did not evaluate an exercise programme specific to the hand or wrist \\
\hline Hawkes 1985 & Did not compare an exercise programme to a non-exercise comparator \\
\hline Hawkes 1986 & Did not compare an exercise programme to a non-exercise comparator \\
\hline Khedekar 2017 & Did not compare an exercise programme to a non-exercise comparator \\
\hline Kiraly 2015 & Did not evaluate an exercise programme specific to the hand or wrist \\
\hline Lineker 2001 & Did not evaluate an exercise programme specific to the hand or wrist \\
\hline Maxwell 2005 & Study did not use a randomised design. \\
\hline Minor 1995 & Did not evaluate an exercise programme specific to the hand or wrist \\
\hline Orlova 2016 & Did not evaluate an exercise programme specific to the hand or wrist \\
\hline Piga 2014 & Did not compare an exercise programme to a non-exercise comparator \\
\hline Pineda-Juárez 2016 & Did not evaluate an exercise programme specific to the hand or wrist \\
\hline Pot-Vaucel 2016 & Did not evaluate an exercise programme specific to the hand or wrist \\
\hline Rapoliene 2006 & Study did not use a randomised design. \\
\hline Ronningen 2008 & Study did not use a randomised design. \\
\hline Seneca 2015 & Did not evaluate an exercise programme specific to the hand or wrist \\
\hline Shapoorabadi 2016 & Did not evaluate an exercise programme specific to the hand or wrist \\
\hline Srikesavan 2016 & Did not compare an exercise programme to a non-exercise comparator \\
\hline Tee 2016 & Did not evaluate an exercise programme specific to the hand or wrist \\
\hline Veitiene 2004 & Did not compare an exercise programme to a non-exercise comparator \\
\hline
\end{tabular}

\section{DATA AND ANALYSES}


Comparison 1. Exercise versus no exercise

\begin{tabular}{|c|c|c|c|c|}
\hline Outcome or subgroup title & No. of studies & $\begin{array}{l}\text { No. of partici- } \\
\text { pants }\end{array}$ & Statistical method & Effect size \\
\hline 1 Hand function & 1 & & $\begin{array}{l}\text { Mean Difference (IV, Fixed, 95\% } \\
\mathrm{Cl} \text { ) }\end{array}$ & Subtotals only \\
\hline 1.1 Medium term ( 3 to 11 months) & 1 & 449 & $\begin{array}{l}\text { Mean Difference (IV, Fixed, 95\% } \\
\mathrm{Cl})\end{array}$ & $4.5[1.58,7.42]$ \\
\hline $\begin{array}{l}1.2 \text { Long term ( } 12 \text { months or } \\
\text { more) }\end{array}$ & 1 & 438 & $\begin{array}{l}\text { Mean Difference (IV, Fixed, 95\% } \\
\mathrm{CI})\end{array}$ & $4.30[0.86,7.74]$ \\
\hline 2 Pain & 3 & & $\begin{array}{l}\text { Mean Difference (IV, Random, } \\
95 \% \mathrm{CI} \text { ) }\end{array}$ & Subtotals only \\
\hline $\begin{array}{l}2.1 \text { Pain scores: short term }(<3 \\
\text { months) }\end{array}$ & 2 & 124 & $\begin{array}{l}\text { Mean Difference (IV, Random, } \\
95 \% \mathrm{CI} \text { ) }\end{array}$ & $\begin{array}{l}-27.98[-48.93 \\
-7.03]\end{array}$ \\
\hline 2.2 Pain scores: medium term & 1 & 445 & $\begin{array}{l}\text { Mean Difference (IV, Random, } \\
95 \% \mathrm{CI} \text { ) }\end{array}$ & $-2.80[-6.96,1.36]$ \\
\hline 2.3 Pain scores: long term & 1 & 437 & $\begin{array}{l}\text { Mean Difference (IV, Random, } \\
95 \% \mathrm{Cl} \text { ) }\end{array}$ & $-3.70[-8.10,0.70]$ \\
\hline $\begin{array}{l}3 \text { Hand impairment - power grip } \\
\text { strength: short term }\end{array}$ & 3 & & $\begin{array}{l}\text { Std. Mean Difference (IV, Fixed, } \\
95 \% \mathrm{CI})\end{array}$ & Subtotals only \\
\hline $\begin{array}{l}\text { 3.1 Power grip strength - left } \\
\text { hand: short term }\end{array}$ & 3 & 141 & $\begin{array}{l}\text { Std. Mean Difference (IV, Fixed, } \\
95 \% \mathrm{Cl} \text { ) }\end{array}$ & $0.44[0.11,0.78]$ \\
\hline $\begin{array}{l}\text { 3.2 Power grip strength - right } \\
\text { hand: short term }\end{array}$ & 3 & 141 & $\begin{array}{l}\text { Std. Mean Difference (IV, Fixed, } \\
95 \% \mathrm{Cl})\end{array}$ & $0.46[0.13,0.80]$ \\
\hline $\begin{array}{l}4 \text { Hand impairment - power grip } \\
\text { strength: medium and long term }\end{array}$ & 1 & & $\begin{array}{l}\text { Mean Difference (IV, Fixed, 95\% } \\
\mathrm{Cl})\end{array}$ & Subtotals only \\
\hline $\begin{array}{l}4.1 \text { Mean power grip strength of } \\
\text { both sides: medium term }\end{array}$ & 1 & 400 & $\begin{array}{l}\text { Mean Difference (IV, Fixed, 95\% } \\
\mathrm{CI})\end{array}$ & $1.40[-0.27,3.07]$ \\
\hline $\begin{array}{l}4.2 \text { Mean power grip strength of } \\
\text { both sides: long term }\end{array}$ & 1 & 355 & $\begin{array}{l}\text { Mean Difference (IV, Fixed, 95\% } \\
\mathrm{CI})\end{array}$ & $1.20[-0.62,3.02]$ \\
\hline $\begin{array}{l}5 \text { Hand impairment - pinch grip } \\
\text { strength }\end{array}$ & 3 & & $\begin{array}{l}\text { Mean Difference (IV, Fixed, 95\% } \\
\mathrm{CI} \text { ) }\end{array}$ & Subtotals only \\
\hline $\begin{array}{l}\text { 5.1 Pinch grip strength - left hand: } \\
\text { short term }\end{array}$ & 2 & 120 & $\begin{array}{l}\text { Mean Difference (IV, Fixed, 95\% } \\
\mathrm{CI})\end{array}$ & $0.51[0.13,0.90]$ \\
\hline $\begin{array}{l}5.2 \text { Pinch grip strength - right } \\
\text { hand: short term }\end{array}$ & 2 & 120 & $\begin{array}{l}\text { Mean Difference (IV, Fixed, 95\% } \\
\mathrm{CI})\end{array}$ & $0.82[0.43,1.21]$ \\
\hline $\begin{array}{l}5.3 \text { Mean pinch grip strength of } \\
\text { both sides: medium term }\end{array}$ & 1 & 396 & $\begin{array}{l}\text { Mean Difference (IV, Fixed, 95\% } \\
\mathrm{Cl} \text { ) }\end{array}$ & $0.30[-0.14,0.74]$ \\
\hline $\begin{array}{l}5.4 \text { Mean pinch grip strength of } \\
\text { both sides: long term }\end{array}$ & 1 & 351 & $\begin{array}{l}\text { Mean Difference (IV, Fixed, 95\% } \\
\mathrm{Cl} \text { ) }\end{array}$ & $0.40[-0.08,0.88]$ \\
\hline
\end{tabular}




\begin{tabular}{|c|c|c|c|c|}
\hline Outcome or subgroup title & No. of studies & $\begin{array}{l}\text { No. of partici- } \\
\text { pants }\end{array}$ & Statistical method & Effect size \\
\hline 6 Participant adherence & 1 & & Risk Ratio (M-H, Fixed, 95\% Cl) & Subtotals only \\
\hline $\begin{array}{l}\text { 6.1 Participant adherence: medi- } \\
\text { um term }\end{array}$ & 1 & 438 & Risk Ratio (M-H, Fixed, 95\% Cl) & $1.31[1.15,1.48]$ \\
\hline $\begin{array}{l}6.2 \text { Participant adherence: long } \\
\text { term }\end{array}$ & 1 & 422 & Risk Ratio (M-H, Fixed, 95\% Cl) & $1.09[0.93,1.28]$ \\
\hline 7 General function & 3 & & $\begin{array}{l}\text { Std. Mean Difference (IV, Fixed, } \\
95 \% \mathrm{Cl})\end{array}$ & Subtotals only \\
\hline 7.1 Short term & 2 & 120 & $\begin{array}{l}\text { Std. Mean Difference (IV, Fixed, } \\
95 \% \mathrm{CI})\end{array}$ & $0.79[0.42,1.17]$ \\
\hline 7.2 Medium term & 1 & 449 & $\begin{array}{l}\text { Std. Mean Difference (IV, Fixed, } \\
95 \% \mathrm{CI})\end{array}$ & $1.45[1.24,1.66]$ \\
\hline 8 Disease activity & 2 & & $\begin{array}{l}\text { Std. Mean Difference (IV, Fixed, } \\
95 \% \mathrm{Cl} \text { ) }\end{array}$ & Subtotals only \\
\hline $\begin{array}{l}8.1 \text { Swollen joint count: medium } \\
\text { term }\end{array}$ & 2 & 492 & $\begin{array}{l}\text { Std. Mean Difference (IV, Fixed, } \\
95 \% \mathrm{CI} \text { ) }\end{array}$ & $-0.16[-0.34,0.01]$ \\
\hline $\begin{array}{l}8.2 \text { Tender joint count: medium } \\
\text { term }\end{array}$ & 2 & 492 & $\begin{array}{l}\text { Std. Mean Difference (IV, Fixed, } \\
95 \% \mathrm{Cl})\end{array}$ & $-0.19[-0.37,-0.01]$ \\
\hline
\end{tabular}

Analysis 1.1. Comparison 1 Exercise versus no exercise, Outcome 1 Hand function.

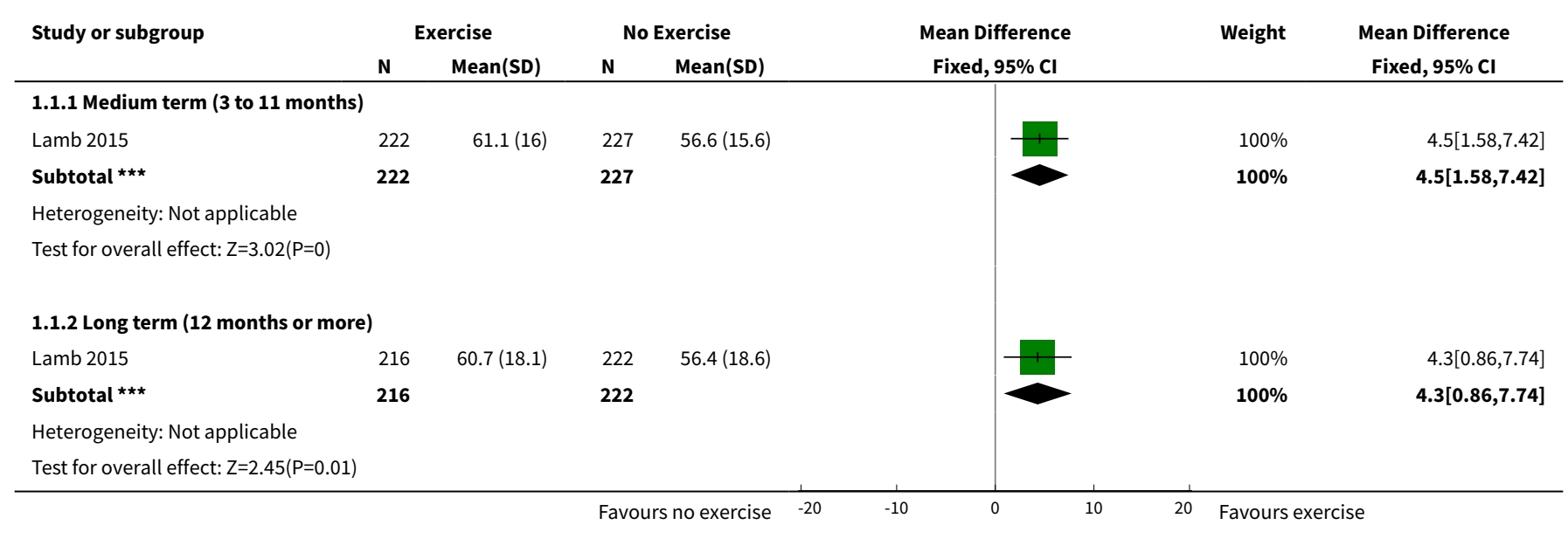


Analysis 1.2. Comparison 1 Exercise versus no exercise, Outcome 2 Pain.

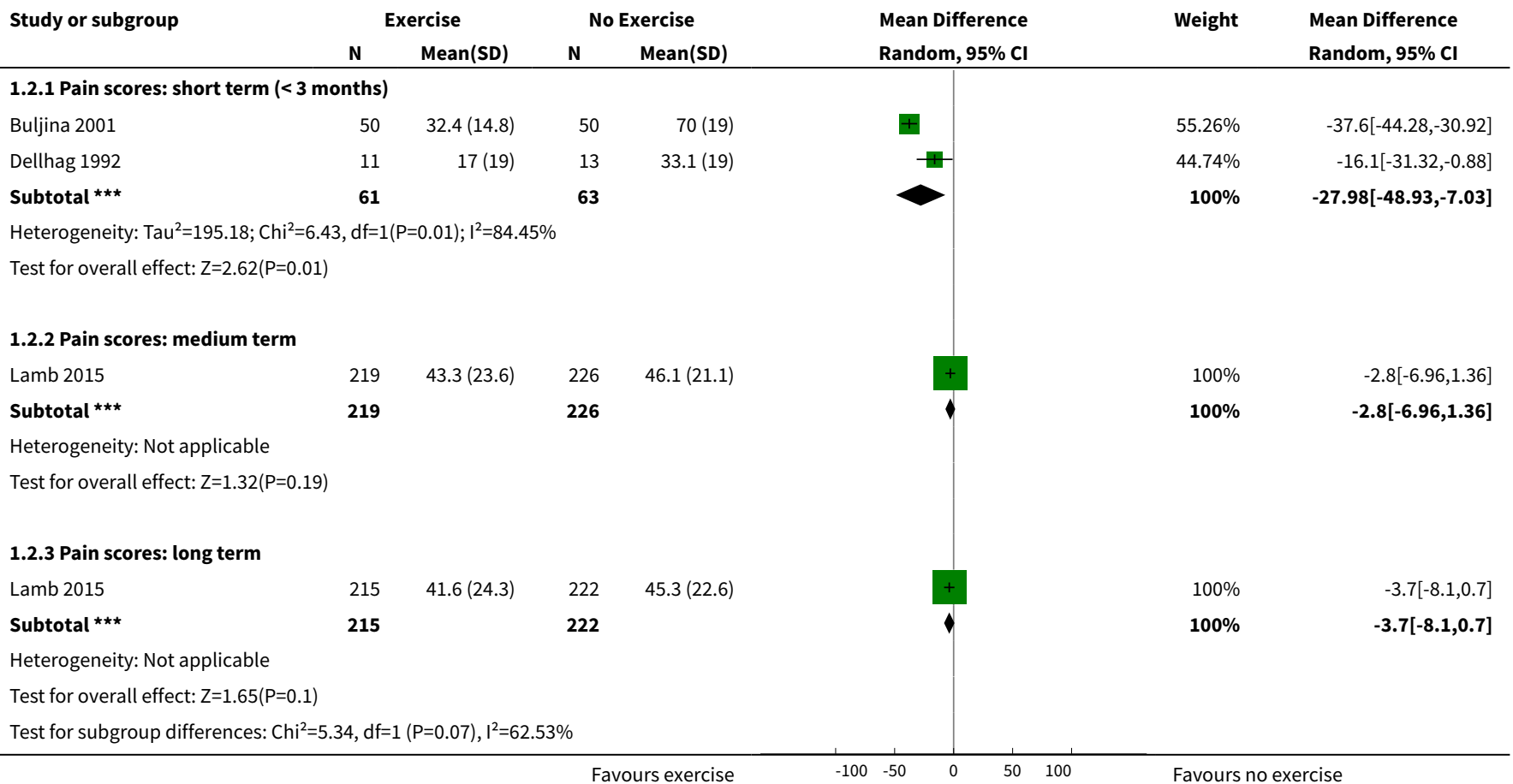

Analysis 1.3. Comparison 1 Exercise versus no exercise, Outcome 3 Hand impairment - power grip strength: short term.

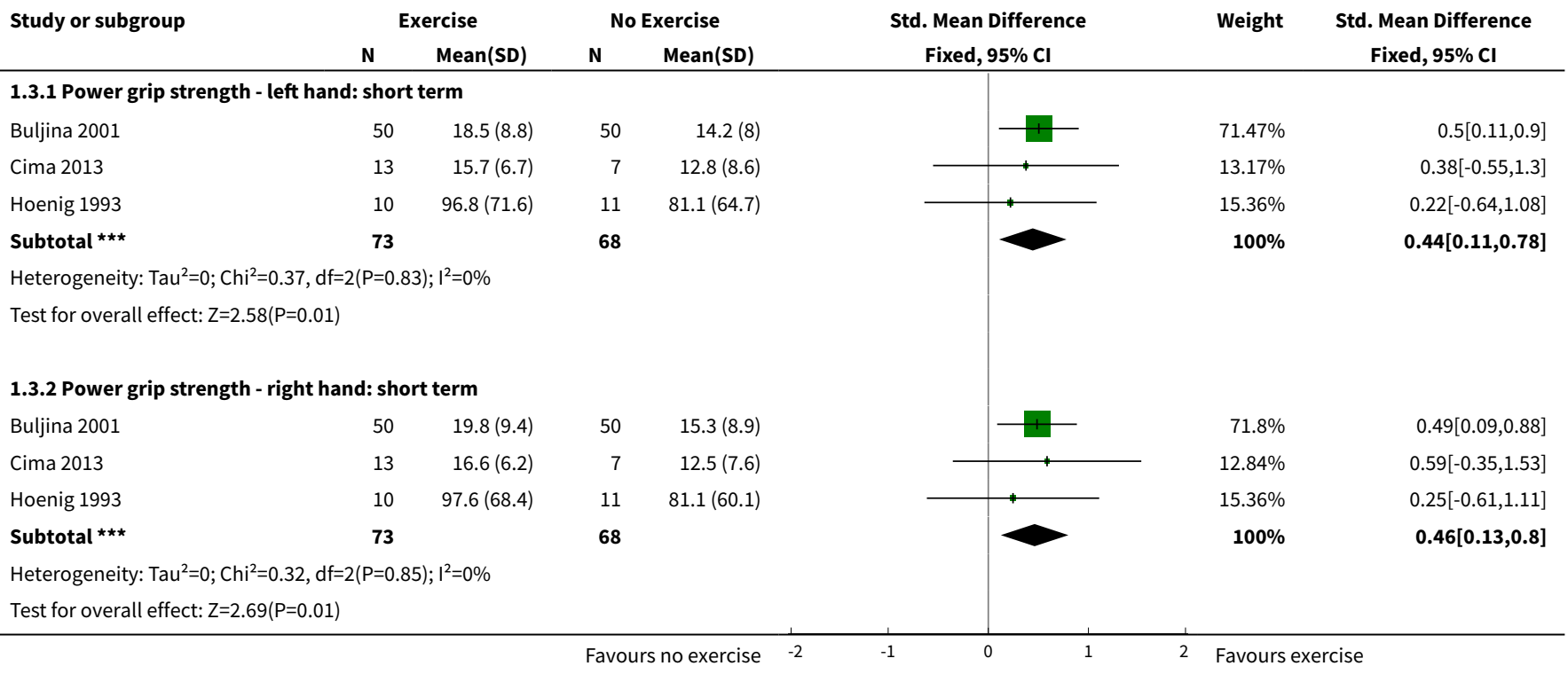


Analysis 1.4. Comparison 1 Exercise versus no exercise, Outcome

4 Hand impairment - power grip strength: medium and long term.

\begin{tabular}{|c|c|c|c|c|c|c|c|}
\hline \multirow[t]{2}{*}{ Study or subgroup } & \multicolumn{2}{|c|}{ Exercise } & \multicolumn{2}{|c|}{ No exercise } & \multirow{2}{*}{$\begin{array}{c}\text { Mean Difference } \\
\text { Fixed, } 95 \% \mathrm{Cl} \\
\end{array}$} & \multirow[t]{2}{*}{ Weight } & \multirow{2}{*}{$\begin{array}{c}\text { Mean Difference } \\
\text { Fixed, } 95 \% \mathrm{Cl} \\
\end{array}$} \\
\hline & $\mathbf{N}$ & Mean(SD) & $\mathbf{N}$ & $\operatorname{Mean}(\mathrm{SD})$ & & & \\
\hline \multicolumn{8}{|c|}{ 1.4.1 Mean power grip strength of both sides: medium term } \\
\hline Lamb 2015 & 195 & $15.6(8.9)$ & 205 & $14.2(8.1)$ & & $100 \%$ & $1.4[-0.27,3.07]$ \\
\hline Subtotal $\star \star \star$ & 195 & & 205 & & & $100 \%$ & $1.4[-0.27,3.07]$ \\
\hline \multicolumn{8}{|c|}{ Heterogeneity: Not applicable } \\
\hline \multicolumn{8}{|c|}{ Test for overall effect: $Z=1.64(P=0.1)$} \\
\hline \multicolumn{8}{|c|}{ 1.4.2 Mean power grip strength of both sides: long term } \\
\hline Lamb 2015 & 171 & $16(9.1)$ & 184 & $14.8(8.3)$ & & $100 \%$ & $1.2[-0.62,3.02]$ \\
\hline Subtotal $* \star \star$ & 171 & & 184 & & & $100 \%$ & $1.2[-0.62,3.02]$ \\
\hline \multicolumn{8}{|c|}{ Heterogeneity: Not applicable } \\
\hline \multicolumn{8}{|c|}{ Test for overall effect: $Z=1.29(P=0.2)$} \\
\hline & & & & urs exercise & -2.5 & Favours $\mathrm{r}$ & ercise \\
\hline
\end{tabular}

Analysis 1.5. Comparison 1 Exercise versus no exercise, Outcome 5 Hand impairment - pinch grip strength.

\begin{tabular}{|c|c|c|c|c|c|c|c|}
\hline \multirow[t]{2}{*}{ Study or subgroup } & \multicolumn{2}{|c|}{ Exercise } & \multicolumn{2}{|c|}{ No exercise } & \multirow{2}{*}{$\begin{array}{c}\text { Mean Difference } \\
\text { Fixed, } 95 \% \mathrm{Cl} \\
\end{array}$} & \multirow[t]{2}{*}{ Weight } & \multirow{2}{*}{$\begin{array}{c}\text { Mean Difference } \\
\text { Fixed, } 95 \% \mathrm{Cl} \\
\end{array}$} \\
\hline & $\mathbf{N}$ & Mean(SD) & $\mathbf{N}$ & Mean(SD) & & & \\
\hline \multicolumn{8}{|c|}{ 1.5.1 Pinch grip strength - left hand: short term } \\
\hline Buljina 2001 & 50 & $1.6(1.1)$ & 50 & $1.1(0.9)$ & + & $92.51 \%$ & $0.46[0.06,0.86]$ \\
\hline Cima 2013 & 13 & $3.6(1.3)$ & 7 & $2.4(1.7)$ & $\longrightarrow$ & $7.49 \%$ & $1.15[-0.26,2.56]$ \\
\hline Subtotal $\star \star \star$ & 63 & & 57 & & $\downarrow$ & $100 \%$ & $0.51[0.13,0.9]$ \\
\hline \multicolumn{8}{|c|}{ Heterogeneity: $\mathrm{Tau}^{2}=0 ; \mathrm{Chi}^{2}=0.85, \mathrm{df}=1(\mathrm{P}=0.36) ; I^{2}=0 \%$} \\
\hline \multicolumn{8}{|c|}{ Test for overall effect: $Z=2.6(P=0.01)$} \\
\hline \multicolumn{8}{|c|}{ 1.5.2 Pinch grip strength - right hand: short term } \\
\hline Buljina 2001 & 50 & $2(1.2)$ & 50 & $1.2(0.9)$ & + & $91.37 \%$ & $0.82[0.41,1.23]$ \\
\hline Cima 2013 & 13 & $3.8(1.2)$ & 7 & $3(1.6)$ & - & $8.63 \%$ & $0.81[-0.52,2.14]$ \\
\hline Subtotal $* \star \star$ & 63 & & 57 & & 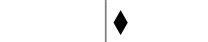 & $100 \%$ & $0.82[0.43,1.21]$ \\
\hline \multicolumn{8}{|c|}{ Heterogeneity: $\operatorname{Tau}^{2}=0 ; \mathrm{Chi}^{2}=0, \mathrm{df}=1(\mathrm{P}=0.99) ; \mathrm{I}^{2}=0 \%$} \\
\hline \multicolumn{8}{|c|}{ Test for overall effect: $Z=4.1(P<0.0001)$} \\
\hline \multicolumn{8}{|c|}{ 1.5.3 Mean pinch grip strength of both sides: medium term } \\
\hline Lamb 2015 & 192 & $4.6(2.3)$ & 204 & $4.3(2.2)$ & + & $100 \%$ & $0.3[-0.14,0.74]$ \\
\hline Subtotal $\star \star \star$ & 192 & & 204 & & 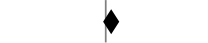 & $100 \%$ & $0.3[-0.14,0.74]$ \\
\hline \multicolumn{8}{|c|}{ Heterogeneity: Not applicable } \\
\hline \multicolumn{8}{|c|}{ Test for overall effect: $Z=1.32(P=0.19)$} \\
\hline \multicolumn{8}{|c|}{ 1.5.4 Mean pinch grip strength of both sides: long term } \\
\hline Lamb 2015 & 169 & $4.8(2.5)$ & 182 & $4.4(2.1)$ & + & $100 \%$ & $0.4[-0.08,0.88]$ \\
\hline 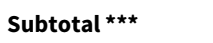 & 169 & & 182 & & 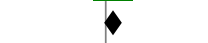 & $100 \%$ & $0.4[-0.08,0.88]$ \\
\hline \multicolumn{8}{|c|}{ Heterogeneity: Not applicable } \\
\hline Test for overall effec & & & & & & & \\
\hline
\end{tabular}


Analysis 1.6. Comparison 1 Exercise versus no exercise, Outcome 6 Participant adherence.

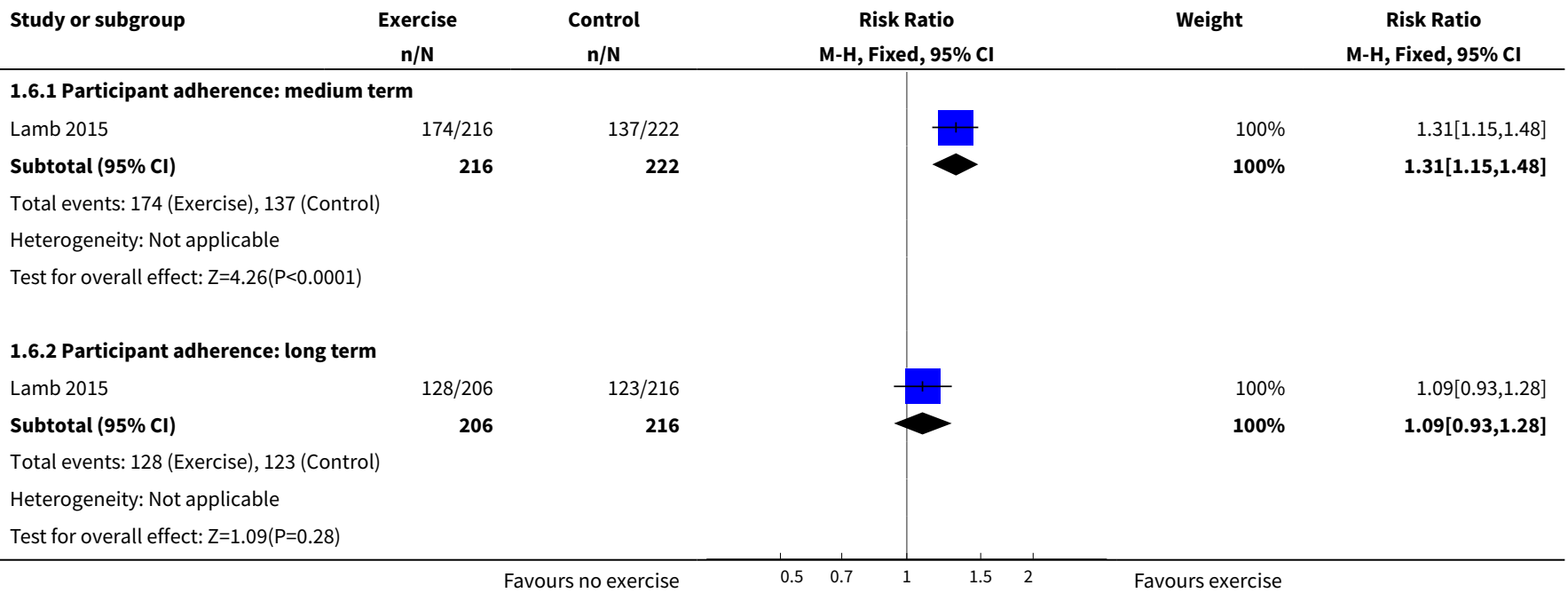

Analysis 1.7. Comparison 1 Exercise versus no exercise, Outcome 7 General function.

\begin{tabular}{|c|c|c|c|c|c|c|c|}
\hline \multirow{3}{*}{$\begin{array}{l}\text { Study or subgroup } \\
\text { 1.7.1 Short term }\end{array}$} & \multicolumn{2}{|c|}{ Exercise } & \multicolumn{2}{|c|}{ No Exercise } & \multirow{2}{*}{$\begin{array}{c}\text { Std. Mean Difference } \\
\text { Fixed, } 95 \% \mathrm{Cl}\end{array}$} & \multirow[t]{2}{*}{ Weight } & \multirow{2}{*}{$\begin{array}{l}\text { Std. Mean Difference } \\
\text { Fixed, } 95 \% \mathrm{Cl}\end{array}$} \\
\hline & $\mathbf{N}$ & Mean(SD) & $\mathbf{N}$ & Mean(SD) & & & \\
\hline & & & & & & & \\
\hline Buljina 2001 & 50 & $4.2(1.1)$ & 50 & $3.2(1.3)$ & & $84.43 \%$ & $0.81[0.4,1.22]$ \\
\hline Cima 2013 & 13 & $-0.8(0.7)$ & 7 & $-1.3(0.3)$ & 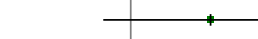 & $15.57 \%$ & $0.71[-0.24,1.66]$ \\
\hline Subtotal ${ }^{\star \star \star}$ & 63 & & 57 & & & $100 \%$ & $0.79[0.42,1.17]$ \\
\hline \multicolumn{8}{|c|}{ Heterogeneity: $\operatorname{Tau}^{2}=0 ; \mathrm{Chi}^{2}=0.04, \mathrm{df}=1(\mathrm{P}=0.85) ; \mathrm{I}^{2}=0 \%$} \\
\hline \multicolumn{8}{|l|}{ 1.7.2 Medium term } \\
\hline Lamb 2015 & 222 & $62.9(24.1)$ & 227 & $26.9(25.5)$ & & $100 \%$ & $1.45[1.24,1.66]$ \\
\hline 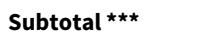 & 222 & & 227 & & & $100 \%$ & $1.45[1.24,1.66]$ \\
\hline \multicolumn{8}{|c|}{ Heterogeneity: Not applicable } \\
\hline \multicolumn{8}{|c|}{ Test for overall effect: $Z=13.64(P<0.0001)$} \\
\hline & & & Favo & no exercise & -1 & 2 Favours & cise \\
\hline
\end{tabular}

Analysis 1.8. Comparison 1 Exercise versus no exercise, Outcome 8 Disease activity.

\begin{tabular}{|c|c|c|c|c|c|c|c|}
\hline \multirow[t]{2}{*}{ Study or subgroup } & \multicolumn{2}{|c|}{ Exercise } & \multicolumn{2}{|c|}{ No Exercise } & \multirow{2}{*}{$\begin{array}{l}\text { Std. Mean Difference } \\
\text { Fixed, } 95 \% \mathrm{Cl}\end{array}$} & \multirow[t]{2}{*}{ Weight } & \multirow{2}{*}{$\begin{array}{l}\text { Std. Mean Difference } \\
\text { Fixed, } 95 \% \mathrm{Cl}\end{array}$} \\
\hline & $\mathbf{N}$ & Mean(SD) & $\mathbf{N}$ & Mean(SD) & & & \\
\hline \multicolumn{8}{|c|}{ 1.8.1 Swollen joint count: medium term } \\
\hline Lamb 2015 & 222 & $3.2(4.6)$ & 227 & $4(5.3)$ & + & $91.28 \%$ & $-0.16[-0.35,0.02]$ \\
\hline O'Brien 2006 & 21 & $2.3(3.5)$ & 22 & $3.3(5.6)$ & $\rightarrow$ & $8.72 \%$ & $-0.2[-0.8,0.4]$ \\
\hline Subtotal $\star \star \star ~$ & 243 & & 249 & & 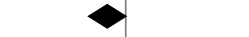 & $100 \%$ & $-0.16[-0.34,0.01]$ \\
\hline \multicolumn{8}{|c|}{ Heterogeneity: Tau $^{2}=0 ; \mathrm{Chi}^{2}=0.01, \mathrm{df}=1(\mathrm{P}=0.91) ; \mathrm{I}^{2}=0 \%$} \\
\hline \multicolumn{8}{|c|}{ Test for overall effect: $Z=1.81(P=0.07)$} \\
\hline & & & & urs exercise & -1 & Favours $\mathrm{r}$ & xercise \\
\hline
\end{tabular}




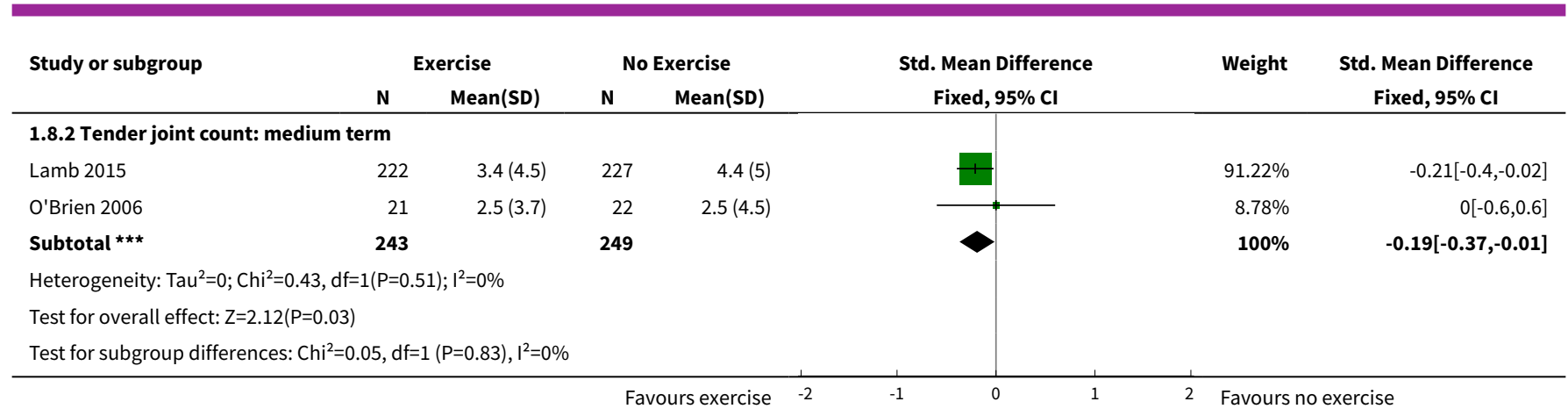

\section{ADDITIONAL TABLES}

Table 1. Characteristics of interventions

\begin{tabular}{|c|c|c|}
\hline Author & Exercise arm intervention & $\begin{array}{l}\text { Control arm interven- } \\
\text { tion }\end{array}$ \\
\hline Brighton 1993 & $\begin{array}{l}\text { 1) daily dexterity, ROM, and strengthening exercises for } 4 \text { years (with 6-month } \\
\text { follow-up visits) }\end{array}$ & No exercises \\
\hline Buljina 2001 & $\begin{array}{l}\text { 1) daily faradic baths, wax, ROM, and strengthening exercise programme for } 3 \\
\text { weeks }\end{array}$ & Waiting list \\
\hline Dellhag 1992 & $\begin{array}{l}\text { 1) wax bath + exercises; 2) ROM exercises only; 3) wax bath only, } 3 \text { times week- } \\
\text { ly for } 4 \text { weeks }\end{array}$ & No treatment \\
\hline Hoenig 1993 & $\begin{array}{l}\text { 1) daily ROM exercises; 2) strengthening exercises; 3) daily ROM and strength- } \\
\text { ening. } 12 \text {-week programme }\end{array}$ & $\begin{array}{l}\text { Normal medication reg- } \\
\text { imen and physician } \\
\text { care }\end{array}$ \\
\hline O'Brien 2006 & $\begin{array}{l}\text { 1) joint protection + daily ROM + strengthening; } 2 \text { ) joint protection + daily ROM } \\
\text { for } 6 \text { months }\end{array}$ & Joint protection advice \\
\hline Cima 2013 & $\begin{array}{l}\text { 1) strengthening exercises; 2) motor co-ordination; 3) ROM, } 5 \text { days a week for } 2 \\
\text { months, supervised and unsupervised }\end{array}$ & No treatment \\
\hline Lamb 2015 & $\begin{array}{l}\text { 1) } 7 \text { mobility exercises; 2) } 4 \text { strength exercises, daily for } 12 \text { weeks, supervised } \\
\text { and unsupervised }\end{array}$ & $\begin{array}{l}\text { Usual hand care typical- } \\
\text { ly provided in UK NHS }\end{array}$ \\
\hline
\end{tabular}

NHS: National Health Service; ROM: range of motion

Table 2. Raw data - hand function

\begin{tabular}{llll}
\hline & Dellhag 1992 & O'Brien 2006 & $\begin{array}{l}\text { Lamb 2015 (also reported in } \\
\text { Williams 2015) }\end{array}$ \\
\hline Measurement & $\begin{array}{l}\text { Grip function, } \\
\text { Sollerman test }\end{array}$ & $\begin{array}{l}\text { AlMS2 upper limb subscale and hand and finger } \\
\text { function subscale }\end{array}$ & MHQ overall hand function score \\
\hline Follow-up periods & Baseline, 4 weeks & Baseline, 1, 3, and 6 months & Baseline, 4 and 12 months \\
\hline
\end{tabular}


Table 2. Raw data - hand function (Continued)

\begin{tabular}{|c|c|c|c|}
\hline Pre-intervention & $\begin{array}{l}\text { Group } 2 \text { (exercise) } \\
74.8 \text {; Group } 4 \text { (con- } \\
\text { trol) } 75.2\end{array}$ & -------------------------------- & $\begin{array}{l}\text { Exercise group } 52.1 \text { (15.2); con- } \\
\text { trol group } 52.1 \text { (16.4) }\end{array}$ \\
\hline Postintervention & $\begin{array}{l}\text { Group } 2 \text { (exercise) } \\
76.1 \text {; Group } 4 \text { (con- } \\
\text { trol) } 75.0\end{array}$ & ----------------------------- & $\begin{array}{l}4 \text { months: } \\
\text { - exercise group: } 61.1(16.0) \\
\text { - control group: } 56.6(15.6) \\
12 \text { months: } \\
\text { - exercise group: } 60.7 \text { (18.1) } \\
\text { - control group: } 56.4(18.6)\end{array}$ \\
\hline \multirow[t]{6}{*}{ Change } & - & $\begin{array}{l}0 \text { to } 1 \text { month - upper limb subscale: } \\
\text { - Group 1: } 0.31(1.14) \\
\text { - Group 2: }-0.25(1.08) \\
\text { - Group 3: }-0.22(1.25)\end{array}$ & $\begin{array}{l}0 \text { to } 4 \text { months - MHQ overall hand } \\
\text { function: } \\
\text { - exercise group: } 8.73 \text { (6.83 to } \\
\text { 10.64) } \\
\text { - control group: } 4.04 \text { ( } 2.17 \text { to } \\
5.91)\end{array}$ \\
\hline & & $\begin{array}{l}0 \text { to } 3 \text { months - upper limb subscale: } \\
\text { - Group 1: } 0.63(1.59) \\
\text { - Group 2: }-0.56(1.47) \\
\text { - Group 3: }-0.06(1.21)\end{array}$ & $\begin{array}{l}0 \text { to } 12 \text { months - MHQ overall } \\
\text { hand function: } \\
\text { - exercise group: } 7.93 \text { ( } 5.98 \text { to } \\
9.88 \text { ) } \\
\text { - control group: } 3.56 \text { (1.45 to } \\
5.68 \text { ) }\end{array}$ \\
\hline & & $\begin{array}{l}0 \text { to } 6 \text { months - upper limb subscale: } \\
\text { - Group 1: } 1.00(1.07) \\
\text { - Group 2: }-0.18(1.54) \\
\text { - Group 3: }-0.30(1.22)\end{array}$ & 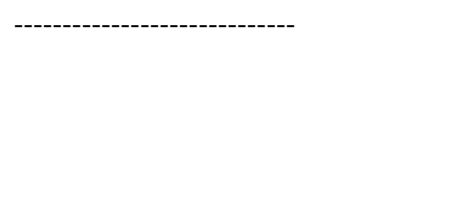 \\
\hline & & $\begin{array}{l}0 \text { to } 1 \text { month - hand and finger function subscale: } \\
\text { - Group 1: } 0.97(1.04) \\
\text { - Group 2: -0.13(1.54) } \\
\text { - Group 3: } 0.53(1.37)\end{array}$ & \\
\hline & & $\begin{array}{l}0 \text { to } 3 \text { months - hand and finger function subscale: } \\
\text { - Group 1: } 0.47(1.60) \\
\text { - Group 2: }-0.47(1.41) \\
\text { - Group 3: } 0.34(1.67)\end{array}$ & \\
\hline & & $\begin{array}{l}0 \text { to } 6 \text { months - hand and finger function subscale: } \\
\text { - Group 1: } 0.97(1.72) \\
\text { - Group 2: } 0.18(2.07) \\
\text { - Group 3: } 0.38(1.68)\end{array}$ & \\
\hline $\begin{array}{l}\text { Authors' conclu- } \\
\text { sions }\end{array}$ & $\begin{array}{l}\text { No significant dif- } \\
\text { ferences between } \\
\text { groups }\end{array}$ & $\begin{array}{l}\text { Statistically significant improvement in test group } \\
\text { compared to control (and mobilising exercis- } \\
\text { es-alone group) }\end{array}$ & $\begin{array}{l}\text { Statistically significant improve- } \\
\text { ment in exercise group compared } \\
\text { to control }\end{array}$ \\
\hline
\end{tabular}


Table 2. Raw data - hand function (Continued)

$\begin{array}{ll}\text { Notes } & \text { No standard devia- } \\ \text { tions }\end{array}$

AIMS2: Arthritis Impact Measurement Scales 2

MHQ: Michigan Hand Outcomes Questionnaire

Table 3. Raw data - pain

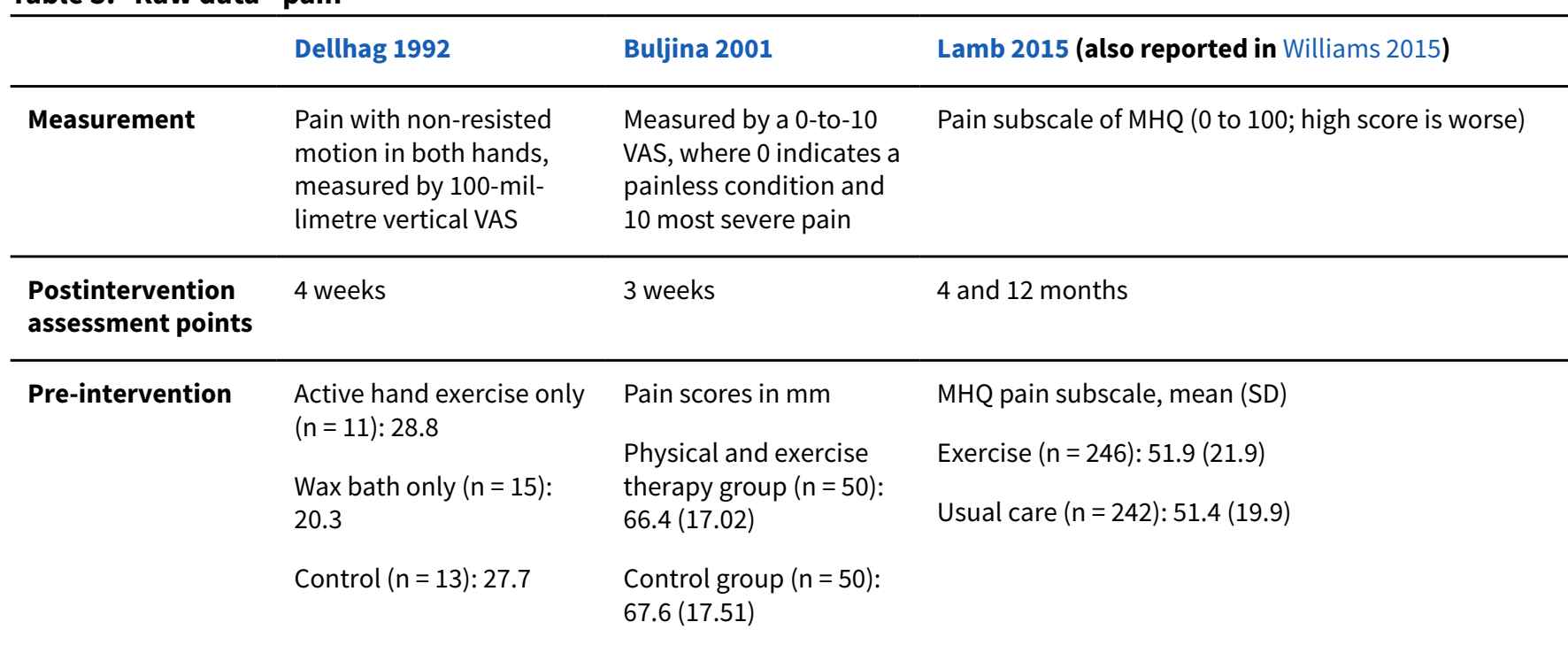

\begin{tabular}{|c|c|c|c|}
\hline \multirow[t]{7}{*}{ Postintervention } & At 4 weeks & Pain scores in $\mathrm{mm}$ & MHQ pain subscale, mean (SD) \\
\hline & Active hand exercise only & At 3 weeks & 4 months: \\
\hline & & Physical and exercise & - exercise group $(n=219): 43.3$ (23.6) \\
\hline & $\begin{array}{l}\text { Wax bath only }(n=15) \text { : } \\
25.9\end{array}$ & $\begin{array}{l}\text { therapy group }(n=50) \text { : } \\
32.4(14.78)\end{array}$ & - usual care $(n=226): 46.1(21.1)$ \\
\hline & & & 12 months: \\
\hline & Control $(n=13): 33.1$ & $\begin{array}{l}\text { Control group }(n=50) \text { : } \\
70(19.04)\end{array}$ & - exercise group $(n=215)$ : $41.6(24.3)$ \\
\hline & & & - usual care $(n=222): 45.3(22.6)$ \\
\hline
\end{tabular}

\section{Change}

MHQ pain subscale

4 months

Mean change from baseline pain scores (95\% confidence interval)

- exercise: -7.6 (-9.94 to -5.26$)$

- usual care: -5.11 (-7.58 to -2.63$)$

Mean treatment difference, adjusted for centre, sex, age, and drug groups (DMARDs and oral steroids):
$-3.30(-6.50$ to -0.11$), P=0.0433$
12 months
Mean change (95\% confidence interval)
- exercise: $-8.26(-10.83$ to -5.7$)$
- usual care: $-6.01(-8.74$ to -3.29$)$ 
Table 3. Raw data - pain (Continued)

Mean treatment difference, adjusted for centre, sex, age, and drug groups (DMARDs and oral steroids):

$-2.40(-5.92$ to 1.12$), P=0.1814$

\begin{tabular}{llll}
\hline $\begin{array}{l}\text { Authors' conclu- } \\
\text { sions }\end{array}$ & $\begin{array}{l}\text { Significant pain reduc- } \\
\text { tion in the exercise on- } \\
\text { ly group, } \mathrm{P}<0.05 \mathrm{com}- \\
\text { pared to control group } \\
\text { and compared to group } \\
\text { that received wax thera- } \\
\text { py only }\end{array}$ & $\begin{array}{l}\text { Significant improve- } \\
\text { ment in the physical } \\
\text { and exercise therapy } \\
\text { group, } \mathrm{P}<0.005\end{array}$ & $\begin{array}{l}\text { No statistically significant differences in pain scores } \\
\text { between groups at } 4 \text { and } 12 \text { months }\end{array}$ \\
\hline Notes & No standard deviations & & \\
\hline
\end{tabular}

DMARD: disease-modifying antirheumatic drug MHQ: Michigan Hand Outcomes Questionnaire SD: standard deviation

VAS: visual analogue scale

\section{AP PE N D I E S}

\section{Appendix 1. MEDLINE (OVID SP) search strategy}

1. exp arthritis, rheumatoid/

2. ((rheumatoid or reumatoid or revmatoid or rheumatic or reumatic or revmatic or rheumat\$ or reumat\$ or revmarthrit\$) adj3 (arthrit\$ or artrit\$ or diseas\$ or condition\$ or nodule\$)).tw.

3. (felty\$ adj2 syndrome).tw.

4. (caplan\$ adj2 syndrome).tw.

5. (sjogren\$ adj2 syndrome).tw.

6. (sicca adj2 syndrome).tw.

7. still\$ disease.tw.

8. bechterew\$ disease.tw.

9. or/1-8

10. Hand/

11. wrist/

12. exp Hand Deformities/

13. hand\$.tw.

14. wrist\$.tw.

15. finger\$.tw.

16. Thumb\$.tw.

17. or $/ 10-16$

18. exp Exercise Therapy/

19. exp Physical Therapy Modalities/ 
20. exercis\$.tw.

21. Physical therap\$.tw.

22. physiotherap\$.tw.

23. (resistance or strength\$).tw.

24. (muscle\$ adj (stretch\$ or manipulat\$)).tw.

25. ((muscle\$ or musculoskeletal) adj (stretch\$ or manipulat\$)).tw.

26. or $/ 18-25$

27. and $/ 9,17,26$

28. randomised controlled trial.pt.

29. controlled clinical trial.pt.

30. randomized.ab.

31. placebo.ab.

32. drug therapy.fs.

33. randomly.ab.

34. trial.ab.

35. groups.ab.

36. or $/ 28-35$

37. (animals not (humans and animals)).sh.

38. 36 not 37

39. 27 and 38

\section{H I S T O R Y}

Protocol first published: Issue 4, 2002

Review first published: Issue 7, 2018

\begin{tabular}{lll}
\hline Date & Event & Description \\
\hline 4 January 2012 & $\begin{array}{l}\text { New citation required and major } \\
\text { changes }\end{array}$ & $\begin{array}{l}\text { New authors. Substantial changes to methodology since proto- } \\
\text { col last published, including updated 'Risk of bias' tool, addition } \\
\text { of 'Summary of findings' table, and a priori specification of out- } \\
\text { comes to be included in the 'Summary of findings' table }\end{array}$ \\
\hline 12 September 2008 & Amended & Converted to new review format \\
& CMSG ID: C126-P \\
\hline
\end{tabular}

\section{CONTRIBUTIONS OF AUTHORS}

All authors contributed to the development of the review.

MA Williams. Co-ordinator of the review. Independent for: study selection, assessment of methodological quality, and data extraction. Review analysis, drafting, and updating. 
C Srikesavan. Updated searches in all databases for studies published from May 2015 to 2016 and July 2017. Review analysis, drafting, and updating.

PJ Heine. Independent for: study selection, assessment of methodological quality, and data extraction. Review analysis, drafting, and updating.

J Bruce. Arbiter for: study selection, assessment of methodological quality, and data extraction. Review analysis and drafting.

L Brosseau. Registered a prior version of the review. Review analysis and drafting.

N Hoxey-Thomas. Independent for: study selection, assessment of methodological quality, and data extraction. Review analysis, drafting, and updating.

SE Lamb. Oversee review process and drafting of final review.

\section{DECLARATIONS OF INTEREST}

Mark Williams was involved in an included randomised controlled trial: Strengthening and Stretching for Rheumatoid Arthritis of the Hand (SARAH - ISRCTN 89936343). This was funded by the UK National Institute for Health Research Health Technology Assessment Programme.

Peter Heine was involved in an included randomised controlled trial: Strengthening and Stretching for Rheumatoid Arthritis of the Hand (SARAH - ISRCTN 89936343). This was funded by the UK National Institute for Health Research Health Technology Assessment Programme.

Sarah E Lamb was involved in an included randomised controlled trial: Strengthening and Stretching for Rheumatoid Arthritis of the Hand (SARAH - ISRCTN 89936343). This was funded by the UK National Institute for Health Research Health Technology Assessment Programme.

Lucie Brosseau: none known.

Julie Bruce: none known.

Cynthia Srikesavan: none known.

No funding from a private or pharmaceutical company was received for conducting this review.

\section{SOURCES OF SUPPORT}

\section{Internal sources}

- Nuffield Department of Orthopaedics, Rheumatology and Musculoskeletal Sciences, University of Oxford, UK.

In kind support (Williams, Hoxey-Thomas, Lamb)

- Warwick Clinical Trials Unit, University of Warwick, UK.

In kind support (Heine, Bruce)

- School of Rehabilitation Sciences, Faculty of Health Sciences, University of Ottawa, Ottawa, Canada.

In kind support (Brosseau)

- National Institute for Health Research (NIHR) Collaboration for Leadership in Applied Health Research \& Care (CLAHRC) Oxford, UK.

This review has been developed in association with the NIHR Collaboration for Leadership in Applied Health Research \& Care (CLAHRC) Oxford (Williams, Hoxey-Thomas, Srikesavan, and Lamb). The views and opinions expressed therein are those of the authors and do not necessarily reflect those of the NIHR, NHS, or the UK Department of Health.

- National Institute for Health Research (NIHR) Oxford Musculoskeletal Biomedical Research Unit, UK.

This review been developed in association with the NIHR Oxford Musculoskeletal Biomedical Research Unit (Williams, Hoxey-Thomas, and Lamb). The views and opinions expressed therein are those of the authors and do not necessarily reflect those of the NIHR, NHS, or the UK Department of Health.

- National Institute for Health Research Doctoral Fellowship Programme, UK.

Heine is supported by a National Institute for Health Research Doctoral Research Fellowship. The views expressed in this publication are those of the author(s) and not necessarily those of the NHS, the National Institute for Health Research, or the UK Department of Health.

\section{External sources}

- No sources of support supplied 


\section{DIFFERENCES BETWEEN PROTOCOL AND REVIEW}

1. We planned in the protocol to report outcome assessments from the included studies in three time frames: short term (<3 months), medium term ( 3 to 12 months), and long term ( $>12$ months). We revised the time frames in the review to: short term ( 3 months), medium term ( 3 to 11 months), and long term (12 months and beyond).

2. Nicolette Hoxey-Thomas and Cynthia Srikesavan were added as authors.

3. The review title was changed to: 'Exercise for rheumatoid arthritis of the hand'.

\section{INDEX TERMS}

\section{Medical Subject Headings (MeSH)}

*Hand; Arthritis, Rheumatoid [ ${ }^{\star}$ therapy]; Exercise Therapy [adverse effects] [ ${ }^{*}$ methods]; Hand Strength; Pain Measurement [methods]; Randomized Controlled Trials as Topic; Time Factors; Treatment Outcome

\section{MeSH check words}

Adult; Aged; Aged, 80 and over; Humans; Middle Aged; Young Adult 